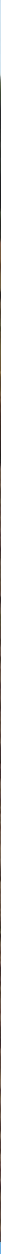

Spray drift simulations to estimate the exposure of residents to pesticides close to a sprayed field

H.J. Holterman, J.C. van de Zande 



\section{Spray drift simulations to estimate the exposure of residents to pesticides close to a sprayed field}

H.J. Holterman, J.C. van de Zande

This study was carried out by the Wageningen Research Foundation (WR) and was commissioned and financed by RIVM within the research project Onderzoek Bestrijdingsmiddelen Omwonenden (project number 3710434304; ОВО Deliverable 085).

WR is part of Wageningen University \& Research, the collaboration of Wageningen University and Wageningen Research Foundation.

Wageningen, November 2019

Report WPR-878 
H.J. Holterman, J.C. van de Zande, 2019. Spray drift simulations to estimate the exposure of residents to pesticides close to a sprayed field. Wageningen Research, Report WPR-878. 70 pp.; 56 fig.;

16 tab. ; 11 ref.

This report can be downloaded for free at https://doi.org/10.18174/467149

Downwind deposits and airborne emissions of spray drift after a pesticide application on flower bulb fields were computed using the IDEFICS spray drift model. The simulations closely followed real spray applications that took place on selected flower bulb fields. Spray deposits on the ground down to $5 \mathrm{~m}$ off the downwind field edge were determined. Vertical airborne emission profiles were determined at the same distance. 14 cases were studied; the airborne emission results of these are to be used as input for a spray and vapour dispersion model.

Key words: Spray drift, airborne emission, simulation model, exposure risk, residents

(C) 2019 Wageningen, Stichting Wageningen Research, Wageningen Plant Research, P.O. Box 16, 6700 AA Wageningen, The Netherlands; T +31 (0)317 4807 00; www.wur.eu/plant-research

Chamber of Commerce no. 09098104 at Arnhem

VAT NL no. 8065.11.618.B01

Stichting Wageningen Research. All rights reserved. No part of this publication may be reproduced, stored in an automated database, or transmitted, in any form or by any means, whether electronically, mechanically, through photocopying, recording or otherwise, without the prior written consent of the Stichting Wageningen Research.

Stichting Wageningen Research is not liable for any adverse consequences resulting from the use of data from this publication.

Report WPR-878

Photo cover: H.J. Holterman 


\section{Contents}

$\begin{array}{ll}\text { Preface } & 5\end{array}$

$\begin{array}{ll}\text { Samenvatting } & 7\end{array}$

$\begin{array}{ll}\text { Summary } & 9\end{array}$

1

$\begin{array}{ll}\text { Introduction } & 11\end{array}$

2

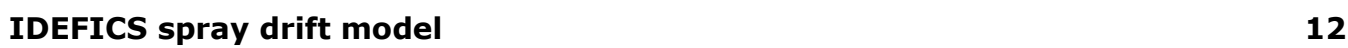

3

Set-up of spray drift simulations $\quad 14$

$\begin{array}{lll}3.1 & \text { Selection of spraying events to simulate } & 14\end{array}$

$\begin{array}{ll}3.2 & \text { Set-up of simulations } \\ 3.3 & 15\end{array}$

$\begin{array}{lll}3.3 & \text { Output data handling } & 16\end{array}$

3.3.1 Correction for unfinished particle tracks 16

$\begin{array}{lll}3.3 .2 & \text { Ground deposits } & 17\end{array}$

$\begin{array}{ll}3.3 .3 & \text { Airborne emissions }\end{array}$

3.3.4 Drift reducing application techniques 17

3.3.5 Dealing with missing application data 17

3.3.6 Dealing with various units to express deposits 18

4.1 Case 1: location 101, May 26, 2016

4.1.1 Ground deposits $\quad 20$

4.1.2 Airborne emission $\quad 21$

4.2 Case 2: location 111, July 20, $2016 \quad 23$

4.2.1 Ground deposits 24

4.2.2 Airborne emission $\quad 24$

4.3 Case 3: location 121, February 24, $2017 \quad 25$

4.3.1 Ground deposits 26

4.3.2 Airborne emission $\quad 27$

4.4 Case 4: location 121, May 9, $2017 \quad 30$

$\begin{array}{lll}4.4 .1 & \text { Ground deposits } & 31\end{array}$

4.4.2 Airborne emission 31

4.5 Case 5: location 131 and 132, January 30, 2017

4.5.1 Ground deposits $\quad 35$

4.5.2 Airborne emission $\quad 35$

4.6 Case 6: location 131 and 132, June 14, $2017 \quad 36$

$\begin{array}{lll}4.6 .1 & \text { Ground deposits } & 38\end{array}$

4.6.2 Airborne emission 38

4.7 Case 7: location 142, May 9, $2017 \quad 39$

4.7.1 Ground deposits 40

4.7.2 Airborne emission 40

4.8 Case 8: location 142, May 22, $2017 \quad 41$

4.8.1 Ground deposits $\quad 42$

4.8.2 Airborne emission 43

4.9 Case 9: location 174, August 1, $2017 \quad 45$

4.9.1 Ground deposits $\quad 45$

4.9.2 Airborne emission $\quad 46$

4.10 Case 10: location 174, August 14, 2017

4.10.1 Ground deposits $\quad 47$ 
4.11 Case 11: location 152, March 30, 2017

4.11.1 Ground deposits 49

4.11.2 Airborne emission 50

4.12 Case 12: location 152, June 18, 2017

4.12.1 Ground deposits 51

4.12.2 Airborne emission $\quad 52$

4.13 Case 13: location 181, May 26, 2017

4.13.1 Ground deposits $\quad 54$

4.13.2 Airborne emission 54

4.14 Case 14: location 182, April 13, $2017 \quad 55$

4.14.1 Ground deposits $\quad 56$

4.14.2 Airborne emission 56

$\begin{array}{lll}4.15 & \text { Case } 4 \text { under worse conditions } & 57\end{array}$

$\begin{array}{llr}5 & \text { Discussion } & 61\end{array}$

$\begin{array}{llr}6 & \text { Conclusions } & 63\end{array}$

$\begin{array}{ll}\text { References } & 64\end{array}$

$\begin{array}{lll}\text { Annex } 1 & \text { Specification of settings for simulations } & 65\end{array}$ 


\section{Preface}

The research presented in this paper was performed within the Research on exposure of residents to pesticides (OBO-project) and financed by the Dutch ministries of Infrastructure and the Environment and of Economic Affairs. The research is carried out in a research consortium, consisting of: Institute for Risk Assessment Sciences (IRAS) of Utrecht University, TNO, University Medical Centre Groningen (UMCG), Radboud University Medical Centre Nijmegen, Wageningen University and Research, Centre for Agricultural Environment (CLM), Schuttelaar \& Partners and is coordinated by the National Institute for Health and the Environment (RIVM).

Wageningen, November 2019 


\section{Samenvatting}

In Nederland wonen ongeveer 90000 mensen binnen een afstand van $50 \mathrm{~m}$ van percelen met bloembollen of fruitteelt. Het is onduidelijk hoeveel van deze mensen blootgesteld worden aan gewasbeschermingsmiddelen die in deze teelten gebruikt worden en welk gezondheidsrisico zij lopen. Het onderzoeksproject "Onderzoek Bestrijdingsmiddelen Omwonenden" is daarom opgezet om de blootstelling van omwonenden rond percelen met bloembollen te inventariseren (OBO). OBO wordt uitgevoerd door een consortium van onderzoeksinstituten onder coördinatie van het RIVM. Er worden metingen gedaan om de blootstellingsroutes van het veld naar de omwonenden te kwantificeren: spuitdrift tijdens de toediening, verdamping vanaf het bespoten gewas na de toediening, het transport naar de huizen van de omwonenden, de depositie in en om de woningen en wat opgenomen wordt door de omwonenden door middel van urinemonsters. In het consortium doet Wageningen Plant Research onderzoek naar de blootstellingsroute spuitdrift tijdens de toediening van gewasbeschermingsmiddelen. De drift depositie benedenwinds van een bespoten perceel en de drift in de lucht wordt gekwantificeerd.

Naast metingen wordt ook een traject van modellen ingezet om de blootstelling te berekenen. In deze simulaties wordt een aantal (14) praktijksituaties nagerekend, waarvoor ook meetgegevens beschikbaar zijn. Elke situatie omvat een bespuiting op een of meer bloembollenvelden op een bepaalde dag in een bepaalde regio. Bij elke situatie is er een 'basisveld' waarvan alle benodigde gegevens bekend zijn. Dit betreft gegevens aangaande de bespuiting zelf en het gewas dat bespoten wordt, als ook weersgegevens op de spuitdag en daaropvolgende dagen. Vaak worden op dezelfde dag nog andere percelen behandeld met soortgelijke middelen. Omdat emissies van deze percelen kunnen bijdragen aan de blootstelling, worden deze ook meegenomen in de beschrijving en berekeningen.

De uiteindelijk berekende blootstelling is het resultaat van een serie opeenvolgende modelberekeningen. Het huidige rapport staat aan het begin van de 'modellentrein' en beschrijft de bespuitingen en de daarbij optredende drift van spuitmiddelen, berekend met het driftmodel IDEFICS. Voor alle 14 situaties zijn driftsimulaties uitgevoerd aan de benedenwindse zijden van de bespoten percelen. Daarbij is rekening gehouden met concentraties van middelen in de spuitvloeistof, instellingen van de spuit (en eventueel gebruikte driftreducerende technieken) en de relevante weersomstandigheden op het uur waarin de bespuitingen plaats vonden. De resultaten omvatten zowel benedenwindse deposities op de grond als emissies naar de lucht gedurende het uur van toediening van de bespuiting. Deposities op de grond zijn berekend tot $5 \mathrm{~m}$ naast het perceel. Op die afstand is ook het verticale emissieprofiel bepaald in de lucht. Dit verticale emissieprofiel is input voor het verspreidingsmodel OPS van Deliverable 87.

Het hoofdstuk Discussion bevat allerhande opmerkingen en kanttekeningen bij de gevolgde methode en de modelresultaten. In het hoofdstuk Conclusions worden conclusies beschreven en aanbevelingen gedaan. 


\section{Summary}

In the Netherlands approximately 90,000 people reside within 50 m of fields with flower bulb or fruit cultivation. It is unclear how many of these people are exposed to pesticides or whether their health is at risk. Therefore, the research project "Onderzoek Bestrijdingsmiddelen Omwonenden" (OBO) was set up to assess the exposure of residents to pesticides next to flower bulbs fields. The research is done by a consortium of research institutes and coordinated by RIVM. Measurements are done to quantify the different exposure routes from the field (spray drift and vapour drift during application, volatilization from a treated crop after application) to the residents' houses and what is taken up by participant residents as measured in urine samples. In this research consortium Wageningen Plant Research quantifies spray drift during application resulting in spray drift deposition on soil surface downwind of the treated area as well as airborne spray drift.

Apart from doing measurements, also models have been used to compute exposure to pesticides. The simulations involved 14 cases for which also measurements have been carried out. The simulations were designed to mimic the real cases as far as possible. Each case represents a spray treatment on one or more flower bulb fields on a specific day and local region. For the 'basis field' all relevant information is known to model the real situation. This involves information on the crop, settings of sprayer and weather conditions on the day of application and subsequent days. Often, several other fields are treated using similar products on the same day. Since pesticide emissions from these additional fields may contribute to the exposure, these fields are accounted for in the simulations.

The finally computed exposure is the result of a series of subsequent model calculations. The current report is the first in line of this 'model train' and describes spray applications and corresponding emissions of spray drift, computed using the IDEFICS spray drift model. For all 14 cases the spray drift is modelled at the downwind edges of the treated fields. The simulations accounted for concentrations of products in the spray mixture, settings of the sprayer (including the possible use of drift reducing techniques) and relevant weather conditions during the hour the application took place. The model results comprise downwind deposits on the ground and airborne emission profiles in the hour of application. Ground deposits have been computed down to $5 \mathrm{~m}$ next to the treated fields. The airborne emission profile was determined at the same distance. This airborne profile is used as input for the OPS dispersion model of Deliverable 87.

Various remarks on the methods used and on the model results are combined in the Discussion section. This is followed by the section on Conclusions which contains recommendations as well. 


\section{Introduction}

In the Netherlands approximately 90,000 people reside within $50 \mathrm{~m}$ of flower bulb or fruit cultivation. It is unclear how many of these people are exposed to pesticides or whether their health is at risk. Therefore, the research project "Onderzoek Bestrijdingsmiddelen Omwonenden" was set up to assess the exposure of residents to pesticides next to flower bulbs fields (Bogers et al., 2014; OBO, 2017). The research is done by a consortium of research institutes coordinated by RIVM. Measurements are done to quantify the different exposure routes from the field (spray drift and vapour drift during application, volatilization from a treated crop after application) to the residents' houses and what is taken up by participant residents as measured in urine samples. In this research consortium Wageningen Plant Research quantifies spray drift during application resulting in spray drift deposition on soil surface downwind of the treated area as well as airborne spray drift.

Important sources for the exposure routes discriminated are spray drift during application and volatilization from the treated field (Figure 1). Spray drift is defined as the quantity of plant protection product that is carried out of the sprayed (treated) area by the action of air currents during the application process (ISO 22866, 2005).

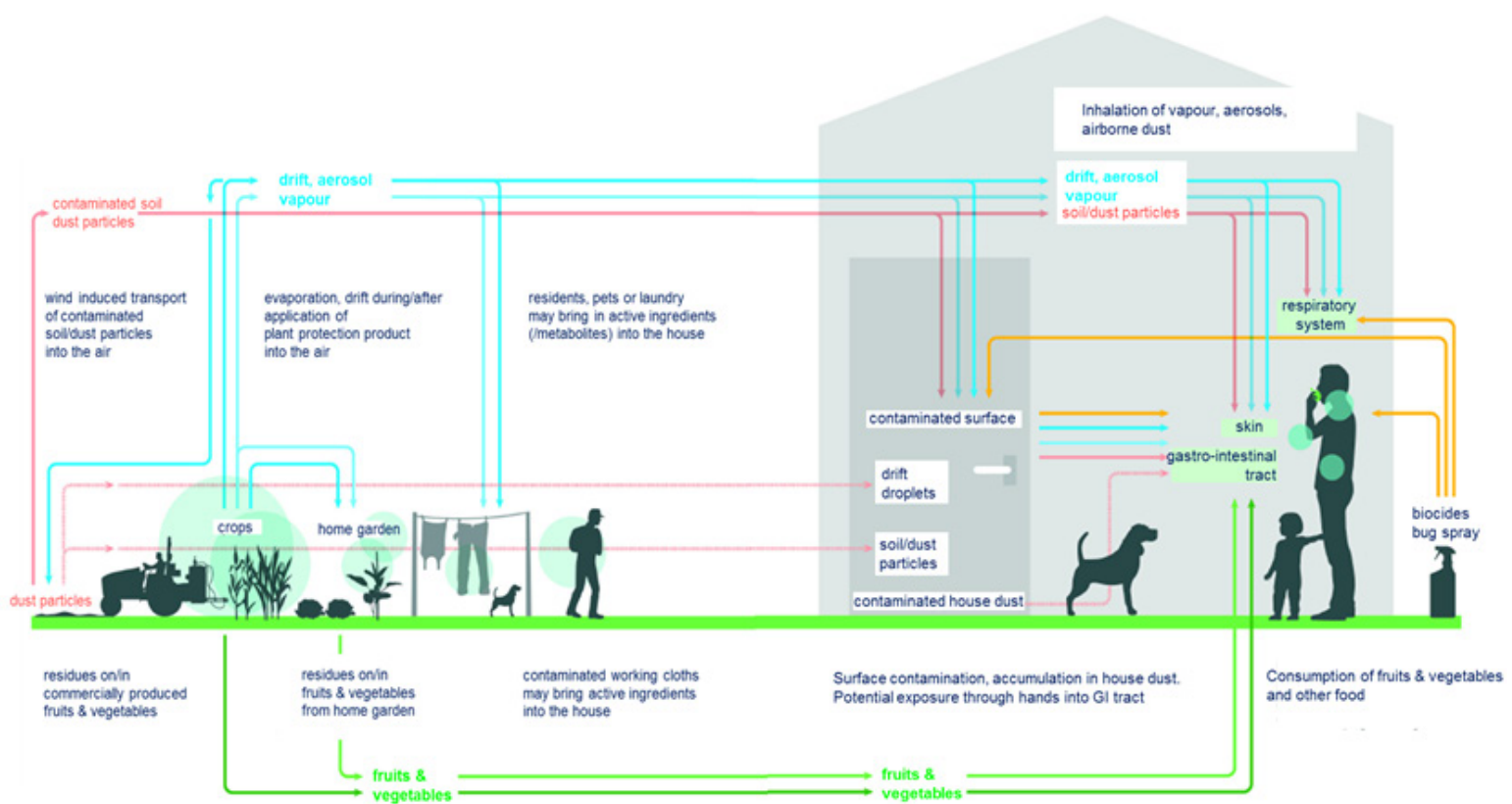

Figure 1 Possible routes leading to exposure of residents to plant protection products. (Health Council of The Netherlands, 2014)

In spray drift experiments both ground deposits and airborne emissions were measured next to a treated field up to $50 \mathrm{~m}$ downwind (Zande et al., 2018). Results of these measurements can be used to extend the validation of the spray drift model IDEFICS (Holterman et al., 1997). The current report deals with simulations using the IDEFICS model. These simulations were carried out such that these mimicked spray applications in OBO field trials as good as possible. Results of the IDEFICS model were used also as input of the dispersion model OPS (Jacobs et al., 2018) which described the transport of spray drift towards to residents' dwellings.

Chapter 2 gives a short introduction on the IDEFICS spray drift model. In Chapter 3 the methods are described how the IDEFICS model is applied to the current project. Chapter 4 describes model results for all 14 cases of the project. 


\section{IDEFICS spray drift model}

Conventionally, PPPs are applied by spraying a solution or suspension of PPP in water. The sprays produced consist of droplets of a wide range of sizes, depending on nozzle type and liquid pressure. Although the sprays are usually directed towards the target - for example, the crop - the smaller drops can easily be caught by the wind and be blown to off-target regions. For downward directed applications (that is, using boom sprayers), the IDEFICS model (Holterman et al., 1997) computes the paths of many large and small drops from nozzle outlet down to the place where the drops deposit (Figure 2). The latter position can be on the crop or on the ground downwind from the treated field. The model has an imaginary vertical boundary downwind; very small drops that are still airborne at this boundary, are recorded and contribute to the vertical airborne emission profile at this boundary.

The spray created at the outlet of the nozzles has a specific drop size distribution. Other important features are spray cone angle and initial velocity of the drops. All of these features depend on nozzle type and liquid pressure. Drops follow a path through air depending on average wind speed, local turbulence and ballistic properties. Typically, drops consist initially mainly of water and the PPP concentration in the drops usually is relatively low. The water solvent evaporates relatively fast. This causes the drop size to reduce and the PPP concentration in the solvent to increase while the drop is still airborne. Finally, if the drop has not deposited yet, all solvent has evaporated and a 'dry' particle of pure formulated PPP remains. In the time frame of spray applications, evaporation of the PPP itself is very slow and the dry particle can be considered non-volatile. Such particles can be very small (0-30 $\mu \mathrm{m})$ and remain airborne for a long time, while travelling long distances. The IDEFICS model distinguishes 'wet' and 'dry' particles, mainly because path computations for evaporating wet particles is slightly different from that of dry particles.

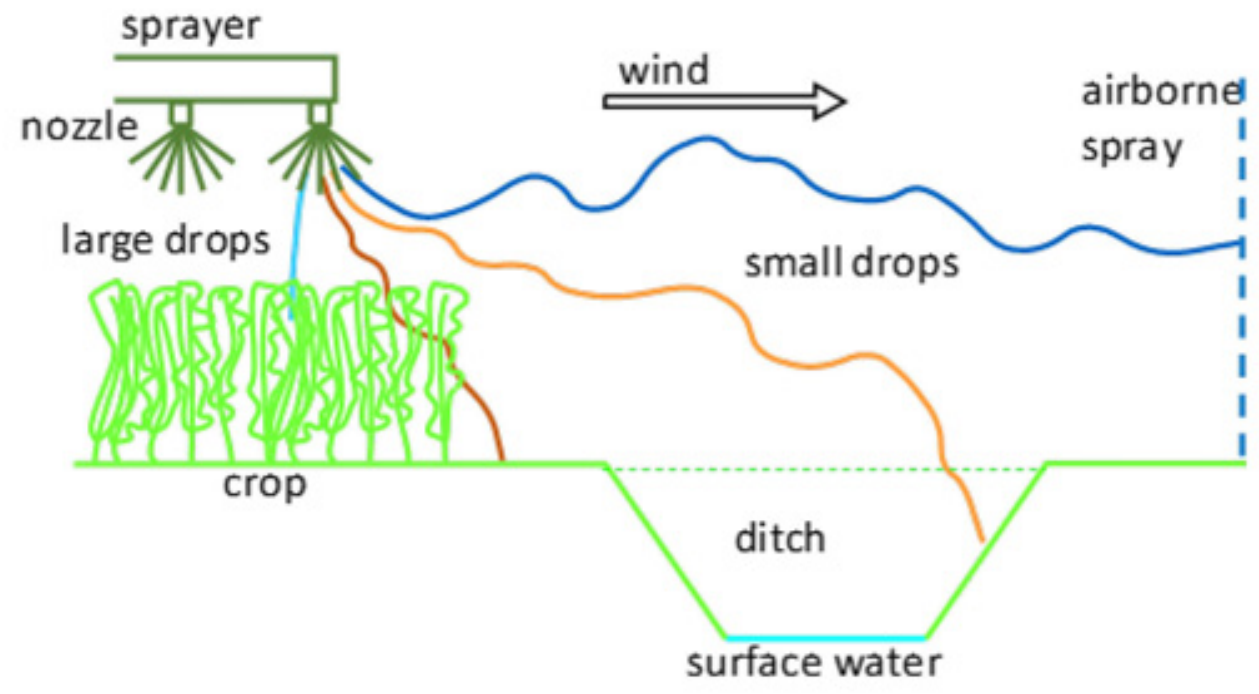

Figure 2 Schematic view of some droplet paths in the IDEFICS model.

To simulate spray drift from a full-field application, the contribution to spray drift of a representative set of nozzles along the sprayer boom is computed and accumulated. Contributions to spray drift from nozzles that are not simulated is estimated by interpolation and extrapolation. The IDEFICS model was initiated as a model to describe downwind deposits onto the ground next to the treated field. The model was validated for downwind deposits on the ground (Holterman et al., 1998). Currently, only limited validation of airborne emissions has been carried out. So far, airborne emissions can be simulated and there is no doubt about the shapes of vertical concentration profiles, yet absolute drift 
values need to be checked more thoroughly. Similarly, as the focus was on ground deposits, the presentation of results for airborne emission is limited. Vertical emission profiles at one downwind location (to be selected by the user) are presented, as well as average particle size at that location, as a function of height. Particle size distributions (as a function of height above the ground) are implicitly available. 


\section{Set-up of spray drift simulations}

\subsection{Selection of spraying events to simulate}

Table 1 lists the situations where a spray treatment on selected fields was followed. Each case involves one or more fields that were treated on a single day. Usually, one field was the 'basis' field for which all relevant information was recorded in the CLM survey (OBO Deliverable 112). Often, several other flower bulb fields were treated on the same day, using the same or a slightly different product mixture to be applied. For these additional fields less information was available. Typically, it is unknown at what time the spraying event took place for these fields. Apparently, for the farmer of the basis field the time of day was right to apply the spray. It is likely that his neighbouring farmers would spray their fields at about the same time. Therefore, in most cases the same time of day was assumed for spray application on additional fields. Generally, for spray drift computations this is not a limitation, since often average weather conditions do not change too much between subsequent hours.

For cases 1 and 2 the time of spraying for the additional fields was selected different from the time for the basis field. However, since the weather conditions may change during the day, the selected time of spraying may affect results for both spray drift (hour of application) and volatilization from the treated field (subsequent hours). As the time of application is unknown, any time (during daylight) is equally likely. Therefore, for case 3 and onward, the time of application for additional fields was selected equal to that for the basis field.

Table 1 Selected cases of spray treatment in flower bulb areas.

\begin{tabular}{|c|c|c|c|c|c|}
\hline & Case index & Field index ${ }^{1}$ & $\begin{array}{c}\text { Spray event date } \\
\text { [yyyy.mm.dd] }\end{array}$ & $\begin{array}{l}\text { Event time } \\
\text { [UT] }^{5}\end{array}$ & Treatment ${ }^{4}$ \\
\hline & 1 & $101^{*}, 102,111,103,106,113$ & 2016.05 .26 & $12^{2}$ & fung, ins \\
\hline & 3 & 121 & 2017.02 .24 & 16 & herb \\
\hline & 4 & $121 *, 114$ & 2017.05 .09 & 12 & fung, ins \\
\hline & 6 & $131 *, 132 *$, many & 2017.06 .14 & 16 & fung, ins \\
\hline & 7 & $142 *, 144,044$ & 2017.05 .09 & 14 & fung, ins \\
\hline & 8 & $142 *$, many & 2017.05 .22 & 14 & fung, ins \\
\hline & 9 & 174 & 2017.08 .01 & 9 & herb, ins \\
\hline & 13 & 181 & 2017.05 .26 & 11 & fung, ins \\
\hline & 14 & 182 & 2017.04 .13 & 16 & fung \\
\hline \multicolumn{6}{|c|}{1 star-marked field is the basis field } \\
\hline \multicolumn{6}{|c|}{2 additional fields assumed to be treated at 10 UT } \\
\hline \multicolumn{6}{|c|}{3 additional fields assumed to be treated at 16 UT } \\
\hline \multicolumn{6}{|c|}{4 type of treatment (fungicide, insecticide, herbicide); all in one mixture and one spraying event } \\
\hline & time mentioned & ac used in KNMI datahace. 1 IT is h & ing from 0.00 HT to & & \\
\hline
\end{tabular}

For all cases the information regarding spray application were recorded by CLM (Deliverable 112). The information included date and time of spraying, sprayer equipment, nozzles used and liquid pressure, driving speed, sprayer boom height, type and amount of formulated products and active ingredients in the tank mixture. In cases where information was missing, a reasonable choice was made to be able to carry out the spray drift simulations. In some cases missing relevant information became available 
afterwards, often appearing to be slightly different form the choices made earlier to carry out the simulations. For those cases, the consequences of these differences are discussed in the results in Chapter 4.

A full list of information regarding the information of the spray applications is given in Table A.1 of Annex 1. The corresponding meteorological conditions and sprayer settings of the simulations is given in Table A. 2 of Annex 1.

\subsection{Set-up of simulations}

In the standardized simulation set-up, spray drift is computed for a $20 \mathrm{~m}$ boom sprayer. Such a boom sprayer would have 40 nozzles (assuming a nozzle distance of $0.5 \mathrm{~m}$ ). The simulation was carried out for a selected set of 14 nozzles along this boom. These 14 nozzles comprised the outer 7 nozzles and 7 other nozzles at other positions along the sprayer boom. The contribution of the other (not simulated) nozzles was estimated by interpolation. For each nozzle, the paths of 30,000 droplets were tracked from nozzle to their final position (deposition at the crop or downwind ground area, or when passing the imaginary vertical screen where airborne emission was evaluated). The droplets consisted of relatively involatile products dissolved of suspended in the solvent (water). While drops followed their path through air, their diameter decreased gradually by evaporation of the solvent. Small droplets might stay airborne long enough to lose all their solvent. In that case a more or less 'dry' particle consisting of formulated products remained, the size of which was determined by initial concentration of the products in the tank and the initial size of the drop upon creation at the nozzle outlet.

For ground deposits, the contribution to spray drift from subsequent swaths was estimated by extrapolation. This method works fine for ground deposits, since the contributions of subsequent swaths usually is very low. However, in case of airborne emissions the contribution of nozzles far upwind appeared to decrease relatively slowly with increasing upwind nozzle position. Consequently, subsequent swaths appeared to contribute significantly to the downwind airborne emission. To avoid the risk of extrapolation errors, swaths 2 and 3 were simulated as well, covering a $60 \mathrm{~m}$ treated field width. The emissions from swaths 2 and 3 were extrapolated to estimate airborne emissions from subsequent swaths further upwind than $60 \mathrm{~m}$.

Many fields could be considered rectangular, roughly. This implied that typically two field edges were on the upwind side and two edges on the downwind side. Spray drift can occur on the downwind sides only. The effective wind direction is defined as the angle between actual wind direction and the direction perpendicular to the field edge. Effective wind direction was computed from the actual wind direction during the spray treatment and the orientation of the (downwind) field edge.

Settings same for all simulations:

- Crop height was $0.50 \mathrm{~m}$ in most cases, except for spraying events in January (case 5) and February (case 3); in those two cases a bare soil treatment was assumed

- Neutral atmospheric stability was assumed

- No crop was present in area downwind from the treated field (i.e. grass or bare soil assumed)

- Outer nozzle was positioned above crop edge

- Driving direction of sprayer was parallel to crop edge

- Mass density of formulated products in tank was assumed $1500 \mathrm{~kg} / \mathrm{m}^{3}$

- For each nozzle 30,000 particle tracks were simulated

- Resolution of ground deposits was $0.25 \mathrm{~m}$ (down to position where airborne emissions were quantified: $5.0 \mathrm{~m}$ downwind)

- Resolution of vertical airborne emissions was $0.25 \mathrm{~m}$, up to $6.25 \mathrm{~m}$ height; airborne emissions could be evaluated only at one downwind distance, which also served as the downwind edge of the simulation area (see Figure 2). 
In most cases the nozzle spacing at the sprayer boom was $0.50 \mathrm{~m}$. Only in cases 11,12 and 13 the nozzle spacing was $0.25 \mathrm{~m}$. Similarly, the height of boom sprayer above the crop was $0.50 \mathrm{~m}$ except for cases 11 and 12 (boom height $0.30 \mathrm{~m}$ ) and case 13 (boom height $0.35 \mathrm{~m}$ ).

The mass density of formulated products affects the mass of drops, particularly when almost all solvent has evaporated. Fortunately, results are not very sensitive to this parameter and a value of $1500 \mathrm{~kg} / \mathrm{m}^{3}$ was a reasonable assumption.

Per nozzle, 30,000 drops were selected and their paths through air were simulated. Initial drop sizes were selected randomly from the measured drop size distribution with tap water (no effect of formulation and tank mixture known) belonging to the nozzle type and liquid pressure used.

Forward (driving) speed of the sprayer was computed based on flow rate of the nozzles used (at given liquid pressure) and liquid dose rate in the field. In some cases the driving speed was mentioned in the CLM survey as well, and plausibility was checked with the computed speed value.

The relevant weather conditions for spray drift simulation involved average wind speed, wind direction, ambient temperature and relative humidity, all at the hour when the spraying event took place. Meteorological data were obtained from the KNMI database of the nearest weather station. For cases 1 through 10 weather station De Kooij was used, for cases 11 through 14 the weather station at Schiphol was nearest. Weather data at an hourly basis was used. The average wind speed in the KNMI database is given at $10 \mathrm{~m}$ height. For IDEFICS, the wind speed at $2 \mathrm{~m}$ height is required. The latter was estimated from the wind speed at $10 \mathrm{~m}$ assuming a logarithmic wind speed profile with height about a field of cut grass, in neutral atmospheric conditions. A spraying event of one field takes place well within one hour. Also the cloud of spray drift flows downwind within the same hour. This implies that for spray drift only the first hour is relevant. A summary of meteorological conditions and sprayer settings for each case is given in Table A. 2 of Annex 1.

The output of IDEFICS serves as the input for the OPS dispersion model. As IDEFICS computes the source of spray drift as well as (nearby) downwind dispersion, it is convenient to define a certain (downwind) location where OPS takes over for dispersion further downwind. The downwind location $5 \mathrm{~m}$ from the field edge was chosen as the imaginary boundary between IDEFICS and OPS. At that distance many of the larger drops have settled to the ground, leaving only relatively small drops airborne (typically $<50 \mu \mathrm{m}$ ). This facilitates its use in OPS, since the flow behaviour of those small drops in air is very similar to gaseous flows. In all cases, the drop size distribution of the airborne emission at $5 \mathrm{~m}$ downwind was evaluated and reported with the results (Chapter 4 ).

\subsection{Output data handling}

The full-field simulation comprised results for droplets starting their tracks at 14 selected nozzles per swath. Since typically 3 swaths were simulated, emission results were obtained for 42 nozzles. The final results involved both cumulated deposits for a full-field treatment and tracking information of all individual drops. The latter information could be used to obtain drop size distributions in the airborne emissions at the evaluation distance $(5 \mathrm{~m})$.

\subsubsection{Correction for unfinished particle tracks}

To avoid unnecessary computation time, particle tracking stops at a large but fixed number of steps along the track. Usually, the maximum number of steps is set to 15,000 . When this number is exceeded, the final size and position of the particle is recorded and the unfinished particle track is marked as a 'broken track'. Clearly, the particle ending as a broken track is still airborne, yet has not reached the downwind evaluation plane for airborne emission. If the track would have been extended, the particle might have ended as deposit on crop, on downwind ground area or as airborne emission at the evaluation distance. In principle, the occurrence of broken tracks leads to an underestimation of deposits or airborne emission. As long as the number of broken tracks is small (say $<1 \%$ ) the error made is negligible. However, it turned out that in some cases for drops starting at a nozzle far upwind 
(swaths 2 and 3 ) the number of broken tracks could become relatively large, causing a severe underestimation of airborne emissions at $5 \mathrm{~m}$ downwind. A rerun of one case with a maximum number of steps of 100,000 allowed to make a well-founded partitioning to assign the broken-track particles to crop/ground deposits or airborne emission, without having to do reruns of all cases.

\subsubsection{Ground deposits}

No specific additional handling is required to estimate downwind ground deposits of spray drift. The IDEFICS software uses the results of the first swath to compute full-field downwind ground deposits. The contribution of subsequent swaths to downwind ground deposits is very low and can be estimated effectively by extrapolation. This does not require additional simulations on such swaths (unlike evaluating airborne emissions, see below).

By default the IDEFICS software estimates downwind spray deposits on the ground assuming a field that stretches infinitely in upwind direction. Although this is unrealistic, the contribution of spray drift starting at upwind nozzles and depositing at downwind ground area decreases rapidly when upwind distance increases. This means that differences between downwind deposits for an infinite field and a (say) $60 \mathrm{~m}$ wide field are negligible. Therefore, regarding downwind ground deposits the finite width of actual fields was not accounted for and the results for an infinite field width was used throughout.

To obtain the deposits for each of the a.i. in the mixture, the given deposits must be multiplied by the mass fraction in the mixed product for each a.i. (the last column in Table A.1 in Annex 1).

\subsubsection{Airborne emissions}

At the evaluation distance where an imaginary vertical screen was positioned, airborne emission was estimated giving the total amount of products or a.i. passing that screen, as a function of height. To obtain the emission profiles for each of the a.i. in the mixture, the given emissions must be multiplied by the mass fraction in the mixed product for each a.i. (the last column in Table A.1 in Annex 1).

For each passing droplet the size, the product content and height above the ground was recorded as well. This allowed the computation of the cumulated emission expressed as the relative number of drops in size classes $0-10,10-20, \ldots 90-100 \mu \mathrm{m}$ and a final size class $>100 \mu \mathrm{m}$, both averaged over height and as a function of height above the ground. Particle size of airborne emission is relevant input for the OPS model. When particles are 'small enough' (say $<50 \mu \mathrm{m}$ ) their aerodynamic behaviour in air flows is much like that of gaseous particles and gravitational effects can be neglected.

\subsubsection{Drift reducing application techniques}

In all situations applications were done using Drift Reducing Nozzle (DRN) types. The drift reducing nozzles used belonged to the drift reduction classes 50\%, 75\% and 90\% (TCT, 2018). In several cases $(5,7-10)$ a boom sprayer with air assistance was used. Such a system gives a reduction of downwind ground deposits of spray drift of about $50 \%$ additional to the nozzle type used. In other cases combinations of drift reducing measures were combined: lowering boom height, smaller nozzle spacing with nozzles having a narrower top angle, and air assistance (case 11, 12, 13). These combinations are separately classified in Drift Reducing Technology (DRT) classes; ranging from 50\% to $99 \%$ (TCT, 2018). For air assistance the same reductions as for ground deposition were applied to airborne emissions. To summarize, in all cases drift reducing techniques have been applied that are classified in the range DRT75 - DRT95 (Table A.3 in Annex 1).

\subsubsection{Dealing with missing application data}

In some cases, the required data from the CLM survey (Deliverable 112) for mimicking the actual spray application in the simulations was incomplete. Typically, this involved nozzle type, liquid pressure, liquid dose rate or driving speed. In those cases the required settings were guessed based on common practice. In some cases, additional survey information arrived after the simulations were 
finished. In such cases a correction factor was estimated to apply to airborne emission results, based on the differences between actual sprayer settings and those assumed in the simulations.

In general, liquid flow rate should not affect airborne emissions directly. Assume the actual liquid flow rate was higher than that used in the simulations. To keep the product dose rate $(\mathrm{kg} / \mathrm{ha})$ at the required level, the actual product concentration had to be lower than simulated. Simulated spray drift would be underestimated in volume, but this would be compensated by the higher product concentration in the drops in the simulation. A higher product concentration would lead to dried airborne particles having a slightly larger diameter. Since all airborne drops are relatively small anyway, this would not affect their aerodynamic behaviour. Consequently, correcting for actual liquid dose rate would not affect airborne emission results.

On the other hand, differences in drop size distribution do affect airborne emissions. In general, spray drift is related directly to the volume fraction of small airborne drops. In a first approximation, airborne emission is linearly related to $V_{100}$, the volume fraction of drops with diameter less than $100 \mu \mathrm{m}$. Therefore the ratio of $\mathrm{V}_{100}$ values in simulation and in practice could be used as a correction factor applied to simulated airborne emissions.

\subsubsection{Dealing with various units to express deposits}

Usually, downwind ground deposits of spray drift are expressed as a percentage of the in-field applied dose of pesticides. It gives a relative measure of spray drift compared to what was applied. The advantage of this approach is that different application techniques can be compared easily regarding their performance with respect to the occurrence of spray drift. For the actual exposure of non-target organisms (including humans) to spray drift, the absolute exposure dose can be computed by multiplying the drift percentage and the applied dose.

For instance, assume the applied dose is $1 \mathrm{~kg} / \mathrm{ha}$ onto the crop field. If at some downwind distance the drift deposits are $5 \%$ of the applied dose, the absolute deposits at that location equal 0.5 times the applied dose, that is $0.05 \mathrm{~kg} / \mathrm{ha}$, or $5 \mathrm{mg} / \mathrm{m}^{2}$. Another example of this conversion is given in case 1 , Section 4.1.1.

In this study ground deposits are expressed mainly as percentages of the applied dose, while airborne emissions are expressed as absolute doses, as the latter are used in subsequent models to compute exposure of residents to pesticides. 


\section{$4 \quad$ Simulation results}

The simulations of all 14 cases will be discussed in this chapter. This involves spray drift deposits on the ground next to the treated flower bulb field (0-5 m downwind) and airborne emissions evaluated as vertical concentration or flux profiles up to $6.25 \mathrm{~m}$, at $5 \mathrm{~m}$ downwind from the fields.

In each case one or two fields formed the 'basis' fields, for which all relevant information was recorded in the CLM survey (Deliverable 112). Often, several other flower bulb field were treated on the same day, using the same or a slightly different product mixture. In the simulations the spray applications on these 'secondary' fields was assumed to take place at the same time of day (see Section 3.1). In many cases the drift results obtained for the basis field could be applied to the secondary fields as well. In some situations, additional simulations were required: (a) when product mixture on the secondary fields differed from that at the basis field, or (b) when the orientation of the secondary fields differed significantly from that of the basis field (causing significant differences in effective wind direction).

Typically, two simulation runs were required since there are two downwind field edges. Whenever additional simulations were required, these are stated with the results below.

\subsection{Case 1: location 101, May 26, 2016}

In case 1 , the treatment of 6 fields is followed. Figure 3 shows a layout of these fields. Field 101 is the basis where most information is gathered. Spray was applied at 12 UT (Table 1). The other fields were treated on the same day, yet the time of application was unknown. It was assumed that these fields were sprayed earlier, at 10 UT. The spray mixture is known for each field from the CLM survey (Deliverable 112). For fields 101 and 102 the same tank mixture was applied, whereas for the other fields a slightly different mixture was used (Table 2; extracted from Table A.1 in Annex 1). In case of fields 101 and 102, the mixed products added up to a dose of $2.74 \mathrm{~kg} / \mathrm{ha}$. This was applied by spraying 200 L/ha using Airmix 11003 nozzles, classified as DRT75 (Table A.2, Annex 1). Based on nozzle type and applied dose rate the required concentration in the tank was computed to be $13.7 \mathrm{~g} / \mathrm{L}$. This parameter determines the amount of (involatile) products in each droplet, which subsequently determines the final (dried) particle size when all solvent has evaporated (assuming the particle still is airborne). The product in the tank contained four active ingredients; these are listed in Table 2 . Note that the a.i. contents do not add up to the value given as total product $(2.74 \mathrm{~kg} / \mathrm{ha})$, since the formulated products also contain ingredients not considered a.i.

The table shows that for fields 101 and 102, mancozeb was applied at a rate of $1.5 \mathrm{~kg} / \mathrm{ha}$, whereas the total tank mixture was applied at rate $2.74 \mathrm{~kg} / \mathrm{ha}$. Clearly, the fraction of mancozeb in the mixed products was $1.5 / 2.74=0.547$. Therefore, emissions computed by IDEFICS (relating to the total mixture) can be simply multiplied by 0.547 to determine the emissions of mancozeb in this case. Emissions for each a.i. were determined in a similar way.

The effective wind direction at the SE edge of field 101 was about $30^{\circ}$ (Table A.2, Annex 1). The effective wind direction at the NE edge of field 102 was about 54\%. Roughly, most fields in Figure 3 were oriented such that the same effective wind directions could be used. All fields are represented by a quadrangle, disregarding the actual boundary layout. Thus it may seem that the edge orientations of some fields (like 103 and 113) do not fit well to those of fields 101 and 102. The dashed lines in Figure 3 show that the actual boundaries are much better represented by SE side of 101 and NE side of 102 . This implied that spray drift results for field 101, SE edge, could be used for other SE edges as well. Similarly, spray drift results for $102-$ NE were applicable to other NE edges. 


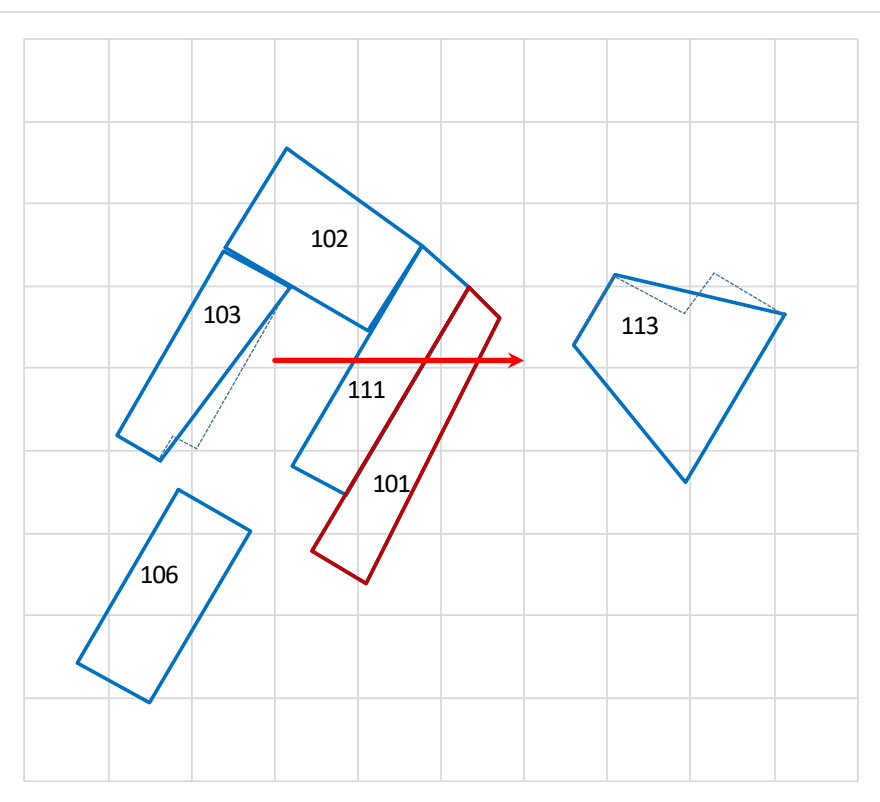

Figure 3 Schematic view of treated flower bulb fields at same day, case 1. Field 101 is the basis field. The arrow indicates wind direction at time of spray application. Squares indicate an $100 \times 100 \mathrm{~m}^{2}$ area. Dashed lines indicate actual field edges.

The tank mixture (total products content) for fields 103, 106, 111 and 113 differed from that for 101 and 102 , so this required a separate simulation. Besides, the assumed time of application was different, which qualified for a separate simulation also. As the drift at NE edges was significantly lower than at the SE edges (due to the larger effective wind direction), it was decided not to carry out additional simulations for NE edges for fields $103,106,111,113$. The results for $102-N E$ should suffice for these fields as well.

Table 2 Tank mixture and active ingredients in treatments of case 1.

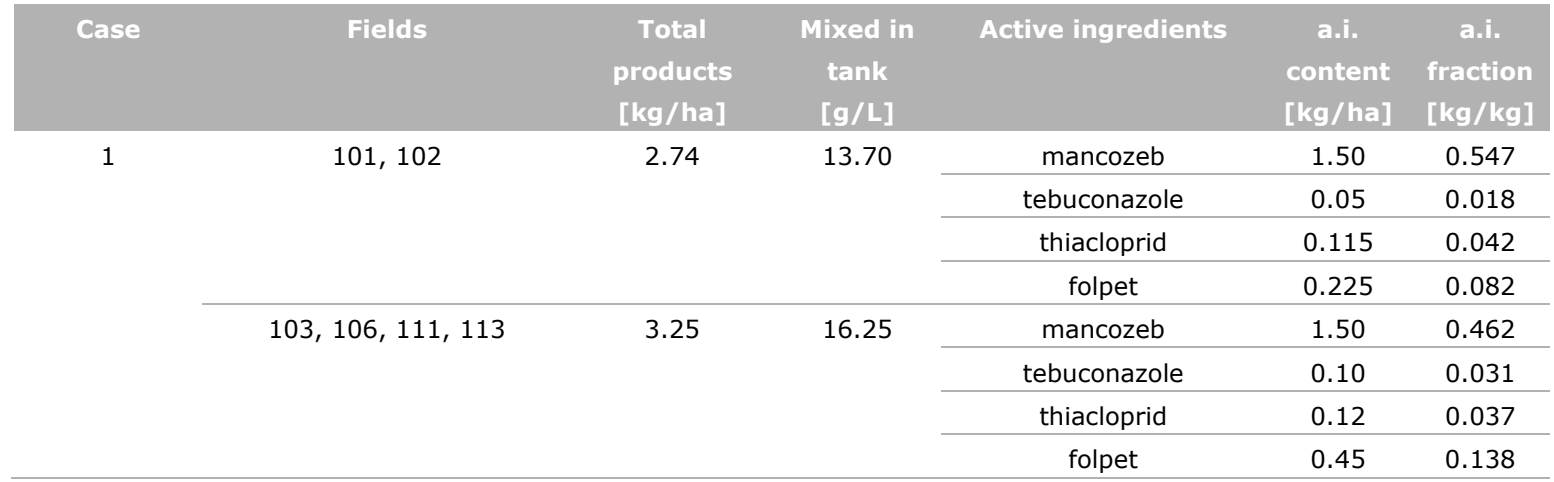

\subsubsection{Ground deposits}

Figure 4 shows the deposits of spray and spray drift at the crop and at the ground downwind from the crop, field 101 SE field edge, field 102 NE edge, field 111 SE edge. The curves are based on simulation for one swath and extrapolated for subsequent swaths, assuming an infinitely extended field in upwind direction. It can be shown that the contributions of swath 2 and beyond are insignificant for these downwind ground deposits. The distance presented in the graph is measured perpendicular to the field edge. Note that within $5 \mathrm{~m}$ the deposits are $<0.1 \%$ of the applied dose onto the crop.

Deposits are given as percentage of applied dose. Absolute deposits can be derived from this easily. For instance, mancozeb is applied at dose rate of $1.50 \mathrm{~kg} / \mathrm{ha}$ (Table 1 ). Figure 4 indicates that at $5 \mathrm{~m}$ 
downwind the ground deposits for $101-\mathrm{SE}$ are about $0.07 \%$ of the applied dose. That is, at that location the deposits of mancozeb are about $0.001 \mathrm{~kg} / \mathrm{ha}$ or $0.1 \mathrm{mg} / \mathrm{m}^{2}$. Similarly, other absolute deposits can be computed.

Deposits for 111-SE are slightly lower, due to the slightly higher concentration of products. A higher concentration of products in the tank has two effects: (a) drops of same size have slightly higher mass, (b) size of dried particles is slightly larger, compared to drops of low-concentration spray liquids. Both effects cause an increased sedimentation of drops and particles, primarily onto the crop. Consequently, spray drift and downwind deposits should decrease. However, the curves in Figure 4 indicate that these effects are only small.

Deposits for 102-NE are significantly lower than the deposits at the SE edges. This is primarily due to a larger effective wind direction ( $54^{\circ}$ compared to $30^{\circ}$ for SE edges). For a drop to reach a certain distance off the edge, the effective travelling distance is increased by $1 / \cos \left(54^{\circ}\right)=1.70$ for NE edges while this is $1 / \cos \left(30^{\circ}\right)=1.15$ for SE edges. A larger travelling distance relates to a lower probability for the drop to reach that point, thus deposits at a certain (perpendicular) distance must decrease when the effective wind direction increases.

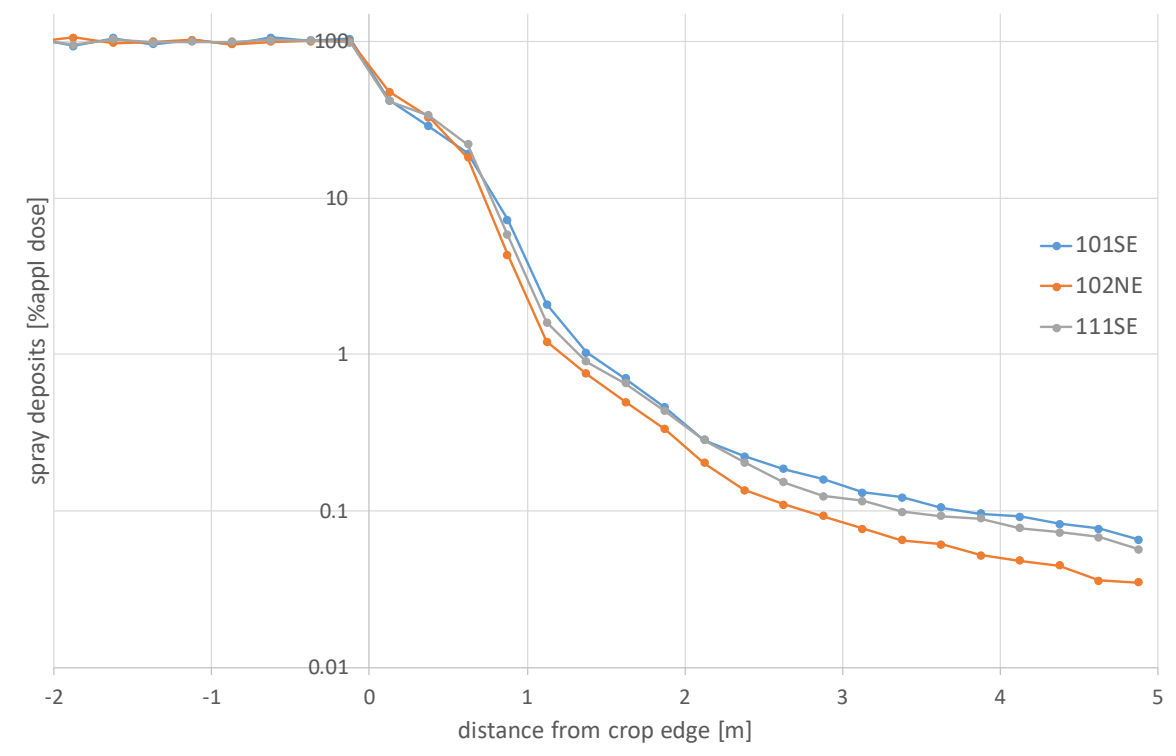

Figure 4 Spray deposits at the crop $(x<0)$ and at the ground downwind from treated field $(x>0)$, as a percentage of applied dose; case 1, field 101, SE edge; 102, NE edge; 111 SE edge. An infinite field is assumed in upwind direction.

\subsubsection{Airborne emission}

Figure 5 shows the vertical profile of airborne emission as a function of height above ground level, determined at $5 \mathrm{~m}$ off the SE field edge for field 101. The emission is cumulative over the time of application, that is, it gives the total mass passing an imaginary vertical screen, per $\mathrm{m}^{2}$ screen size, after the drift cloud has passed completely. The blue curve is the simulation result for 3 swaths, representing a field width of $60 \mathrm{~m}$. The emission decreases rapidly with increasing height. The highest emission occurs at about $0.5 \mathrm{~m}$ height, that is, slightly below the boom height $(1.0 \mathrm{~m}$ above ground level). The dashed orange curve includes extrapolation to an infinite field in upwind direction. It shows that there is significant contribution to airborne emission from a $4^{\text {th }}$ and subsequent swath (if the field width is more than $60 \mathrm{~m}$ ). The relative significance is more pronounced at higher levels above the ground. 


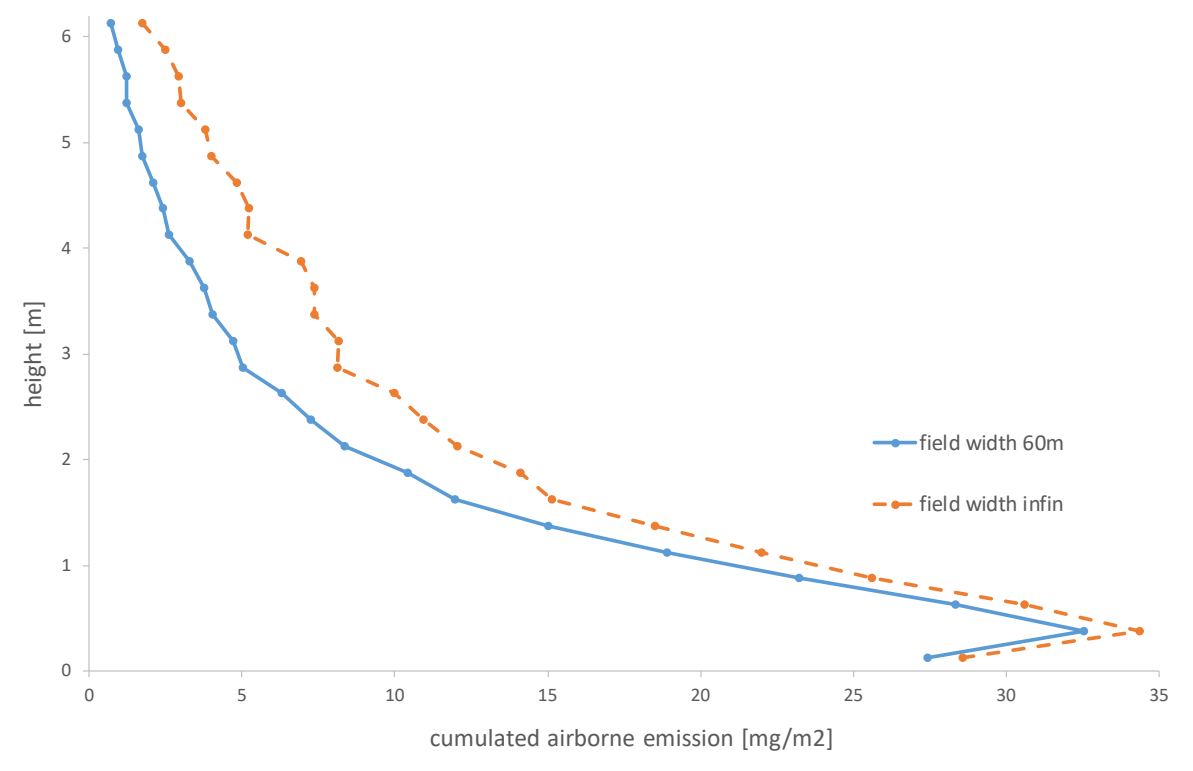

Figure 5 Airborne emission as a function of height; for case 1, field 101 SE edge, 5 m downwind. Blue curve: assuming a $60 \mathrm{~m}$ wide field; orange dashed curve: estimated extrapolation to an infinitely extended field (upwind).

Clearly, infinite field widths do not occur in practice, whereas in Case 1 the $60 \mathrm{~m}$ field width is more realistic for the SE edges (Figure 3). Therefore only the simulation results for $60 \mathrm{~m}$ field widths are used from now on. Considering the NE edges in Case 1, for field 101, 103, 106 and 111 their widths refer to the length of these fields, which is much longer than $60 \mathrm{~m}$. Still, the results for $60 \mathrm{~m}$ width are used for these edges as well; see Discussion section.

Figure 6 shows the results of airborne emissions for a $60 \mathrm{~m}$ wide field at three different edges: 101-SE, 102-NE and 111-SE. Both SE emissions appear to be very similar. A small difference is due to the larger amount of products sprayed at field 111 . The emission 101-SE is considered representative for field 102 as well, since the SE edge of field 102 is parallel to that of 101 and the same products are sprayed (Table 2). Similarly, emission at 111-SE is representative for SE edges of fields 103, 106 and 113. For 102-NE, the effective wind direction is far from perpendicular to the field edge and airborne emissions at $5 \mathrm{~m}$ downwind are significantly lower. This is mainly due to the larger distance travelled by the spray cloud to reach the $5 \mathrm{~m}$ zone (see also section 4.1.1). The results for 102-NE were considered representative for all other NE edges as well. Like for the SE edges, a possible difference due to different tank mixture is likely to be insignificant.

The blue curve gives the emission at the SE edge of field 101; the orange curve that at the NE edge. The latter shows much lower emission, which is caused by the difference in effective wind direction with respect to the SE and NE edges.

Note that the presented values of mass flows refer to the sum of formulated products in the spray liquid. For instance, to obtain the airborne emission profile for mancozeb in this case, the values should be multiplied by 0.547 (see Table 2). This gives peak values of about $16 \mathrm{mg} / \mathrm{m}^{2}$ at $0.5 \mathrm{~m}$ height downwind the SE edge. Compared to ground deposits of mancozeb that are about $0.1 \mathrm{mg} / \mathrm{m}^{2}$ at $5 \mathrm{~m}$ downwind the SE edge (Section 4.1.1), it is clear that airborne emissions can be much higher than ground deposits (in this case approximately 160 times higher). The curves of Figure 6, combined with the a.i. fractions of Table 2 represent input for the OPS dispersion model (Jacobs et al., 2018). The dose of mancozeb applied is $1.5 \mathrm{~kg} / \mathrm{ha}$ or $150 \mathrm{mg} / \mathrm{m}^{2}$ (Table 2). Note that the peak in airborne emission at $5 \mathrm{~m}$ downwind is about $10 \%$ of the applied dose. 


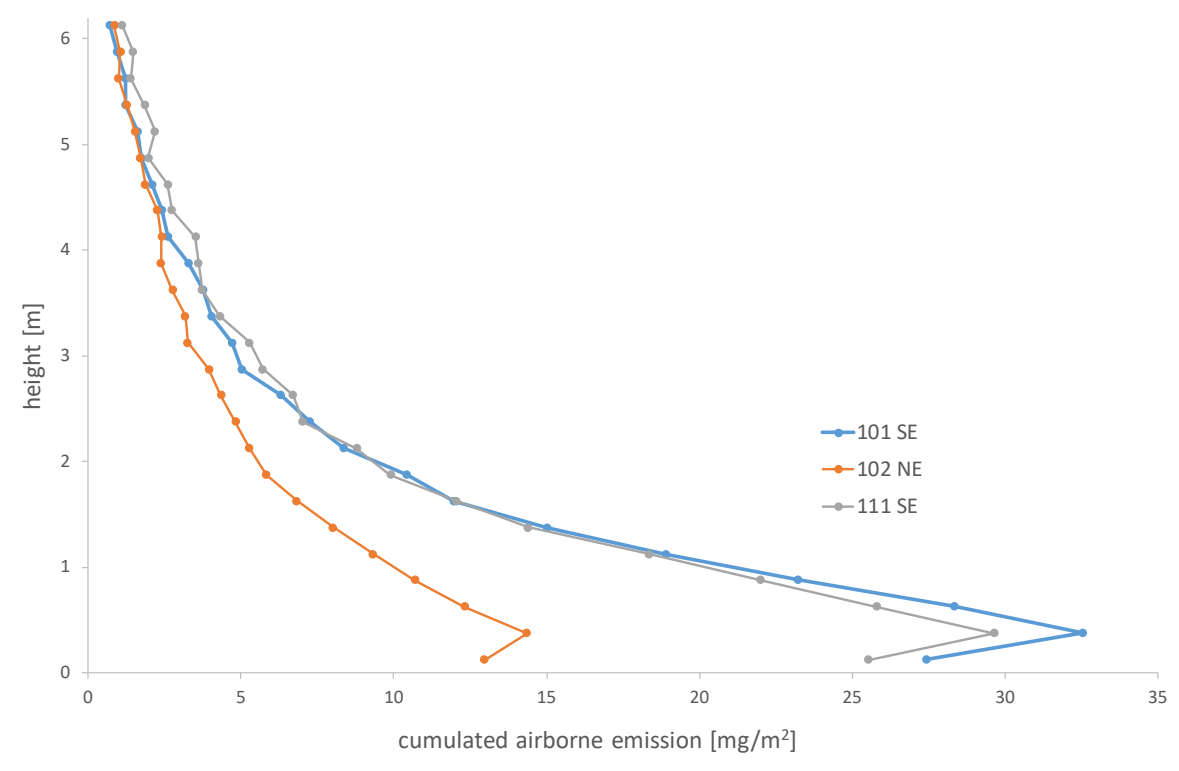

Figure 6 Airborne emission as a function of height; case 1. Simulation results for 60m wide field, edges: 101-SE, 102-NE and 111-SE.

\subsection{Case 2: location 111, July 20, 2016}

In case 2 , in the same area as of case 1 the treatment of 4 fields is followed. Figure 7 shows a layout of these fields. Field 111 is the basis where most information is gathered. Spray was applied at 19 UT (Table 1). The other fields were treated on the same day, yet the time of application was unknown. It was assumed that these fields were sprayed earlier, at 16 UT. The spray mixture is known for each field from the CLM survey (Deliverable 112). For all fields the same tank mixture was applied (Table 3; extracted from Table A.1 in Annex 1). The mixed products added up to a dose of $0.44 \mathrm{~kg} / \mathrm{ha}$. This was applied by spraying 200 L/ha using Airmix 11003 nozzles, classified as DRT75 (Table A.2, Annex 1). This implied that the required concentration in the tank was $2.20 \mathrm{~g} / \mathrm{L}$. The product in the tank contained three active ingredients as listed in Table 3. Note that the a.i. contents do not add up to the value given as total product $(0.44 \mathrm{~kg} / \mathrm{ha})$, since the formulated products also contain ingredients not considered a.i. The last column in the table shows the fraction of each a.i. in the product in the tank. Emissions computed by IDEFICS are based on the full tank mixture and must be multiplied by this fraction to obtain the emission values of each a.i. in the product.

The effective wind direction at the SE edge of field 111 was about $70^{\circ}$ (Table A.2, Annex 1). At the NE edge of field 111 this was about $20^{\circ}$. Roughly, NE and SE edges of the fields in Figure 7 were oriented in a similar way; therefore the same effective wind directions were used for all four fields. This implied that spray drift results for field 111, SE edge, could be applied for the SE edges of the other fields too. Similarly, spray drift results for 111-NE were applicable to other NE edges. As the effective wind direction at NE and SE edges was different, separate spray drift simulations were required.

Table 3 Tank mixture and active ingredients in treatments of case 2.

\begin{tabular}{|c|c|c|c|c|c|c|}
\hline Case & Fields & $\begin{array}{c}\text { Total } \\
\text { products } \\
\text { [kg/ha] }\end{array}$ & $\begin{array}{c}\text { Mixed in } \\
\text { tank } \\
{[\mathrm{g} / \mathrm{L}]}\end{array}$ & Active ingredients & $\begin{array}{c}\text { a.i. } \\
\text { content } \\
\text { [kg/ha] }\end{array}$ & $\begin{array}{c}\text { a.i. } \\
\text { fraction } \\
{[\mathrm{kg} / \mathrm{kg}]}\end{array}$ \\
\hline \multirow{2}{*}{2} & & & & fluopyram & 0.075 & 0.170 \\
\hline & & & & trifloxystrobin & 0.075 & 0.170 \\
\hline
\end{tabular}




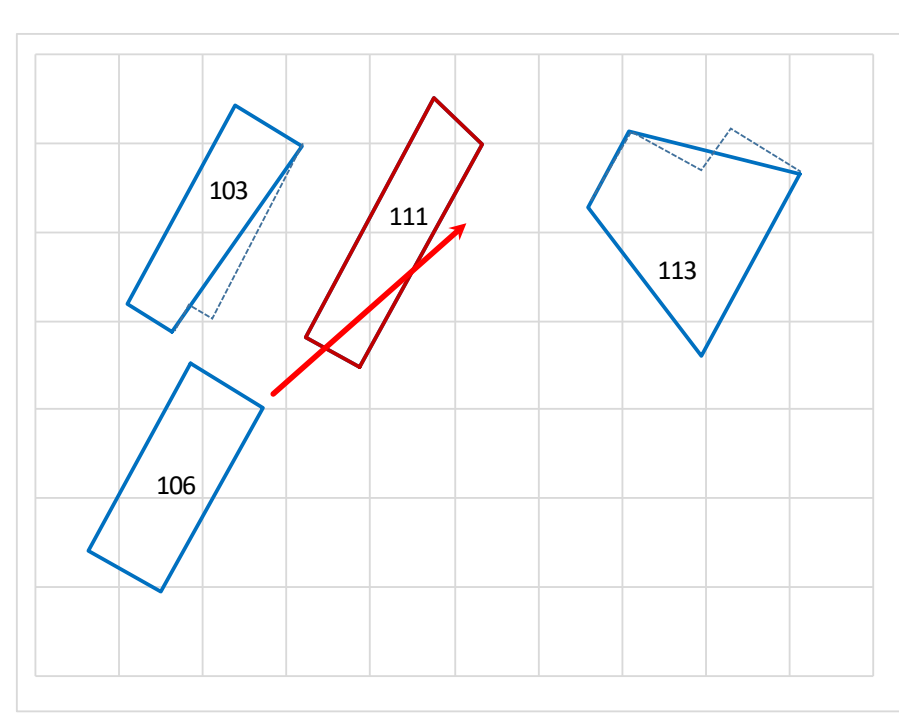

Figure $7 \quad$ Schematic view of treated flower bulb fields at same day, case 2. Field 111 is the basis field. The arrow indicates wind direction at time of spray application. Squares indicate an $100 \times 100 \mathrm{~m}^{2}$ area. Dashed lines indicate actual field edges.

\subsubsection{Ground deposits}

Figure 8 shows the deposits of spray and spray drift at the crop and at the ground downwind from the crop, field 111 SE field edge and field 106 NE edge. The curves are based on simulation for one swath and extrapolated for subsequent swaths, assuming an infinitely extended field in upwind direction. It can be shown that the contributions of swath 2 and beyond are insignificant for these downwind ground deposits. The distance presented in the graph is measured perpendicular to the field edge. Spray drift deposits at $5 \mathrm{~m}$ off the SE edge are significantly lower than at the NE edge, due to difference in effective wind direction which directly affects the effective distance travelled. The distance that spray clouds must travel to reach the $5 \mathrm{~m}$ downwind position is increased by a factor $1 / \cos \left(70^{\circ}\right)=2.92$ and $1 / \cos \left(20^{\circ}\right)=1.06$ for SE and NE edges, respectively.

\subsubsection{Airborne emission}

Figure 9 shows the vertical profile of airborne emission as a function of height above ground level, determined at $5 \mathrm{~m}$ off the SE field edge and NE edge. The emission shown is cumulative over the time of application, that is, it gives the total mass as an areal density $\left(\mathrm{mg} \mathrm{m}^{-2}\right.$ ) passing an imaginary vertical screen after the drift cloud has passed completely. The curves represent emissions for a field width of $60 \mathrm{~m}$. The emission decreases rapidly with increasing height. The highest emission occurs at about $0.5 \mathrm{~m}$ height, which is slightly below the boom height ( $1.0 \mathrm{~m}$ above ground level). Similar to case 1 , it can be shown that the peak value of airborne emission is about 180 times higher than the ground deposits of spray drift at that downwind location. Note the huge difference between the emission at the NE edge and at the SE edge, caused by differences in effective wind direction. However, differences in emission decrease with increasing heights above the ground. The presented values of emission refer to the sum of formulated products in the spray liquid. To obtain emission values for each a.i. the values in the graph should be multiplied by the values in the last column of Table 3.

Compared to the full dose of $0.44 \mathrm{~kg} / \mathrm{ha}$, or $44 \mathrm{mg} / \mathrm{m}^{2}$ (Table 3), the peak airborne emission of slightly above $10 \mathrm{mg} / \mathrm{m}^{2}$ (Figure 9) correspond to almost $25 \%$ of the applied dose. 


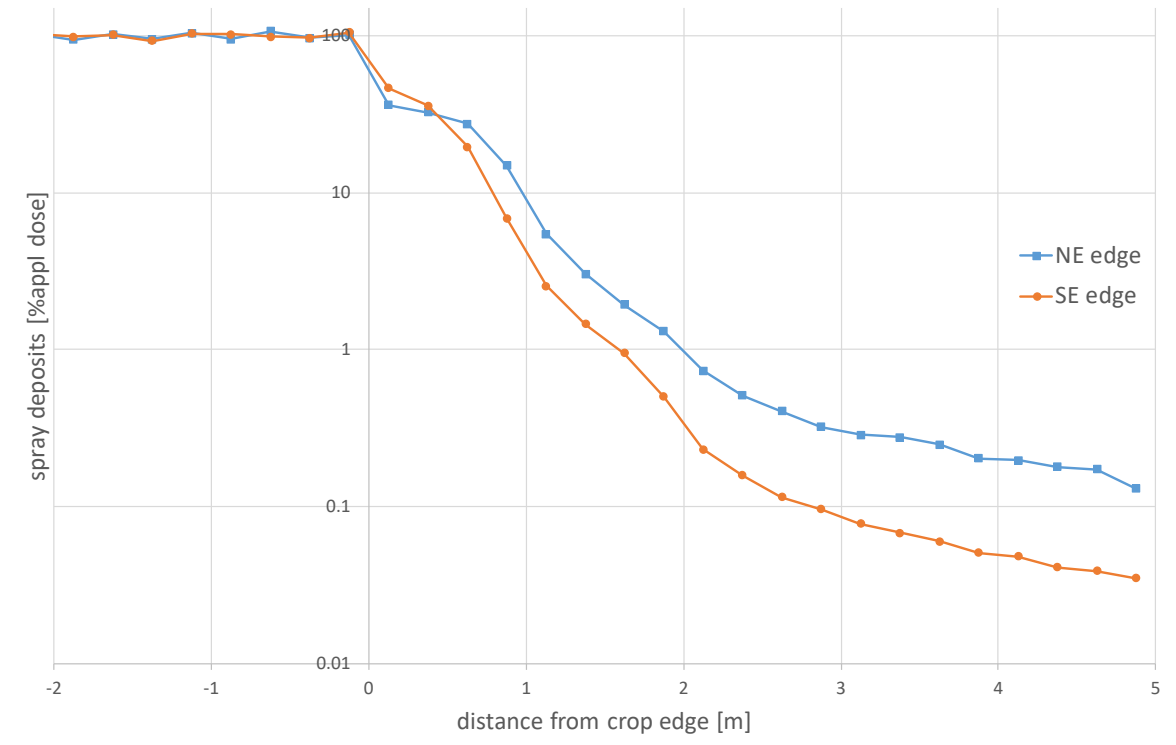

Figure 8 Spray deposits at the crop $(x<0)$ and at the ground downwind from treated field $(x>0)$, as a percentage of applied dose; case 2, field 111 SE edge; field 106 NE edge. An infinite field is assumed in upwind direction.

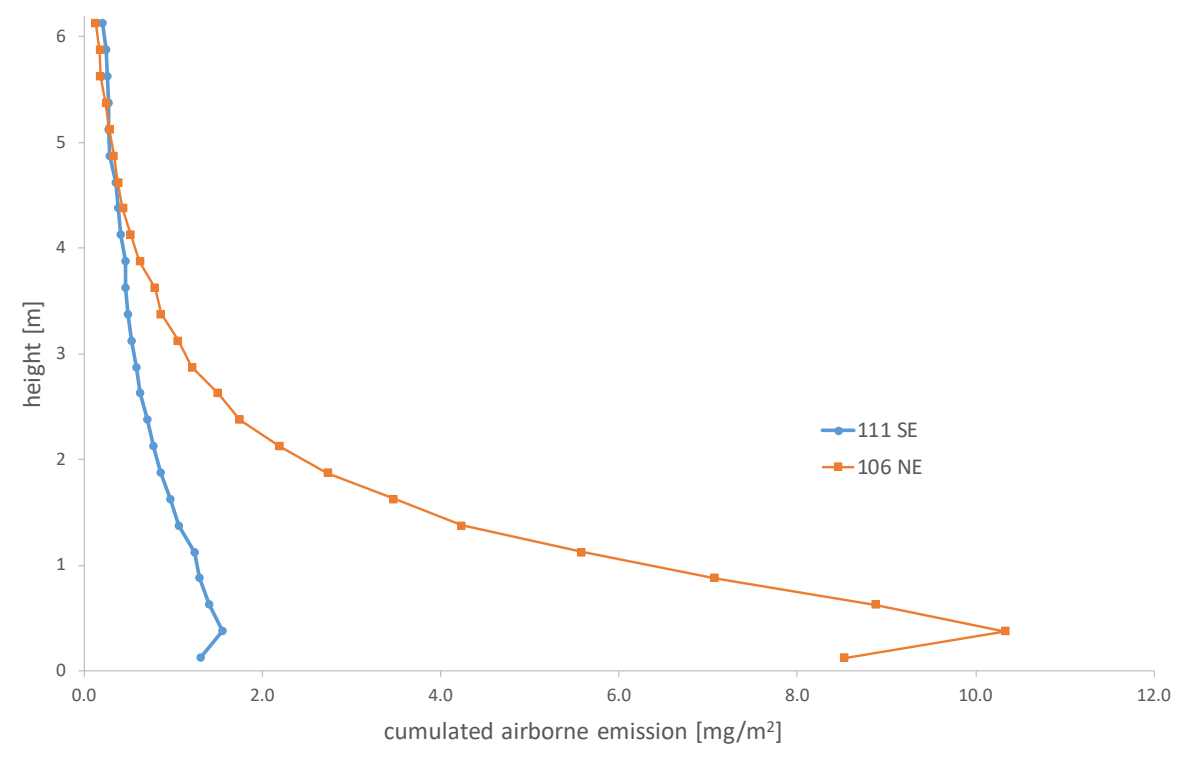

Figure 9 Airborne emission as a function of height; case 2. Simulation results for 60m wide field, edges: 111-SE and 106-NE.

\subsection{Case 3: location 121, February 24, 2017}

In case 3, in the same area as of previous cases the treatment of 1 field (121) is followed. The application involves a herbicide treatment on bare ground. Figure 10 shows a layout of these fields. Dashed fields indicate the position of neighbouring fields from previous cases. Spray was applied at 16 UT (Table 1). The tank mixture consisted of only one product, applied at $2.0 \mathrm{~kg} / \mathrm{ha}$. It contained $40 \%$ chlorpropham as a.i. (Table 4; extracted from Table A.1 in Annex 1). The effective wind direction at the SE and NE edges of field 121 were $10^{\circ}$ and $46^{\circ}$, respectively (Table A.2, Annex 1).

At the time the spray drift simulations were carried out, no information was available on nozzles used and sprayer settings from the CLM survey. Therefore, a common choice was made, assuming ID 11004 
nozzles at a liquid pressure of $300 \mathrm{kPa}$ (DRT90) and a liquid dose rate of $400 \mathrm{~L} / \mathrm{ha}$ (Table A.2, Annex 1). Later on, the CLM survey was completed and indicated that Airmix 11004 nozzles were used at liquid pressure $300 \mathrm{kPa}$ and liquid dose rate of $600 \mathrm{~L} / \mathrm{ha}$. The drop size distributions of the ID 11004 and Airmix 11004 nozzles at the given pressures are almost the same. However, the liquid dose rate from the survey appeared to be 1.5 times higher than that used in the simulations. Since spray drift directly relates to drop size distribution, the simulation results regarding spray drift as a percentage of applied dose should not be affected by the change of nozzles. The liquid dose rate is higher in the survey, yet the actual dose rate of products (in $\mathrm{kg} / \mathrm{ha}$ ) is unchanged, and combined with the same spray drift values, no corrections should be necessary to account for the change of nozzle type. However, a higher liquid dose rate implies a lower concentration of products in the tank, which leads to dried airborne particles to be about $13 \%$ smaller in diameter. This does not affects their aerodynamic behaviour, though.

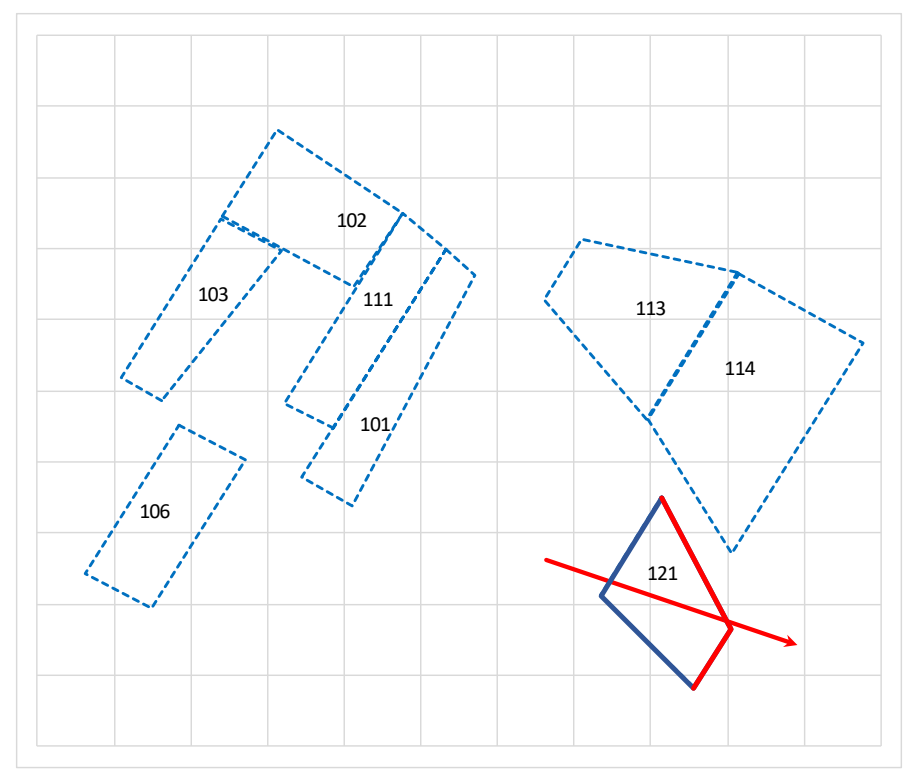

Figure 10 Schematic view of treated flower bulb fields at same day, case 3. Field 121 is the basis field; no other fields were treated on the same day. The arrow indicates wind direction at time of spray application. Squares indicate an $100 \times 100 \mathrm{~m}^{2}$ area. Dashed fields indicate other flower bulb fields in the neighbourhood.

Table 4 Tank mixture and active ingredients in treatments of case 3.

\begin{tabular}{|c|c|c|c|c|c|c|}
\hline Case & Fields & $\begin{array}{c}\text { Total } \\
\text { products } \\
\text { [kg/ha] }\end{array}$ & $\begin{array}{c}\text { Mixed in } \\
\text { tank } \\
\text { [g/L] }\end{array}$ & Active ingredients & $\begin{array}{c}\text { a.i. } \\
\text { content } \\
\text { [kg/ha] }\end{array}$ & $\begin{array}{c}\text { a.i. } \\
\text { fraction } \\
{[\mathrm{kg} / \mathrm{kg}]}\end{array}$ \\
\hline 3 & 121 & 2.0 & 5.0 & chlorpropham & 0.80 & 0.400 \\
\hline
\end{tabular}

\subsubsection{Ground deposits}

Figure 11 shows the deposits of spray and spray drift at the crop and at the ground downwind from the crop, at SE and NE field edges. The curves are based on simulation for one swath and extrapolated for subsequent swaths, assuming an infinitely extended field in upwind direction. It can be shown that the contributions of swath 2 and beyond are insignificant for these downwind ground deposits. The distance presented in the graph is measured perpendicular to the field edge. Spray drift deposits at $5 \mathrm{~m}$ off the NE edge are significantly lower than at the SE edge, due to difference in effective wind direction which directly affects the effective distance travelled. 


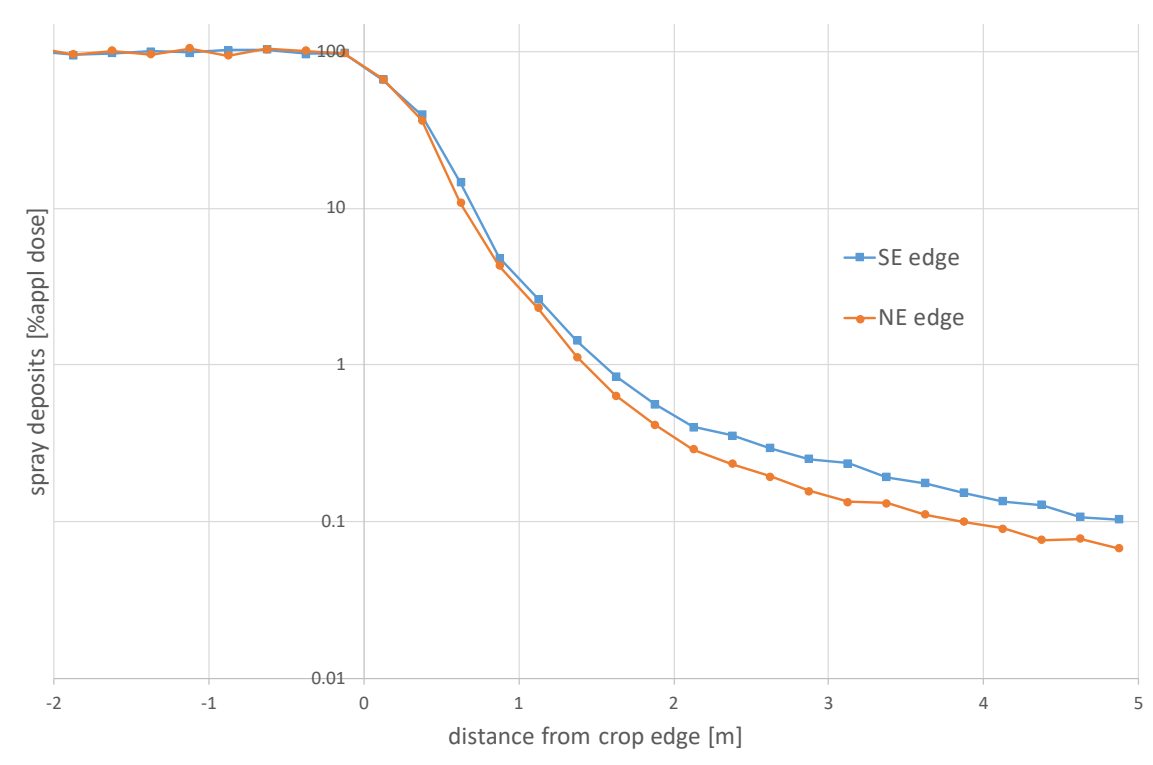

Figure 11 Spray deposits at the crop $(x<0)$ and at the ground downwind from treated field $(x>0)$, as a percentage of applied dose; case 3, field 121 SE and NE edge. An infinite field is assumed in upwind direction.

\subsubsection{Airborne emission}

Figure 12 shows the vertical profile of airborne emission as a function of height above ground level, determined at $5 \mathrm{~m}$ off the SE field edge and NE edge. The emission shown is cumulative over the time of application, giving the total mass as an areal density $\left(\mathrm{mg} \mathrm{m}^{-2}\right)$ passing an imaginary vertical screen after the drift cloud has passed completely. The curves represent emissions for a field width of $60 \mathrm{~m}$. A significant difference between the emission at the NE edge and at the SE edge occur caused by differences in effective wind direction. In the OPS model (Jacobs et al., 2018) the emission profile of chlorpropham was used, which is $40 \%$ of the emission represented by the curves in Figure 12 (see Table 4).

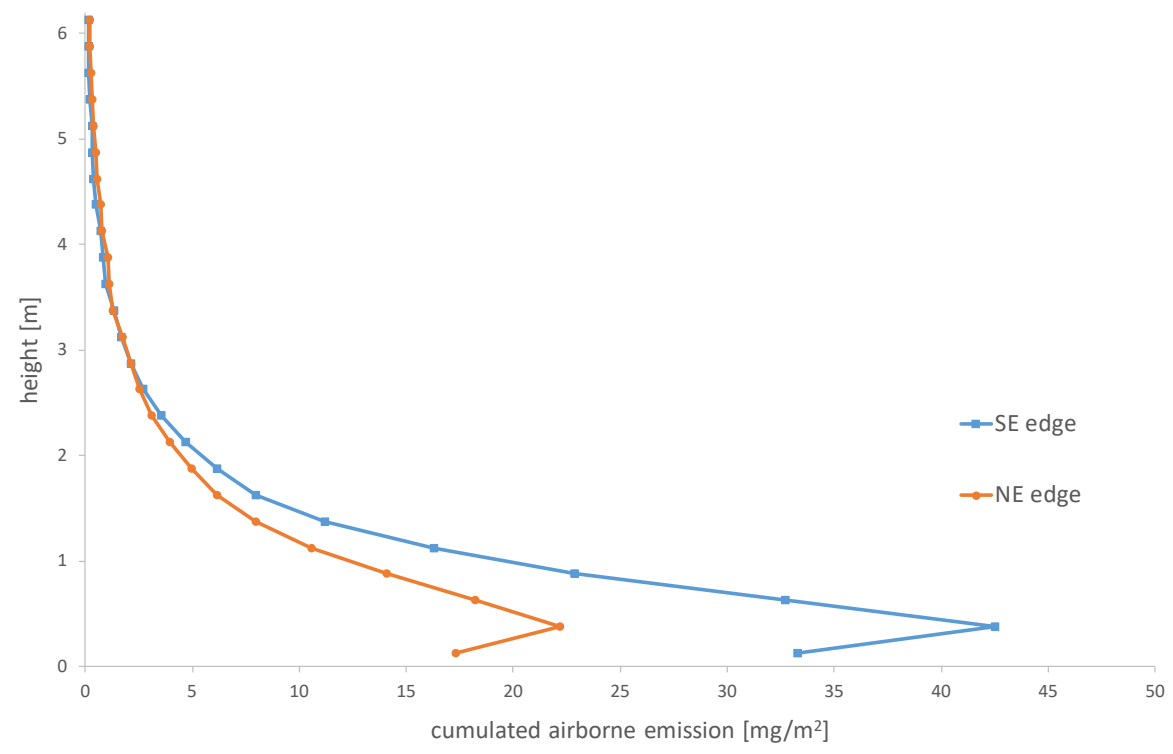

Figure 12 Airborne emission as a function of height; case 3. Simulation results for 60m wide field, SE and NE edges of field 121. 
Case 3 involves an application in February on a bare field (pre-emerging crop). Ambient temperature was relatively low while relative humidity was relatively high, compared to spray treatments in spring or summer. Additionally, average wind speed was relatively high. Consequently, airborne droplets easily reached the $5 \mathrm{~m}$ evaluation zone before losing much of their water solvent. As a result, at $5 \mathrm{~m}$ downwind a significant number of airborne droplets are present that may not be considered 'small' in aerodynamic sense (typically $<50 \mu \mathrm{m}$ ). The blue bars in Figure 13 shows the size distribution (by numbers) of these airborne particles for case 3. When all drops would have been dried completely, the orange bars would have been obtained. Clearly, a lot of drops still have size $>50 \mu \mathrm{m}$. However, the evaporation of the water solvent is continuing and, eventually, at larger distances downwind the drops will dry completely. Therefore, it was not considered worthwhile to treat these drops differently in the following steps of the project.
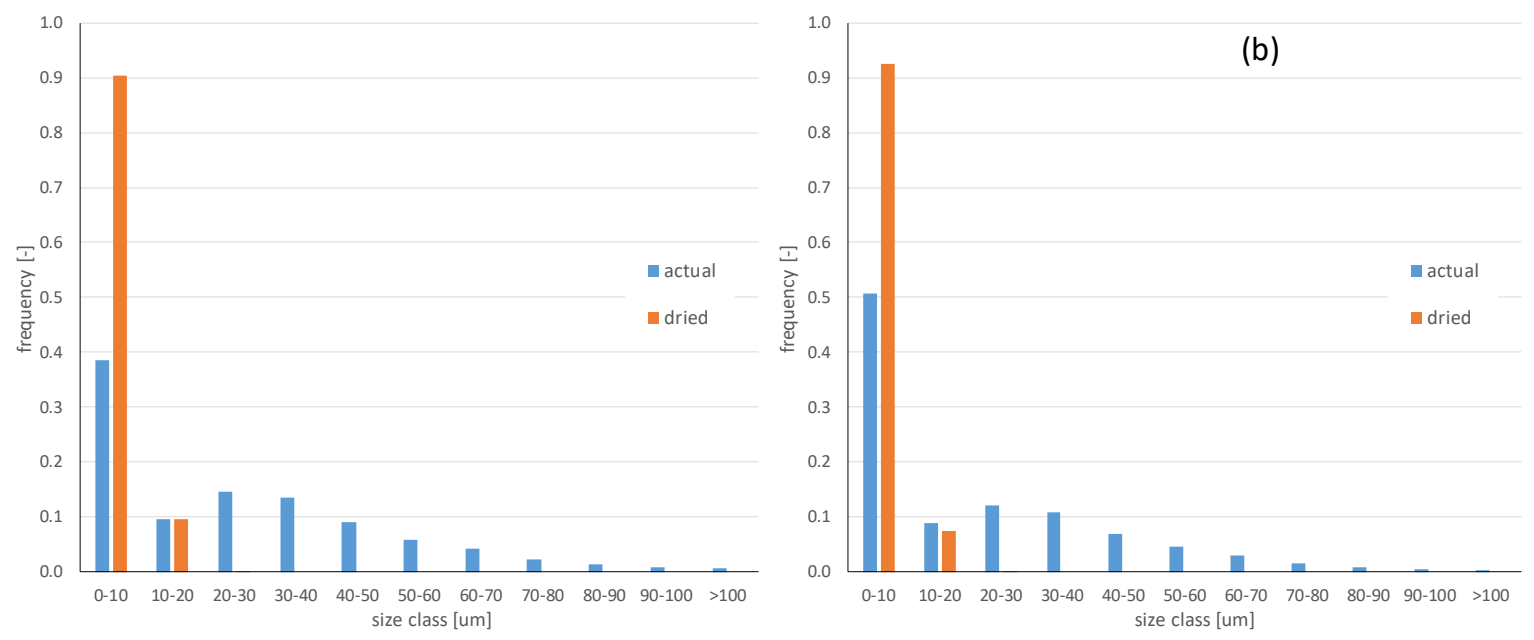

Figure 13 Size distribution of airborne particles at $5 \mathrm{~m}$ downwind from simulations, case 3, field 121. (a) SE edge; (b) NE edge. Blue bars indicate actual size distribution, both droplets and dry particles. Orange bars indicate same distribution, assuming the airborne droplets already would have dried completely.

Additionally, the size of airborne particles at the evaluation location differs with height above the ground. Figure 14 shows this height dependent size distribution. The volume mean diameter $\left(D_{30}\right)$ is shown for emissions at both SE and NE edges. Near the ground the mean diameter is about $40 \mu \mathrm{m}$, but diameter decreases significantly with increasing height. Since particles higher above the ground primarily originate from nozzle further upwind, on average these have lost more water solvent than drops closer to the ground. Assuming all these drops would have dried completely, the curves indicated by 'dried' would be obtained, showing mean particle size is around 7 to $8 \mu \mathrm{m}$ and relatively constant with height. 


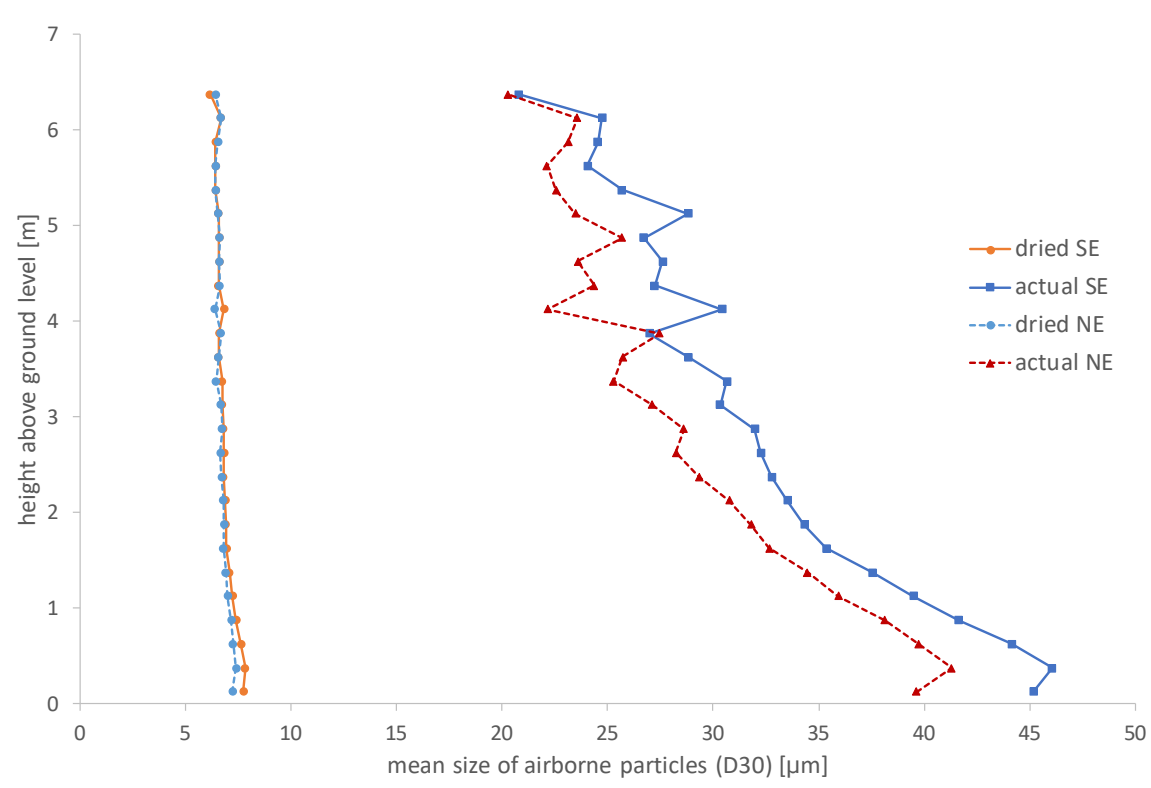

Figure 14 Size distribution of airborne particles vs height above the ground, at $5 \mathrm{~m}$ downwind from simulations, case 3, field 121, SE and NE edges. Actual size: consisting of both drops and dried particles as present at given location. Dried: assuming all actual particles would have dried completely.

For nozzles positioned far enough upwind from the field edge, the spray cloud may extend higher than the $6.25 \mathrm{~m}$ drift pole. Figure 15 shows the estimated fraction of emission for each nozzle that passes above this $6.25 \mathrm{~m}$ level. Spray clouds for nozzle positions 0-20 $\mathrm{m}$ from the edge appear not to spread out higher than $6 \mathrm{~m}$. However, for nozzles further upwind the emission above $6.25 \mathrm{~m}$ increases rapidly. For a nozzle located $60 \mathrm{~m}$ upwind from the SE edge (that is, at the other side of the field) about $2.5 \%$ of its total airborne emission ends up higher than $6.25 \mathrm{~m}$ at the $5 \mathrm{~m}$ evaluation distance downwind. For the NE edge the fraction passing above $6.25 \mathrm{~m}$ is significantly higher (about $8 \%$ ), since the drifting spray cloud starting at the $60 \mathrm{~m}$ nozzle position must travel a much longer distance due to the effective wind direction of $46^{\circ}$. Clearly, the absolute emission of such far field nozzles is very low. Cumulated for a $60 \mathrm{~m}$ wide field, the total fraction passing above the given height is $0.2 \%$ and $1.0 \%$ of total airborne emission at the SE and NE edges, respectively.

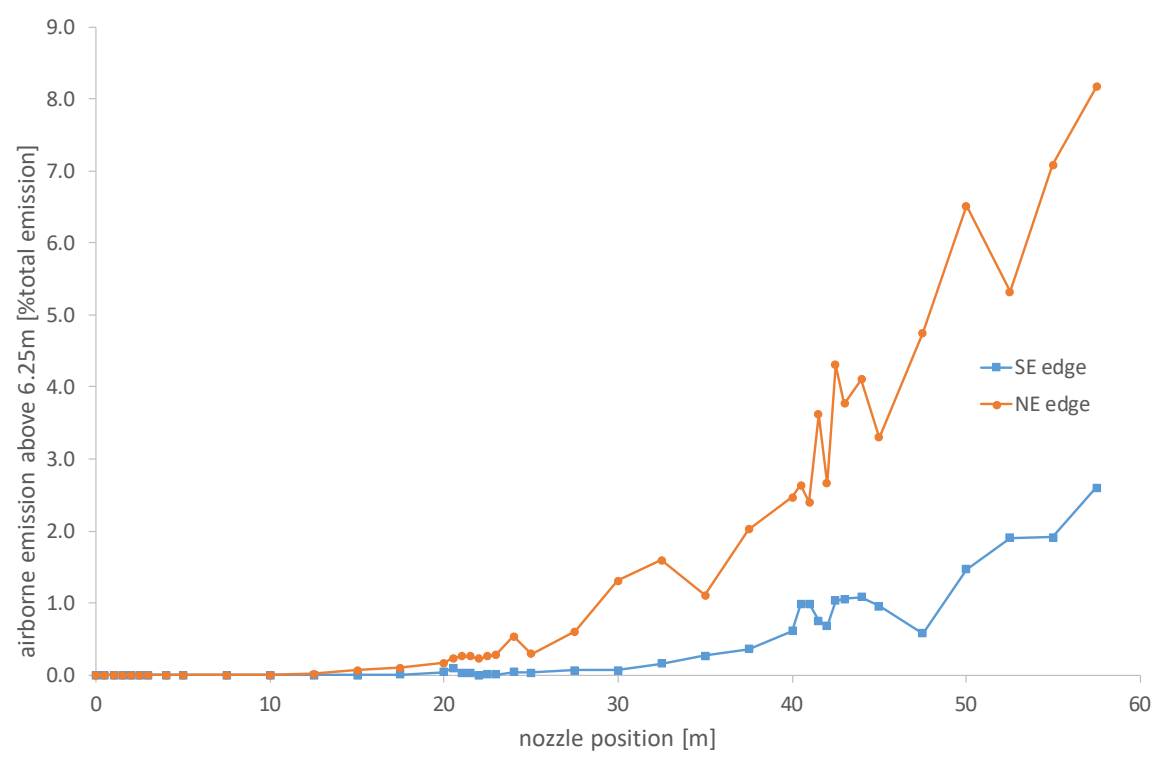

Figure 15 Airborne emission for each nozzle passing above drift pole $(>6.25 \mathrm{~m})$ as a function of upwind nozzle position; case 3, field 121 SE and NE edge. Values shown represent fraction of total airborne emission for each nozzle. 


\subsection{Case 4: location 121, May 9, 2017}

Case 4 involves the same field as that of case 3, yet now a fungicide/insecticide treatment on the flower bulb crop is carried out (Table 1, Section 3.1). Apart from field 121, field 114 is treated on the same day however using a different product mixture (Table 5); see also Figure 16 for layout of the fields and the average wind direction at the time of spray application (12 UT; Table 1). Dashed fields indicate the position of neighbouring fields from previous cases.

In the simulations a liquid dose rate of $200 \mathrm{~L} / \mathrm{ha}$ was assumed using Airmix 11003 nozzles at a liquid pressure of $200 \mathrm{kPa}$ (Table A.2, Annex 1; DRT75). Liquid dose rate and pressure differed from the CLM survey, since at the time the simulations were carried out, the survey was still incomplete and a common assumption was made regarding the application settings. The downwind edges of fields 121 and 114 were on SW and SE side. For field 121 the effective wind directions were $57^{\circ}$ and $50^{\circ}$ at SW and SE sides, respectively. Field 114 had a slightly different shape; the effective wind directions were $70^{\circ}$ and $50^{\circ}$ for SW and SE sides, respectively (Table A.2, Annex 1).

The CLM survey mentioned the use of the same nozzles (Airmix 11003) as chosen in the simulations, yet at pressure $300 \mathrm{kPa}$ and liquid dose rate of $300 \mathrm{~L} / \mathrm{ha}$. The volume fraction $\mathrm{V}_{100}$ of small drift-prone drops is estimated to be 1.5 times higher in the real situation compared to the simulation, due to the rise in pressure. The higher liquid dose rate leads to 1.5 times more drift (by spray volume), which is equally compensated by the 1.5 times lower concentration of products in the tank mixture. Effectively, spray drift results from the simulations should be corrected by a factor of 1.5 to account for the different $\mathrm{V}_{100}$ values. This correction was applied to airborne emissions only.

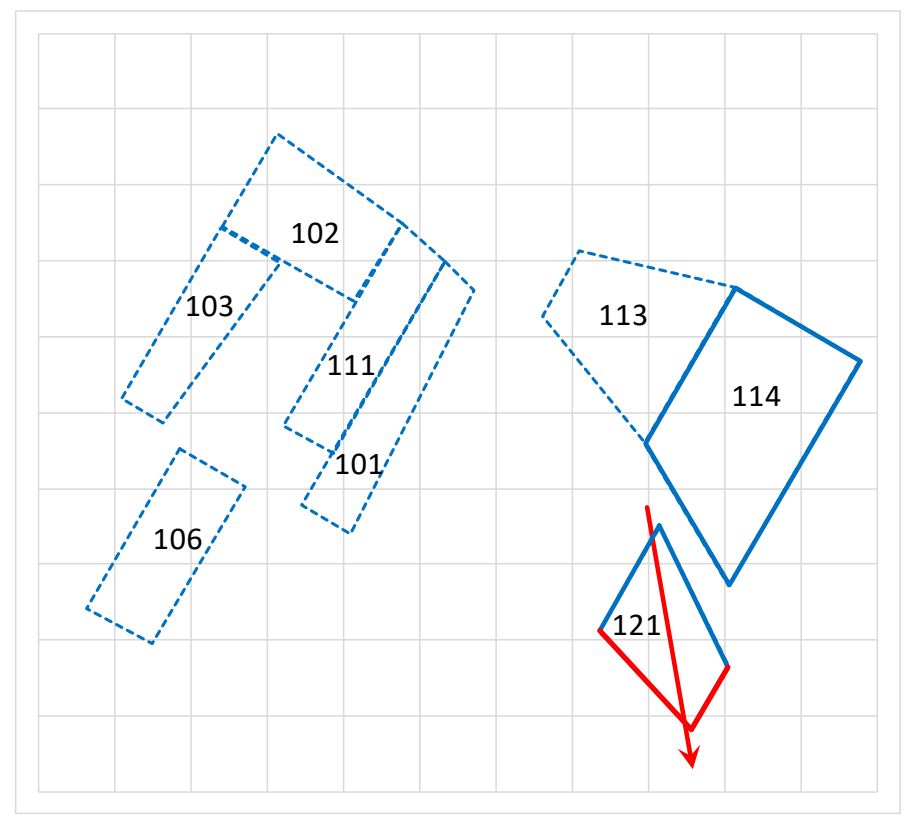

Figure 16 Schematic view of treated flower bulb fields at same day, case 4. Field 121 is the basis field; field 114 was treated on the same day but using a different product mixture. The arrow indicates wind direction at time of spray application. Squares indicate an $100 \times 100 \mathrm{~m}^{2}$ area. Dashed fields indicate other flower bulb fields in the neighbourhood. 
Table 5 Tank mixture and active ingredients in treatments of case 4.

\begin{tabular}{|c|c|c|c|c|c|c|}
\hline Case & Fields & $\begin{array}{c}\text { Total } \\
\text { products } \\
\text { [kg/ha] }\end{array}$ & $\begin{array}{c}\text { Mixed in } \\
\text { tank } \\
\text { [g/L] }\end{array}$ & Active ingredients & $\begin{array}{c}\text { a.i. } \\
\text { content } \\
\text { [kg/ha] }\end{array}$ & $\begin{array}{c}\text { a.i. } \\
\text { fraction } \\
{[\mathrm{kg} / \mathrm{kg}]}\end{array}$ \\
\hline \multirow{4}{*}{4} & & & & tebuconazole & 0.151 & 0.053 \\
\hline & 114 & 3.18 & 15.9 & mancozeb & 1.50 & 0.472 \\
\hline & & & & acetamiprid & 0.046 & 0.014 \\
\hline & & & & mepanipyrim & 0.154 & 0.048 \\
\hline
\end{tabular}

\subsubsection{Ground deposits}

Figure 17 shows the deposits of spray and spray drift at the crop and at the ground downwind from the crop, at SE and NE field edges of fields 121 and 114. The curves are based on simulation for one swath and extrapolated for subsequent swaths, assuming an infinitely extended field in upwind direction. The distance presented in the graph is measured perpendicular to the field edge. Apparently, these deposits (as \% of applied dose) are almost similar and insensitive to the different product dose rates for these fields. However, spray drift deposits at $5 \mathrm{~m}$ off the SW edge of field 114 are significantly lower than the other deposits, due to clear difference in effective wind direction.

\subsubsection{Airborne emission}

The vertical profiles of airborne emission are shown in Figure 18 at $5 \mathrm{~m}$ off the SW and SE edges of fields 121 and 114 . The profile at 114 SW shows lower emissions than with the other three situations, due to a larger effective wind direction. Differences between the other three curves are only small and reflect small effects of wind direction and product concentration in the sprayed liquid. Again, the emission shown is cumulative over the time of application, giving the total mass as an areal density $\left(\mathrm{mg} \mathrm{m}^{-2}\right.$ ) passing the imaginary $5 \mathrm{~m}$ boundary. The curves represent emissions for a field width of $60 \mathrm{~m}$. For use in the OPS dispersion model the values represented by the emission curves should be multiplied by the factors in the last column of Table 5 to obtain emissions per a.i.

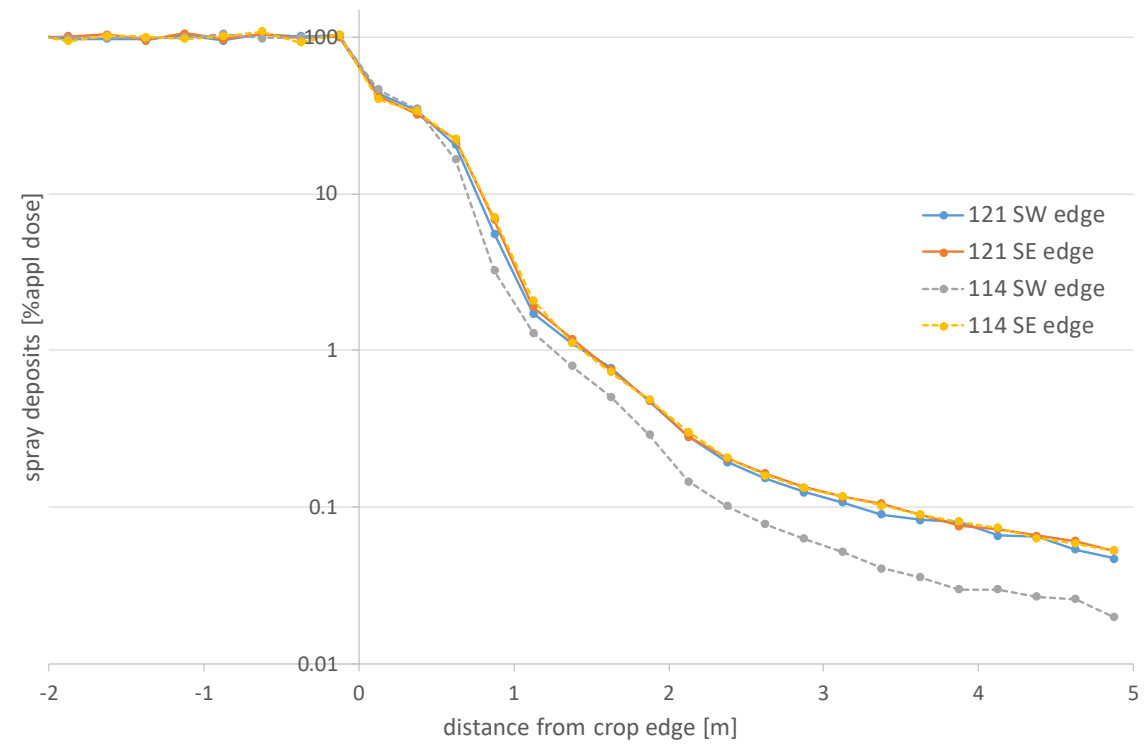

Figure 17 Spray deposits at the crop $(x<0)$ and at the ground downwind from treated field $(x>0)$, as a percentage of applied dose; case 4, fields 121 and 114 at SW and SE edges. An infinite field is assumed in upwind direction. 


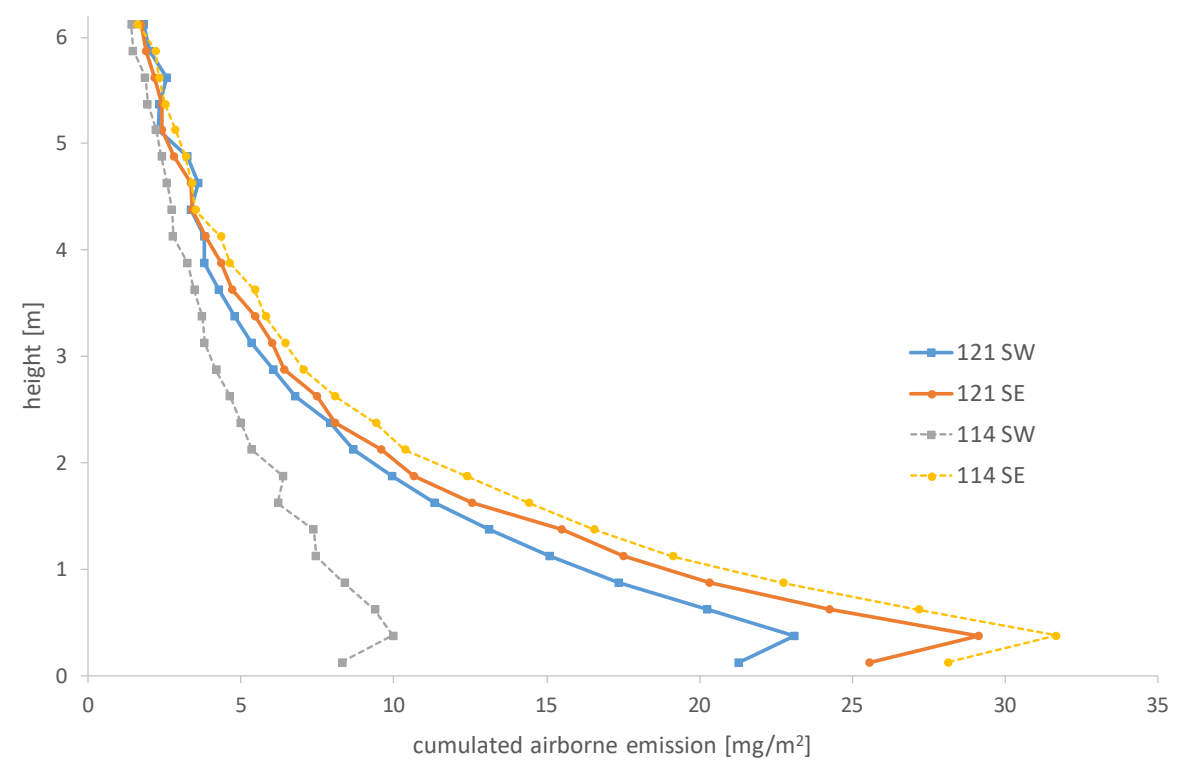

Figure 18 Airborne emission as a function of height; case 4. Simulation results for 60m wide field, at SW and SE edges of fields 121 and 114.

Compared to case 3 , in case 4 wind speed was lower, temperature was higher and relative humidity was lower (Table A.2, Annex 1). As a result, evaporation losses of the water solvent were higher in case 4 than in case 3 . This was supported by looking at the size distribution of the airborne particles at $5 \mathrm{~m}$ downwind. Figure 19 shows the size distributions at the SE edge of field 121 and at the SW edge of field 114 (where effective wind direction was different). The distributions at the SE edge of field 121 and at the SE edge of 114 are similar to figure (a). However, both histograms shown are similar and clearly show hardly any larger particles, which is different from case 3 (Figure 13). The blue bars show the actual size distribution (by numbers) of the airborne particles. When all drops would have been dried completely, the orange bars would have been obtained. The differences between these two situations is small, indicating that many drops already dried when reaching the evaluation zone.
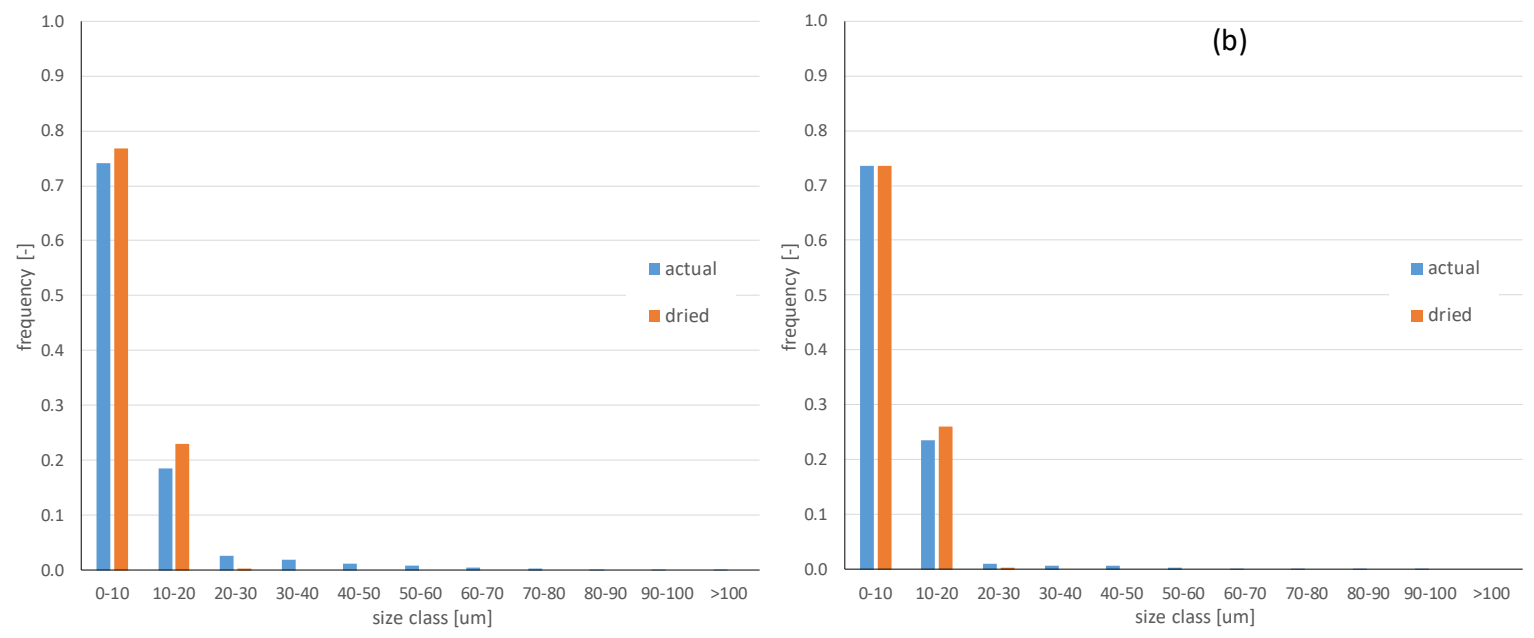

Figure 19 Size distribution of airborne particles at $5 \mathrm{~m}$ downwind from simulations, case 4, fields 121 and 114. (a) SE edge of field 121, representing SW-121 edge and SE-114 edge as well; (b) SW edge of field 114. Blue bars indicate actual size distribution, both droplets and dry particles. Orange bars indicate same distribution, assuming the airborne droplets already would have dried completely. 
Although many drops already have dried before reaching the $5 \mathrm{~m}$ off-target zone, the few drops still present can significantly affect mean particle size. In Figure 20 the vertical profile of mean volume diameter (D30) is shown for both downwind edges of field 121. Both actual and assumedly dried sizes are shown. Compared to case 3 (Figure 14) mean particles sizes are much smaller for all heights. Aerodynamically, such particles may be dealt with as being gaseous, that is, all gravitational effects can be neglected. Still, mean diameter clearly is dependent on height above the ground. Only at the highest level the actual and dried size are similar (i.e. all particles are dried there). The dried particles have a diameter of about $9 \mu \mathrm{m}$, which is slightly larger than those in case 3, due to the higher concentration of products in the tank in case 4 compared to case 3.

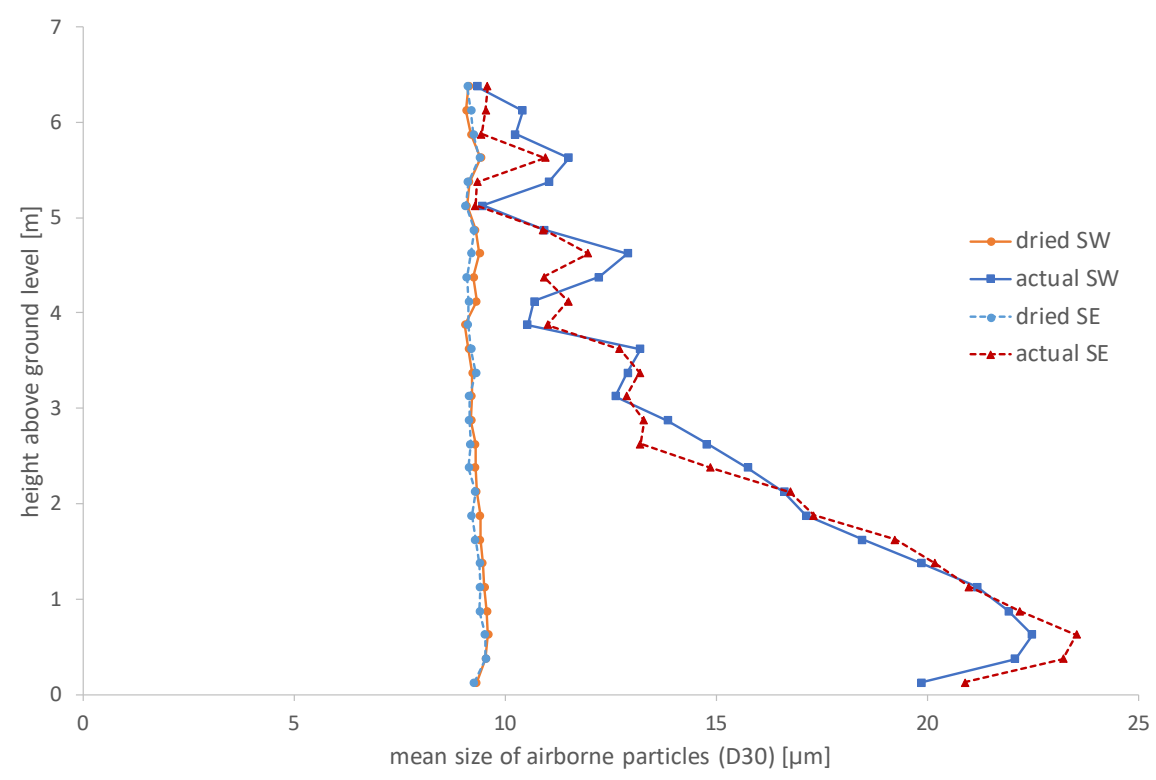

Figure 20 Size distribution of airborne particles vs height above the ground, at $5 \mathrm{~m}$ downwind from simulations, case 4, field 121, SW and SE edges. Actual size: consisting of both drops and dried particles as present at given location. Dried: assuming all actual particles already would have dried completely.

Cumulated for a $60 \mathrm{~m}$ wide field, the total fraction passing above the given height is ca. $9 \%$ and $6 \%$ of the total airborne emission at the SW and SE edges, respectively. This is much higher than in case 3 and mainly due to the higher evaporation rate. A high evaporation rate causes drop sizes to decrease rapidly, resulting in a large amount of small drift-prone particles, even from nozzles far upwind. Looking at Figure 18 indeed the curves appear to extend above $6.25 \mathrm{~m}$, which is clearly different from the curves in case 3 (Figure 12).

\subsection{Case 5: location 131 and 132, January 30, 2017}

Case 5 involves a herbicide treatment on fields 131 and 132 on bare ground in winter. Figure 21 shows the layout of the area. All other fields in this layout were treated on the same day. On most field the same product mixture was applied, except for fields 136 and 137 where a slightly different mixture was used (Table 6). Fields 131 and 132 were treated at 9 UT. All other fields were assumed to be treated during the same hour.

In the simulations a liquid dose rate of $400 \mathrm{~L} / \mathrm{ha}$ was assumed using ID 11004 nozzles at a liquid pressure of $300 \mathrm{kPa}$ (Table A.2, Annex 1), which corresponds to a DRT90 application technique. The CLM survey was incomplete at the time the simulations were carried out. Later additions to the survey indicated that AVI 11003 nozzles were used on fields 131 and 132 (and corresponding fields), with $300 \mathrm{kPa}$ pressure and a liquid dose rate of $350 \mathrm{~L} / \mathrm{ha}$. The volume fraction of small drift-prone drops $\left(\mathrm{V}_{100}\right)$ for ID 11004 at $300 \mathrm{kPa}$ is 2.4. The AVI 11003 produces a slightly coarser drop size spectrum and $\mathrm{V}_{100}$ is $1.5 \%$, that is, about 0.63 times the former $\mathrm{V}_{100}$. As before, differences in liquid dose rate are 
compensated by subsequent adjustments of product concentrations, to assure the applied product dose onto the field remains the same. In effect, only the change in $V_{100}$ should be accounted for and simulation results of airborne emissions were multiplied by the factor 0.63 as given above. This correction was applied to airborne emissions only.

For fields 136 and 137 the CLM survey indicated other nozzle selection as well: DG 8004 nozzles (at still unknown pressure, though) combined with an air assistance technique giving an additional reduction of about $50 \%$ in all emission values. Currently, IDEFICS cannot model the air assistance technique, so such drift reductions have to be applied afterwards. DG 8004 nozzles at $300 \mathrm{kPa}$ have a small droplet fraction $V_{100}$ of $5.6 \%$, which is a factor 2.3 larger than that used in the simulations. Therefore, the airborne emission results for fields 136 and 137 were multiplied by 2.3 to account for actual nozzle use and subsequently were divided by 2 to account for drift reduction by air assistance. For downwind ground deposits of spray drift only the reduction due to air assistance is taken into account. The combined use of both drift reducing nozzles and air assistance leads to an application that can be classified as DRT95

(Table A.3, Annex 1).

The downwind edges were on the SW and NW sides. The effective wind direction at the SW side was $20^{\circ}$ and at the NW side it was $70^{\circ}$ (Table A.2, Annex 1). Considering drift at SW edge, the upwind fetch (field width) of fields 131 and 23 was about $30 \mathrm{~m}$ and $20 \mathrm{~m}$, respectively. This was much less than $60 \mathrm{~m}$ which was used throughout so far. For the airborne emissions the differences taking into account the smaller field width appeared to be relatively small but probably significant (see below). Fields 25 and 26 were next to each other and could be dealt with as one merged field.

Table 6 Tank mixture and active ingredients in treatments of case 5.

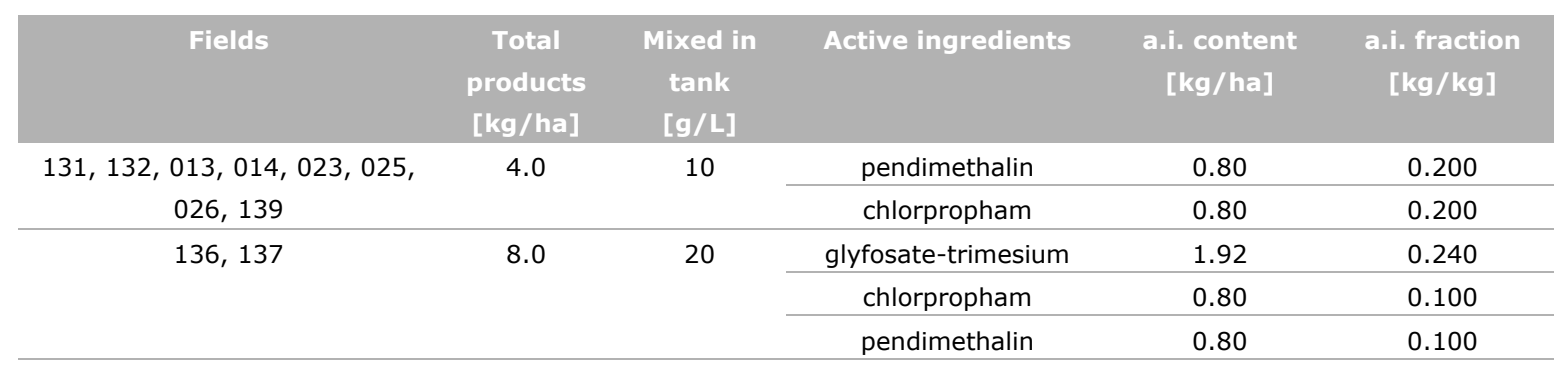

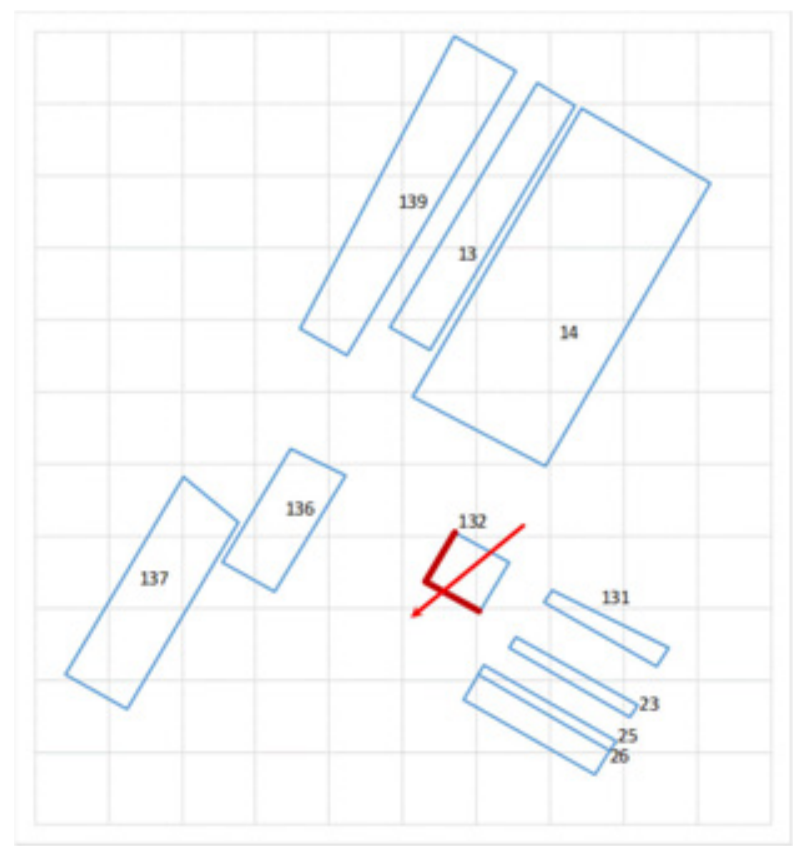

Figure 21 Schematic view of treated flower bulb fields at same day, case 5. Field 131 and 132 are the basis fields; all other fields in the layout were treated on the same day. The arrow indicates wind direction at time of spray application. Squares indicate an $100 \times 100 \mathrm{~m}^{2}$ area. 


\subsubsection{Ground deposits}

Figure 22 shows the deposits of spray and spray drift at the crop and at the ground downwind from the crop, at SW and NW edges of fields 132 and 136. The curves are based on simulation for one swath and extrapolated for subsequent swaths, assuming an infinitely extended field in upwind direction. The distance presented in the graph is measured perpendicular to the field edge. Downwind spray deposits for field 136 were divided by 2 to account for the $50 \%$ reduction due to air assistance. It can be shown that if no air assistance would have been used, the deposition curves for fields 132 and 136 would have been almost equal on corresponding field edges, although the total product concentration in the sprayed liquid was different.

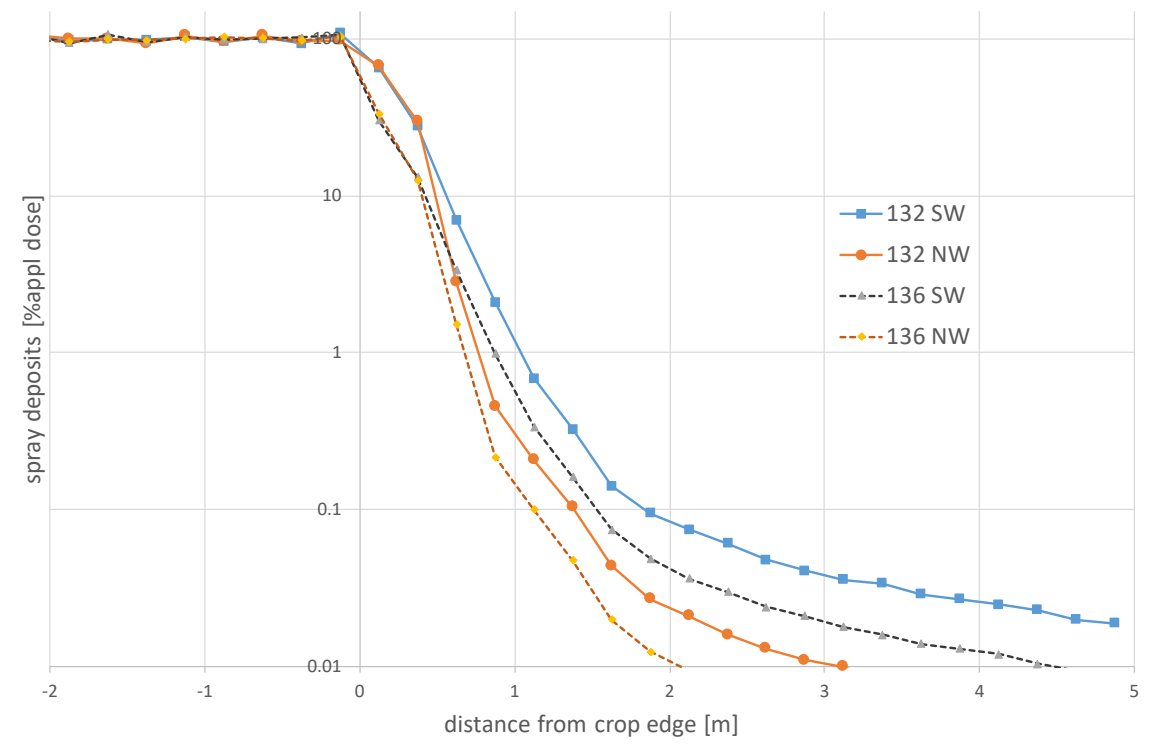

Figure 22 Spray deposits at the crop $(x<0)$ and at the ground downwind from treated field $(x>0)$, as a percentage of applied dose; case 5, fields 132 and 136 at SW and NW edges. An infinite field is assumed in upwind direction. A 50\% drift reduction due to air assistance for field 136 is taken into account.

\subsubsection{Airborne emission}

The vertical profiles of airborne emission are shown in Figure 23 at $5 \mathrm{~m}$ off the SW and NW edges of fields 132 and 136. The observed differences between the SW curves of 132 and 136 could be completely understood from differences in absolute dose rate, drift reduction due to air assistance and nozzles used. Differences between the results for NW edges of these two fields were accountable to the same factors. For use in the OPS dispersion model the values represented by the emission curves should be multiplied by the factors in the last column of Table 6 to obtain emissions per a.i. 


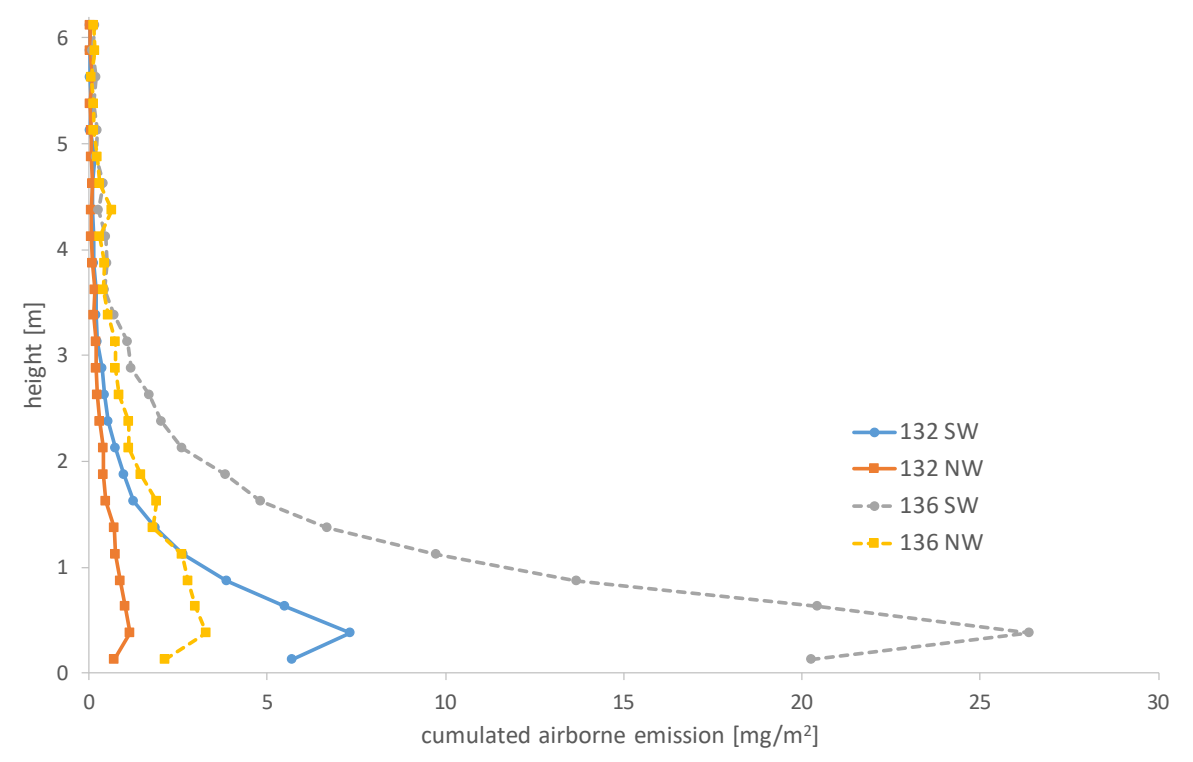

Figure 23 Airborne emission as a function of height; case 5. Simulation results for 60m wide field, at SW and NW edges of fields 132 and 136.

Integrated over height up to $6.25 \mathrm{~m}$, the emission at SW side of 132 was $8.2 \mathrm{mg} / \mathrm{m}$. That is, $8.2 \mathrm{mg}$ of summed products passed an imaginary window of $6.25 \mathrm{~m}$ height and $1.0 \mathrm{~m}$ length during the time of spray application. Field 131 had a width of only $30 \mathrm{~m}$; this accounted for an integrated emission of $7.1 \mathrm{mg} / \mathrm{m}$, which is about $13 \%$ lower. Similarly, field 23 had a width of only $20 \mathrm{~m}$, and its corresponding emission turned out to be $25 \%$ lower than that of field 132 .

Clearly, the airborne emission at the edges of fields 136 and 137 was much higher (Figure 23). This was mainly caused by the higher product dose rate (Table 6) and the use of nozzles (DG 8004) that produced more small drops, at fields 136 and 137. The use of air assistance reduced the emissions by $50 \%$, but that could not compensate the former effects enhancing spray drift.

\subsection{Case 6: location 131 and 132, June 14, 2017}

Case 6 involves a treatment with fungicides and insecticides on the same fields as in Case 5, fields 131 and 132 on a matured crop. Similarly, almost all additional fields of Case 5 were treated in case 6 as well on the same day, except for fields 136 and 137. Figure 24 shows the layout, similar to that of Figure 21, but dashed fields 136 and 137 are untreated on that day. Table 7 shows the mixtures used on the treated fields. On field 131 and three others, the mixture differed from that used on fields 132 and two others. The treatment of field 23 involved almost the same mixture as for field 132, yet the mancozeb content was lower. However, since for spray drift the total amount mixed in the tank is important $(17.75 \mathrm{~g} / \mathrm{L})$, which is unchanged for field 23, the emission results for field 132 could be used for field 23 as well. The spray application on fields 131 and 132 took place at 16 UT; like before, application on the other fields was assumed to take place during the same hour.

According to the survey, AVI 11003 nozzles were used at a liquid pressure of $250 \mathrm{kPa}$. For the simulations no drop size distribution was available at this pressure. Therefore the drop size distribution at $300 \mathrm{kPa}$ was used instead (Table A.2, Annex 1), which is a DRT50 application. At this slightly higher pressure the amount of small drops is slightly enhanced $\left(V_{100}=1.5 \%\right)$. However, the $V_{100}$ value at $250 \mathrm{kPa}$ was unknown, therefore no correction could be made and the emission results might be slightly overestimated in the simulations.

The downwind edges were on the SW and NW sides. The effective wind direction at the SW side was $20^{\circ}$ and at the NW side it was $70^{\circ}$ (Table A.2, Annex 1 ). Considering drift at SW edge, the upwind fetch (field width) of fields 131 and 23 was about $30 \mathrm{~m}$ and $20 \mathrm{~m}$, respectively. This was much less 
than $60 \mathrm{~m}$ which was used throughout so far. It turned out that the smaller field width reduced airborne emissions significantly (see below). Fields 25 and 26 were next to each other, yet a different spray mixture was used on these two fields, so merging them is not possible.

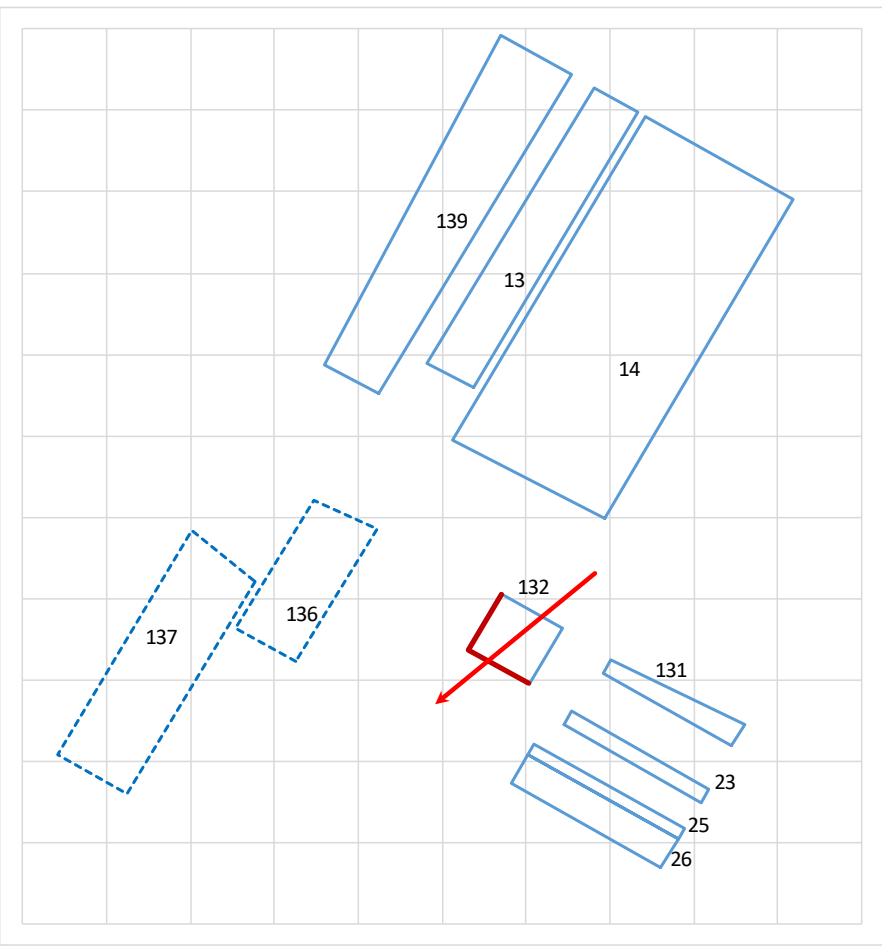

Figure 24 Schematic view of treated flower bulb fields at same day, case 6. Field 131 and 132 are the basis fields; all other fields in the layout were treated on the same day. Dashed fields (136 and 137) were not treated on that day. The arrow indicates wind direction at time of spray application. Squares indicate an $100 \times 100 \mathrm{~m}^{2}$ area.

Table 7 Tank mixture and active ingredients in treatments of case 6.

\begin{tabular}{|c|c|c|c|c|c|}
\hline Fields & $\begin{array}{l}\text { Total } \\
\text { products } \\
\text { [kg/ha] }\end{array}$ & $\begin{array}{c}\text { Mixed in } \\
\text { tank } \\
\text { [g/L] }\end{array}$ & Active ingredients & $\begin{array}{l}\text { a.i. content } \\
\text { [kg/ha] }\end{array}$ & $\begin{array}{c}\text { a.i. fraction } \\
\text { [kg/kg] }\end{array}$ \\
\hline \multirow{2}{*}{$131,013,026,139$} & & & esfenvalerate & 0.010 & 0.004 \\
\hline & & & trifloxystrobin & 0.125 & 0.051 \\
\hline \multirow[t]{4}{*}{$132,014,025$} & 3.55 & 17.75 & mancozeb & 1.238 & 0.349 \\
\hline & & & chlorthalonil & 0.495 & 0.139 \\
\hline & & & prochloraz & 0.158 & 0.044 \\
\hline & & & esfenvalerate & 0.010 & 0.003 \\
\hline \multirow[t]{2}{*}{023} & 3.55 & 17.75 & mancozeb & 0.825 & 0.232 \\
\hline & & & esfenvalerate & 0.010 & 0.003 \\
\hline
\end{tabular}




\subsubsection{Ground deposits}

Figure 25 shows the deposits of spray and spray drift at the crop and at the ground downwind from the crop at SW and NW edges of fields 131 and 132. The curves are based on simulation for one swath and extrapolated for subsequent swaths, assuming an infinitely extended field in upwind direction. The distance presented in the graph is measured perpendicular to the field edge. The limited width of field $131(30 \mathrm{~m}$ ) considering drift at the SW edge did not cause a significant reduction in ground deposits. Even for field 23, downwind deposits on the ground were hardly affected by its limited width (20 m). The main reasons were the relatively coarse spray nozzle used and the relatively fast evaporation of airborne drops. Curves for fields 131 and 132 were very similar, indicating that product concentration had no effect on deposits when expressed as percentage of the applied dose.

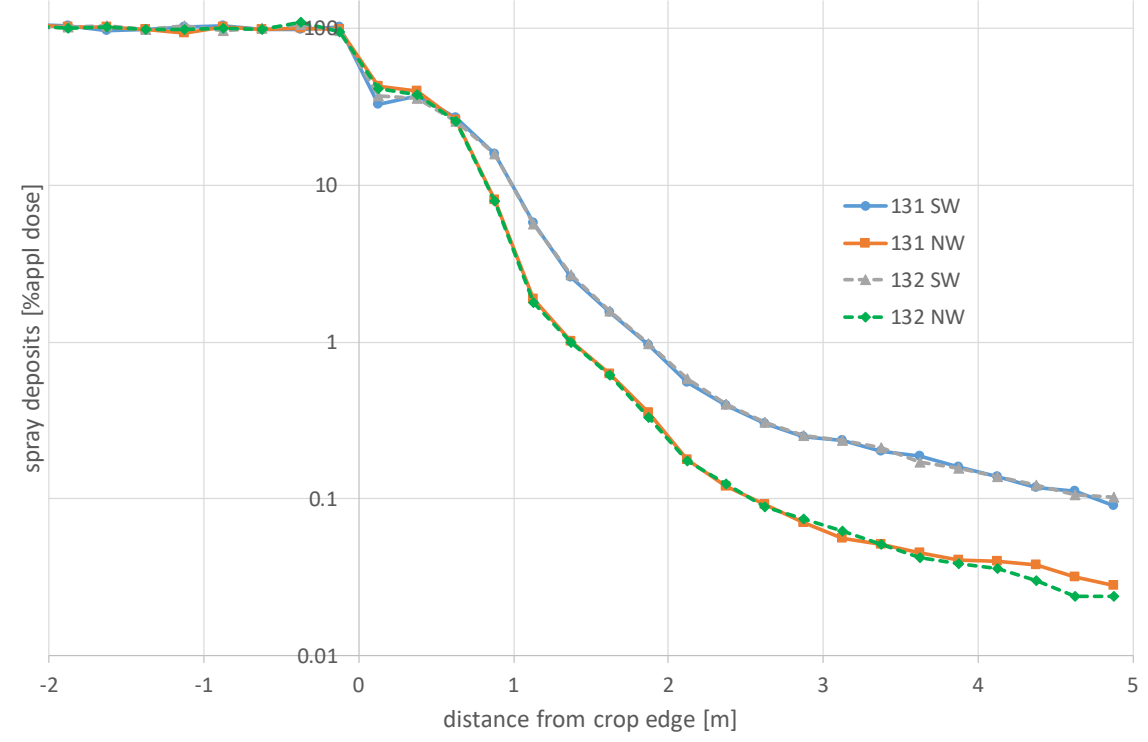

Figure 25 Spray deposits at the crop $(x<0)$ and at the ground downwind from treated field $(x>0)$, as a percentage of applied dose; case 6, fields 131 and 132 at SW and NW edges. An infinite field is assumed in upwind direction.

\subsubsection{Airborne emission}

The vertical profiles of airborne emission are shown in Figure 26 at $5 \mathrm{~m}$ off the SW and NW edges of fields 131 and 132. An upwind field width of $60 \mathrm{~m}$ was assumed. Although this is not true for field 131 at the SW edge, the corresponding curve represented the other fields well $(13,26,139)$ with sufficient widths. Airborne emissions at field 132 were slightly higher than those for field 131, due to the higher product concentration in the sprayed liquid. Emission levels at the NW edges were much lower than those at the SW edges due to the difference in effective wind direction. 


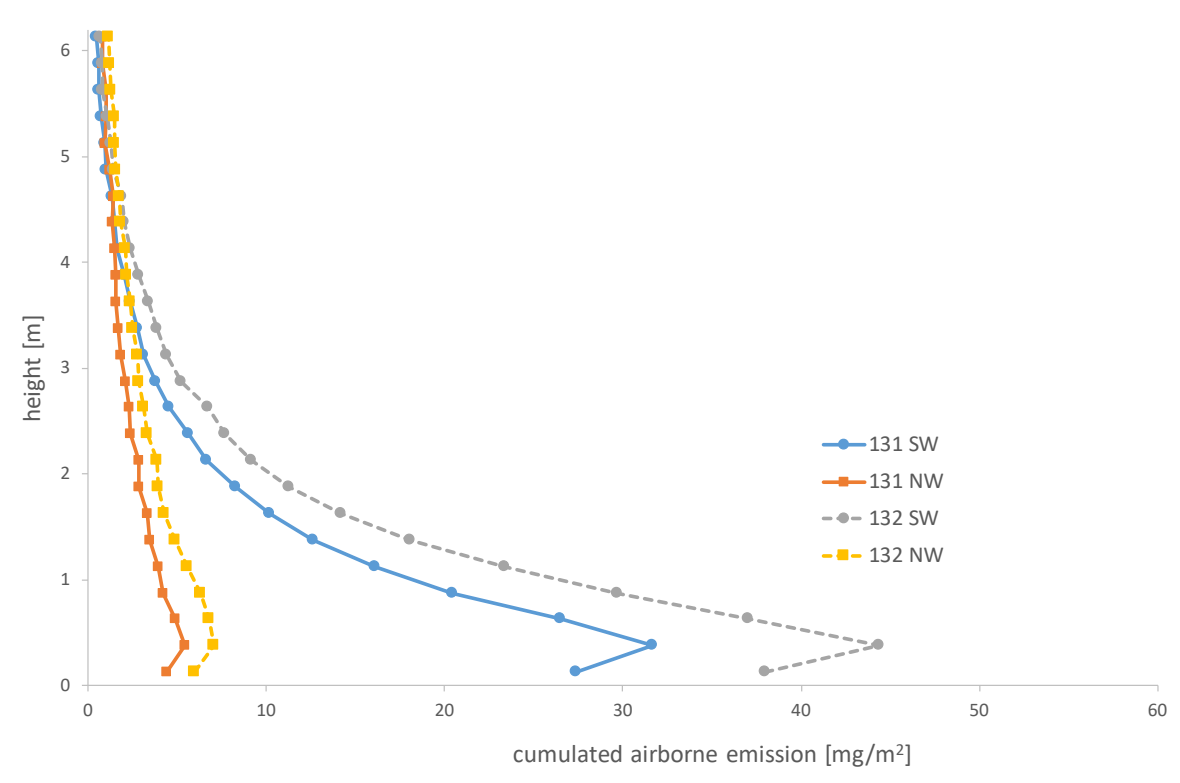

Figure 26 Airborne emission as a function of height; case 6. Simulation results for 60m wide field, at SW and NW edges of fields 131 and 132.

Integrated over height up to $6.25 \mathrm{~m}$, the emission at SW side of 131 was $49 \mathrm{mg} / \mathrm{m}$, assuming a field width of $60 \mathrm{~m}$. Considering the actual field width of $30 \mathrm{~m}$ for this field, the integrated emission turned out to be only $68 \%$ of this value for $60 \mathrm{~m}$ field width. Similarly, at the SW edge of field 132 the integrated emission was $69 \mathrm{mg} / \mathrm{m}$, while airborne emission for field 23 (20 m wide) was only $54 \%$ of this value.

\subsection{Case 7: location 142, May 9, 2017}

Case 7 involves a treatment with fungicides and insecticides on fields 142 (basis), 44 and 144 on a matured crop. Figure 27 shows the layout, including neighbouring flower bulb fields not treated on the given day (dashed fields). Table 8 shows the mixture used on the treated fields. The spray application took place at 14 UT. The boom was supplied with Airmix 11003 nozzles and a liquid pressure of $400 \mathrm{kPa}$ was used (Table A.2, Annex 1). This nozzle type and pressure corresponded with a $\mathrm{V}_{100}$ value of $4.9 \%$ which is not very low. However, air assistance was available on the sprayer boom, reducing emissions by $50 \%$, resulting in an overall DRT90 application technique (Table A.3, Annex 1 ). There was only one downwind edge (at the SE side), with an effective wind direction of $16^{\circ}$ (Table A.2, Annex 1). The sides at SW and NE appeared to be parallel to wind direction and consequently emissions at these sides was zero. 


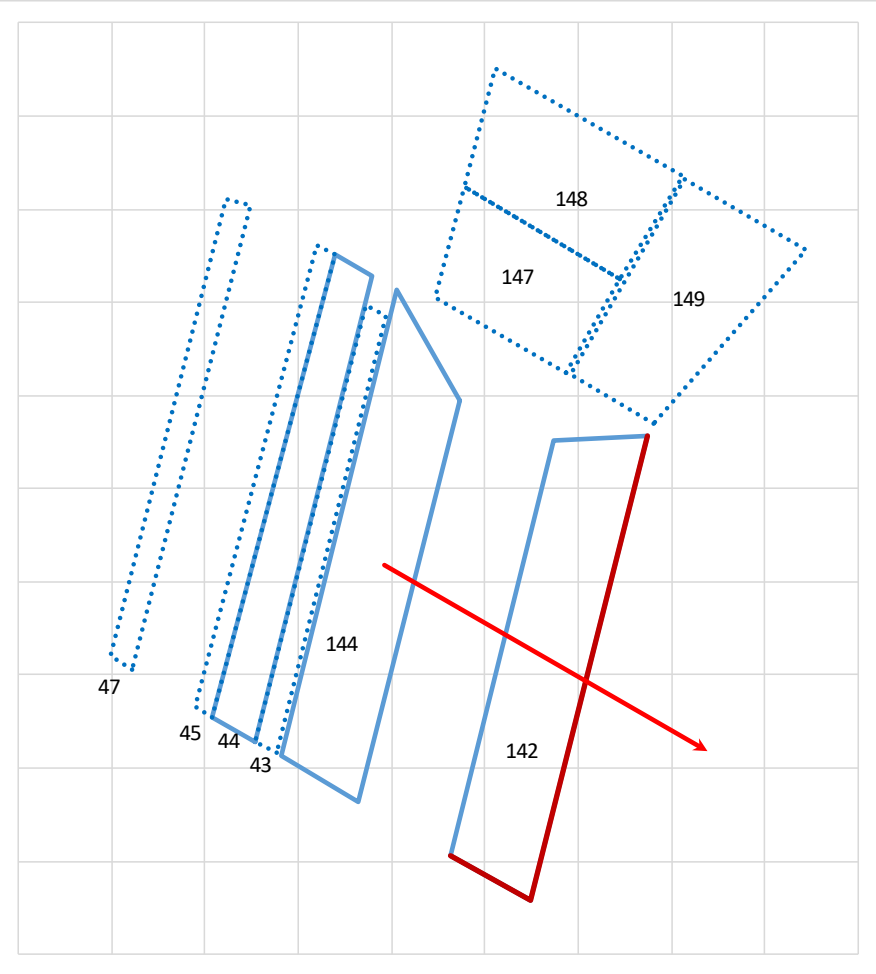

Figure 27 Schematic view of treated flower bulb fields at same day, case 7. Field 142 is the basis field; fields 44 and 144 were treated on the same day using the same spray mixture. Dashed fields were not treated on that day. The arrow indicates wind direction at time of spray application. Squares indicate an $100 \times 100 \mathrm{~m}^{2}$ area.

Table 8 Tank mixture and active ingredients in treatments of case 7.

\begin{tabular}{|c|c|c|c|c|c|}
\hline Fields & $\begin{array}{c}\text { Total } \\
\text { products } \\
\text { [kg/ha] }\end{array}$ & $\begin{array}{c}\text { Mixed in } \\
\operatorname{tank} \\
{[\mathrm{g} / \mathrm{L}]}\end{array}$ & Active ingredients & $\begin{array}{l}\text { a.i. content } \\
\text { [kg/ha] }\end{array}$ & $\begin{array}{l}\text { a.i. fraction } \\
{[\mathrm{kg} / \mathrm{kg}]}\end{array}$ \\
\hline \multirow[t]{4}{*}{$142,044,144$} & \multirow[t]{4}{*}{3.18} & \multirow[t]{4}{*}{15.9} & mancozeb & 1.50 & 0.472 \\
\hline & & & esfenvalerate & 0.010 & 0.003 \\
\hline & & & acetamiprid & 0.046 & 0.014 \\
\hline & & & mepanipyrim & 0.154 & 0.048 \\
\hline
\end{tabular}

\subsubsection{Ground deposits}

Figure 28 shows the deposits of spray and spray drift at the crop and at the ground downwind from the crop at the SE edge of field 142. The curve is based on simulation for one swath and extrapolated for subsequent swaths, assuming an infinitely extended field in upwind direction. The distance presented in the graph is measured perpendicular to the field edge. The use of air assistance implied a reduction of $50 \%$ on all downwind deposits.

\subsubsection{Airborne emission}

The vertical profile of airborne emission is shown in Figure 29 at $5 \mathrm{~m}$ off the SE edge of field 142. An upwind field width of $60 \mathrm{~m}$ was assumed. There appeared to be some contribution from nozzles further upwind than $60 \mathrm{~m}$. If the field would have stretched out infinitely in upwind direction, the dashed curve would represent the airborne emission profile. Cumulated over height up to $6.25 \mathrm{~m}$ the emission for a $60 \mathrm{~m}$ field width is $99 \mathrm{mg} / \mathrm{m}$, for an infinite field width this was estimated to be about $28 \%$ higher. 


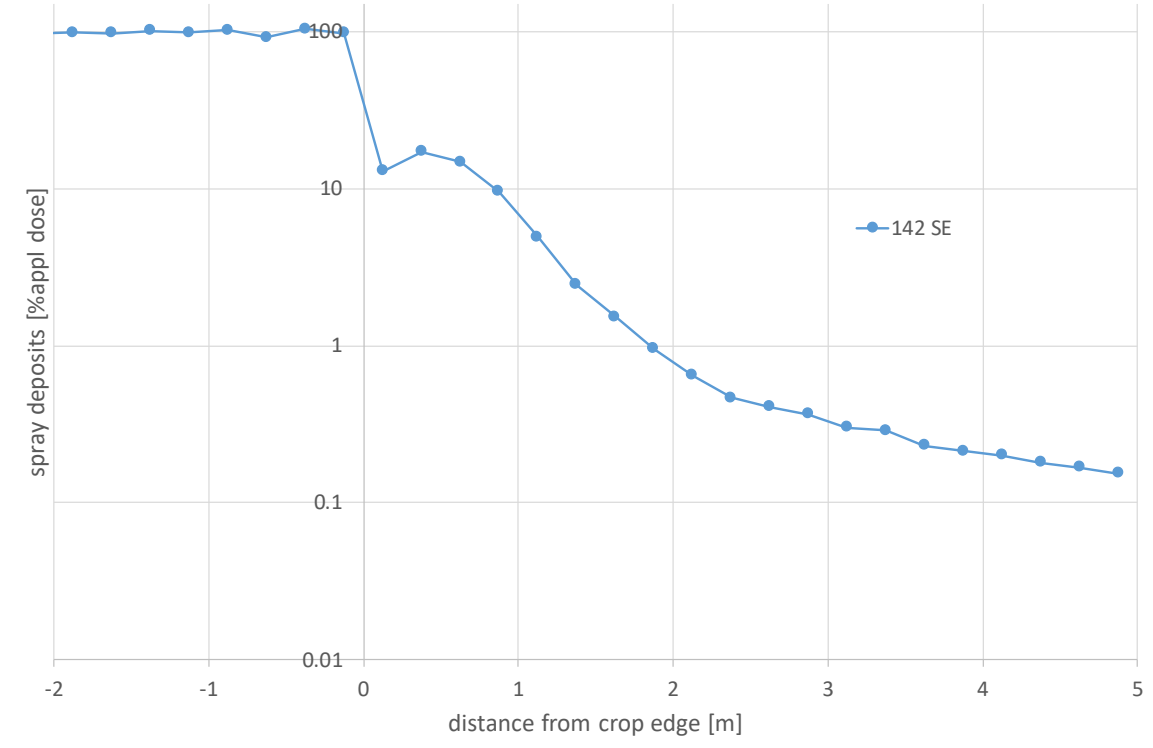

Figure 28 Spray deposits at the crop $(x<0)$ and at the ground downwind from treated field $(x>0)$, as a percentage of applied dose; case 7, field 142 at SE edge. An infinite field is assumed in upwind direction. A 50\% reduction for downwind deposits $(X>0)$ is accounted for.

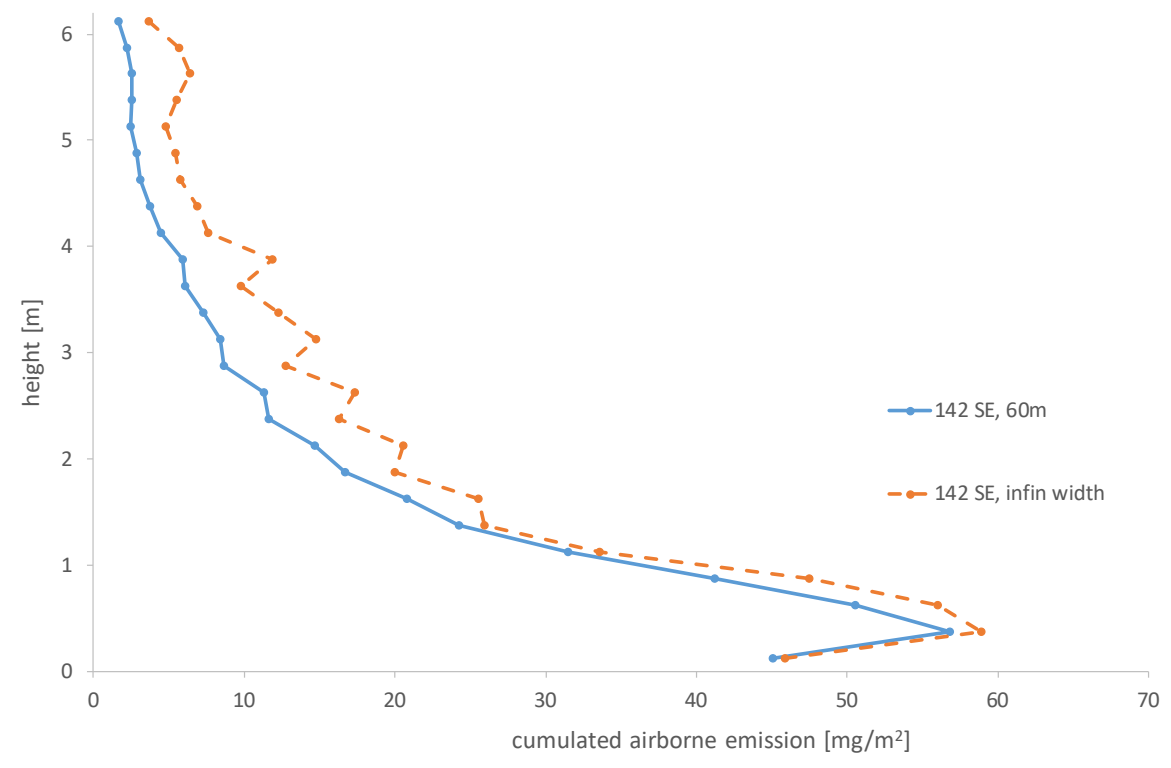

Figure 29 Airborne emission as a function of height; case 7. Simulation results for a 60m wide field and infinite field width, at the SE edge of field 142.

\subsection{Case 8: location 142, May 22, 2017}

Case 8 involves a treatment with fungicides and insecticides on fields 142 (basis) and several other field in its neighbourhood. Figure 30 shows the layout; the long parallel fields in the SW part were all treated with the same spray mixture. Fields 147, 148 and 149 were sprayed using a different mixture (see Table 9). The spray application took place at 14 UT. For field 142 and its parallel fields, the sprayer boom was supplied with Airmix 11003 nozzles; liquid pressure was 400 kPa (Table A.2, Annex 1). An air assistance sprayer was used, reducing emissions by $50 \%$, which combines to a DRT90 application technique. The small drop content $\left(V_{100}\right)$ was 4.9\%. For fields 147-149 twin fluid nozzles TKSS 10/35 were used at a pressure of $300 \mathrm{kPa}$, having a coarser drop size spectrum and a lower $\mathrm{V}_{100}$ value of $1.7 \%$, which corresponds to a DRT75 technique. The TKSS 10/35 nozzles use low 
pressure air supply; however, the survey does not mention which air pressure has been used. Based on the survey and the nozzle characteristics, a forward speed of $0.99 \mathrm{~m} / \mathrm{s}$ was computed, which seems rather low in practice.

Fields were represented by a quadrangle (Figure 30), disregarding the actual boundary layout. Where applicable, the actual field boundaries were drawn by dashed lines in the figure. These dashed lines show that most NW edges were parallel. Similarly, most NE edges were parallel as well. The effective wind direction at the NW edge was $46^{\circ}$, at the NE edge this was $60^{\circ}$ (Table A.2, Annex 1 ).

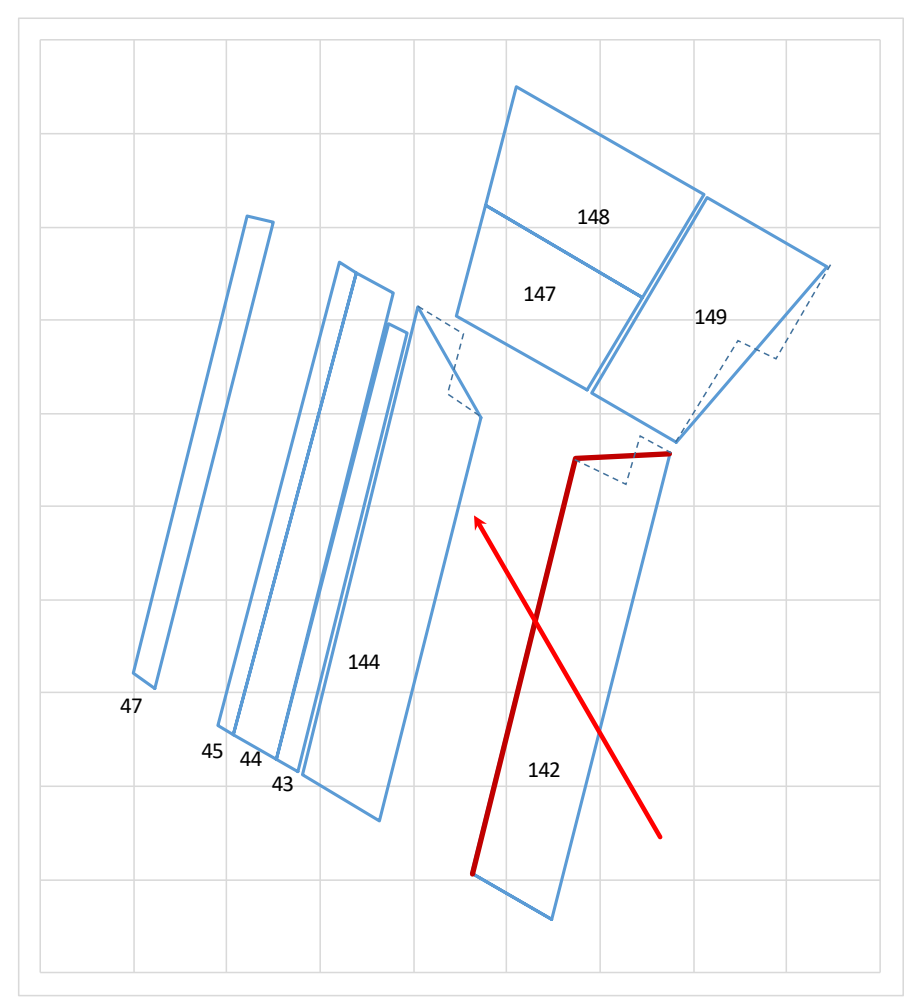

Figure 30 Schematic view of treated flower bulb fields at same day, case 8. Field 142 is the basis field; other fields shown were treated on the same day. Fields 147, 148 and 149 were sprayed with a different mixture. Dashed lines indicate actual field boundaries. The arrow indicates wind direction at time of spray application. Squares indicate an $100 \times 100 \mathrm{~m}^{2}$ area.

\subsubsection{Ground deposits}

Figure 31 shows the deposits of spray and spray drift at the crop and at the ground downwind from the crop at the NE and NW edge of fields 142 and 148. The curves are based on simulations for one swath and extrapolated for subsequent swaths, assuming an infinitely extended field in upwind direction. The distance presented in the graph is measured perpendicular to the field edge. For field 142 , the use of air assistance implied a reduction of $50 \%$ on all downwind deposits. For field 148 a different application technique was used, yet downwind deposits appeared to be very similar to those of field 142, at least when expressed as percentage of applied dose. 
Table 9 Tank mixture and active ingredients in treatments of case 8.

\begin{tabular}{|c|c|c|c|c|c|}
\hline Fields & $\begin{array}{c}\text { Total } \\
\text { products } \\
\text { [kg/ha] }\end{array}$ & $\begin{array}{c}\text { Mixed in } \\
\text { tank } \\
\text { [g/L] }\end{array}$ & Active ingredients & $\begin{array}{l}\text { a.i. content } \\
\text { [kg/ha] }\end{array}$ & $\begin{array}{l}\text { a.i. fraction } \\
\text { [kg/kg] }\end{array}$ \\
\hline \multirow{2}{*}{$\begin{array}{l}142,043,044 \\
045,047,144\end{array}$} & & & tebuconazole & 0.080 & 0.029 \\
\hline & & & flonicamid & 0.070 & 0.026 \\
\hline \multirow[t]{4}{*}{$147,148,149$} & 9.1 & 36.4 & mancozeb & 1.00 & 0.110 \\
\hline & & & mineral oil & 4.80 & 0.527 \\
\hline & & & pymetrozine & 0.10 & 0.011 \\
\hline & & & iprodion & 0.25 & 0.027 \\
\hline
\end{tabular}

\subsubsection{Airborne emission}

The vertical profiles of airborne emission are shown in Figure 32 at $5 \mathrm{~m}$ off the NW and NE edges of fields 142 and 148. An upwind field width of $60 \mathrm{~m}$ was assumed. Airborne emissions at the edges of field 148 were higher than those for field 142, mainly due to the higher product concentration in the sprayed liquid applied to field 148. Emissions at NE edges were slightly lower than those at the NW edges caused by a difference in effective wind direction.

The cumulated airborne emission over height up to $6.25 \mathrm{~m}$, for a $60 \mathrm{~m}$ field width, is shown in Table 10. For field 148 the highest emissions so far have been obtained, primarily due to the relatively high concentration of products in the spray liquid.

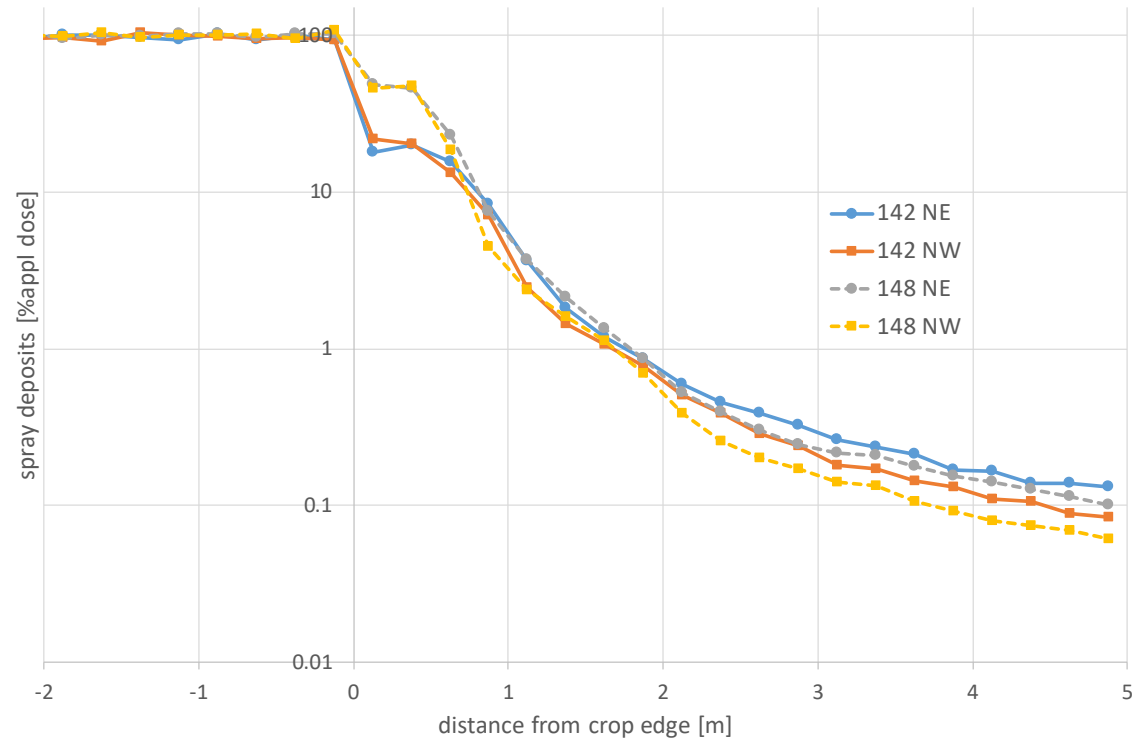

Figure 31 Spray deposits at the crop $(x<0)$ and at the ground downwind from treated field $(x>0)$, as a percentage of applied dose; case 8, field 142 at NE and NW edges; 50\% reduction for downwind deposits $(X>0)$ is accounted for. Field 148 was sprayed on same day, using a different application technique. An infinite field is assumed in upwind direction. 


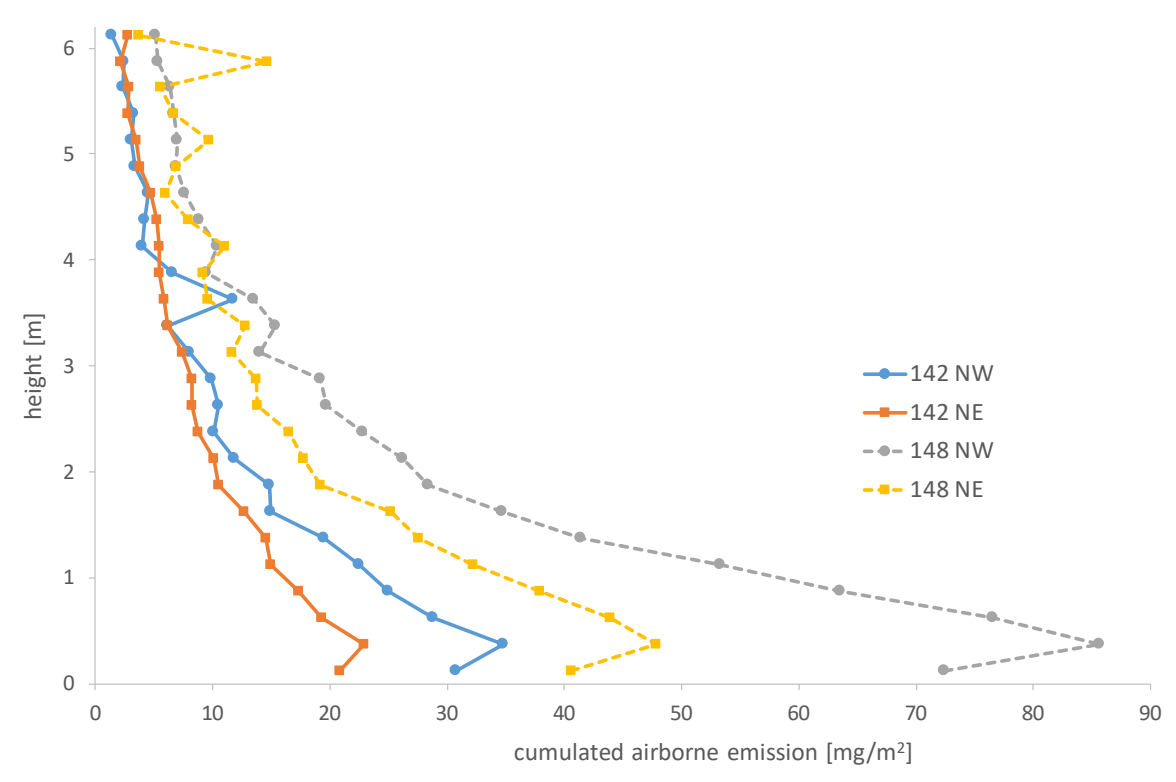

Figure 32 Airborne emission as a function of height; case 8. Simulation results for a 60m wide field at the NW and NE edges of fields 142 and 148.

Table 10 Cumulated airborne emission over 6.25 m height; Case 8.

\begin{tabular}{ccccc} 
Field, edge & $142 \mathrm{NW}$ & $142 \mathrm{NE}$ & $148 \mathrm{NW}$ & $148 \mathrm{NE}$ \\
Cumul airborne emission $[\mathrm{mg} / \mathrm{m}]$ & 78 & 62 & 181 & 127 \\
\hline
\end{tabular}

The relatively high concentration of product applied to field 148 (and 147, 149) is reflected in the size distribution of airborne particles at $5 \mathrm{~m}$ downwind. Figure 33 (a) shows the particle size distribution at the NW edge of field 142, whereas Figure 33 (b) shows the size distribution at the NW edge of field 148. In both cases the differences between the distributions for actual and dried particles were very small, indicating that most particles dried quickly. This is well understood from the high temperature and low humidity on the time of application $\left(\mathrm{T}=24^{\circ} \mathrm{C}, \mathrm{RH}=38 \%\right.$; Table A.2, Annex 1$)$. There is a significant difference in particle sizes for the two field edges, yet in both situations particles are small enough to behave the same aerodynamically.
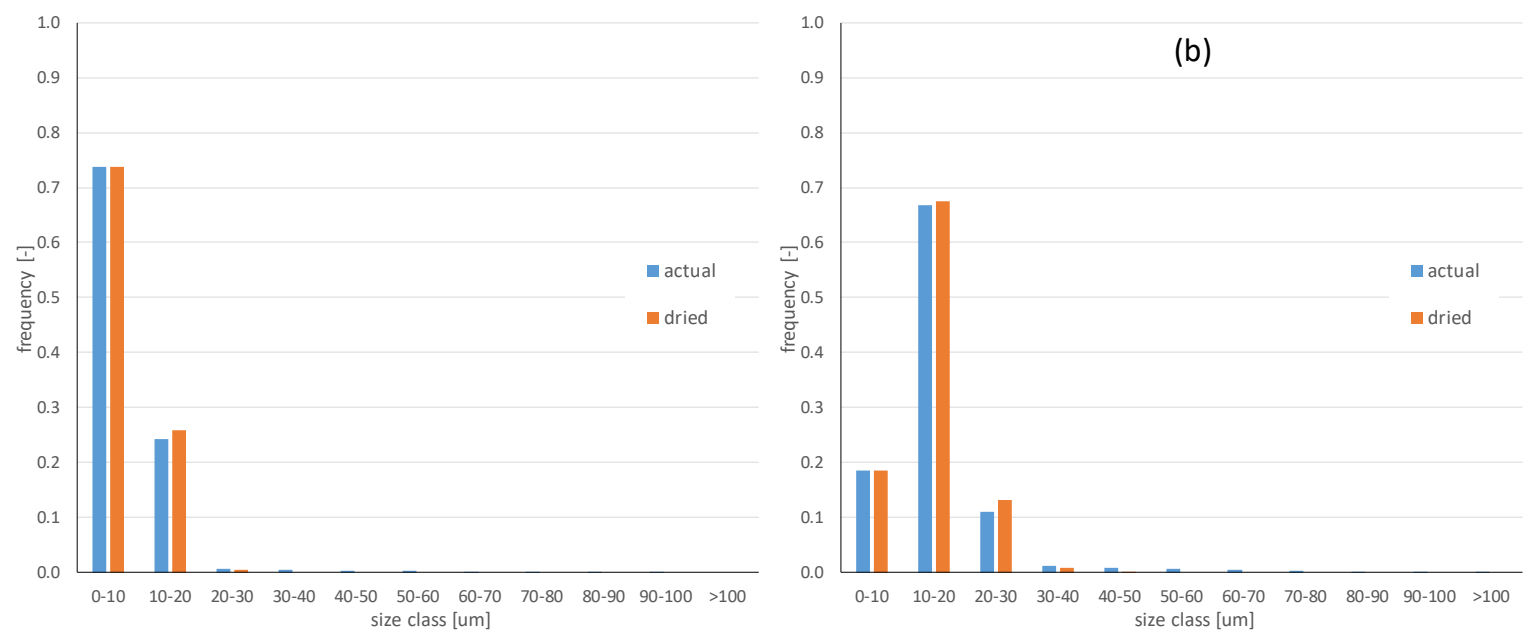

Figure 33 Size distribution of airborne particles at $5 \mathrm{~m}$ downwind, case 8. (a) field 142 NW edge; (b) field 148 NW edge. Blue bars indicate actual size distribution, both droplets and dry particles. Orange bars indicate same distribution, assuming the airborne droplets already would have dried completely. 


\subsection{Case 9: location 174, August 1, 2017}

Case 9 involves a treatment with a mixture of herbicides and insecticides on field 174; no other fields were treated on the same day. Figure 34 shows the layout; the mixture used is given in Table 11 . The spray application took place at 9 UT. The sprayer boom was supplied with Airmix 11003 nozzles; liquid pressure was $300 \mathrm{kPa}$ (Table A.2, Annex 1). An air assistance technique was used, reducing emissions by $50 \%$; the application is classified as DRT90. The small drop content $\left(V_{100}\right)$ was $3.1 \%$. The effective wind direction at the NE edge was $20^{\circ}$, at the SE edge this was $71^{\circ}$ (Table A.2, Annex 1 ).

\subsubsection{Ground deposits}

Figure 35 shows the deposits of spray and spray drift at the crop and at the ground downwind from the crop at the NE and SE edges of field 174. The curves are based on simulations for one swath and extrapolated for subsequent swaths, assuming an infinitely extended field in upwind direction. The distance presented in the graph is measured perpendicular to the field edge. The use of air assistance implied a reduction of $50 \%$ on all downwind deposits.

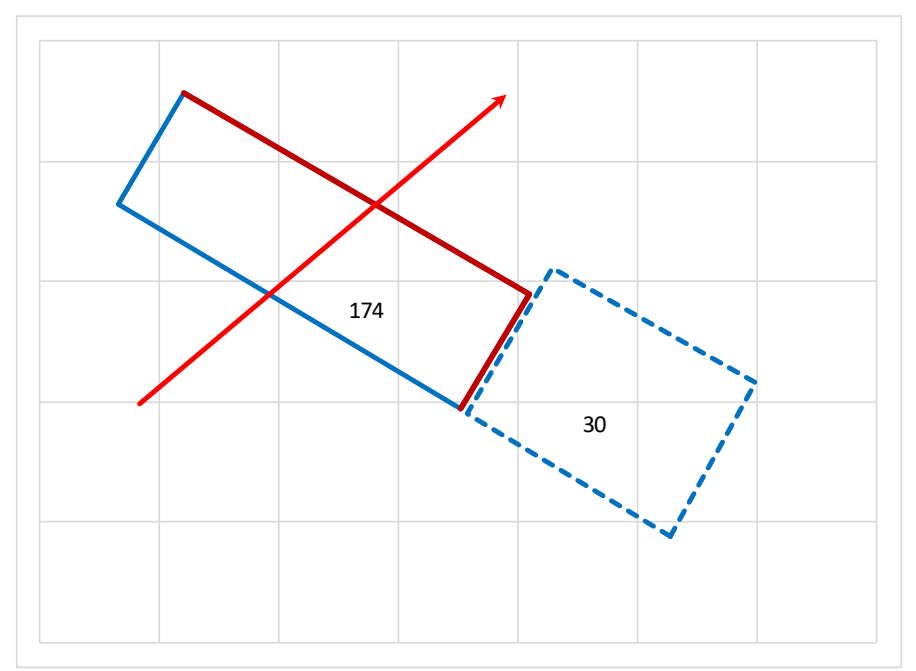

Figure 34 Schematic view of treated flower bulb fields at same day, case 9. Field 174 is the basis field; the adjacent field 30 (dashed) was not treated that day. The arrow indicates wind direction at time of spray application. Squares indicate an $100 \times 100 \mathrm{~m}^{2}$ area.

Table 11 Tank mixture and active ingredients in treatments of case 9.

\begin{tabular}{|c|c|c|c|c|c|}
\hline Fields & $\begin{array}{c}\text { Total } \\
\text { products } \\
\text { [kg/ha] }\end{array}$ & $\begin{array}{c}\text { Mixed in } \\
\text { tank } \\
{[\mathrm{g} / \mathrm{L}]}\end{array}$ & Active ingredients & $\begin{array}{l}\text { a.i. content } \\
\text { [kg/ha] }\end{array}$ & $\begin{array}{c}\text { a.i. fraction } \\
\text { [kg/kg] }\end{array}$ \\
\hline \multirow{3}{*}{174} & & & lambda-cyhalothrin & 0.01 & 0.001 \\
\hline & & & mineral oil & 4.80 & 0.658 \\
\hline & & & quinmerac & 0.028 & 0.004 \\
\hline
\end{tabular}




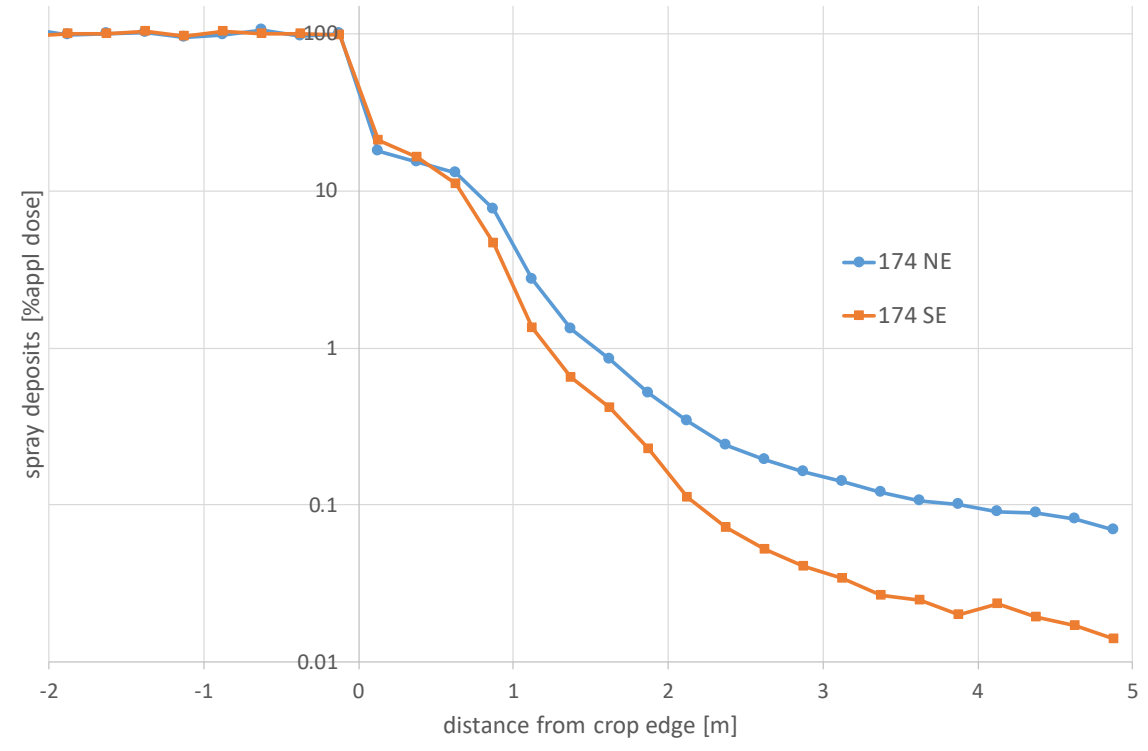

Figure 35 Spray deposits at the crop $(x<0)$ and at the ground downwind from treated field $(x>0)$, as a percentage of applied dose; case 9, field 174 at NE and SE edges. 50\% reduction (air assistance) for downwind deposits $(X>0)$ is accounted for. An infinite field is assumed in upwind direction.

\subsubsection{Airborne emission}

The vertical profiles of airborne emission are shown in Figure 32 at $5 \mathrm{~m}$ off the NE and SE edges of field 174. An upwind field width of $60 \mathrm{~m}$ was assumed. Emissions at SE edge were much lower than those at the NE edge due to the difference in effective wind direction.

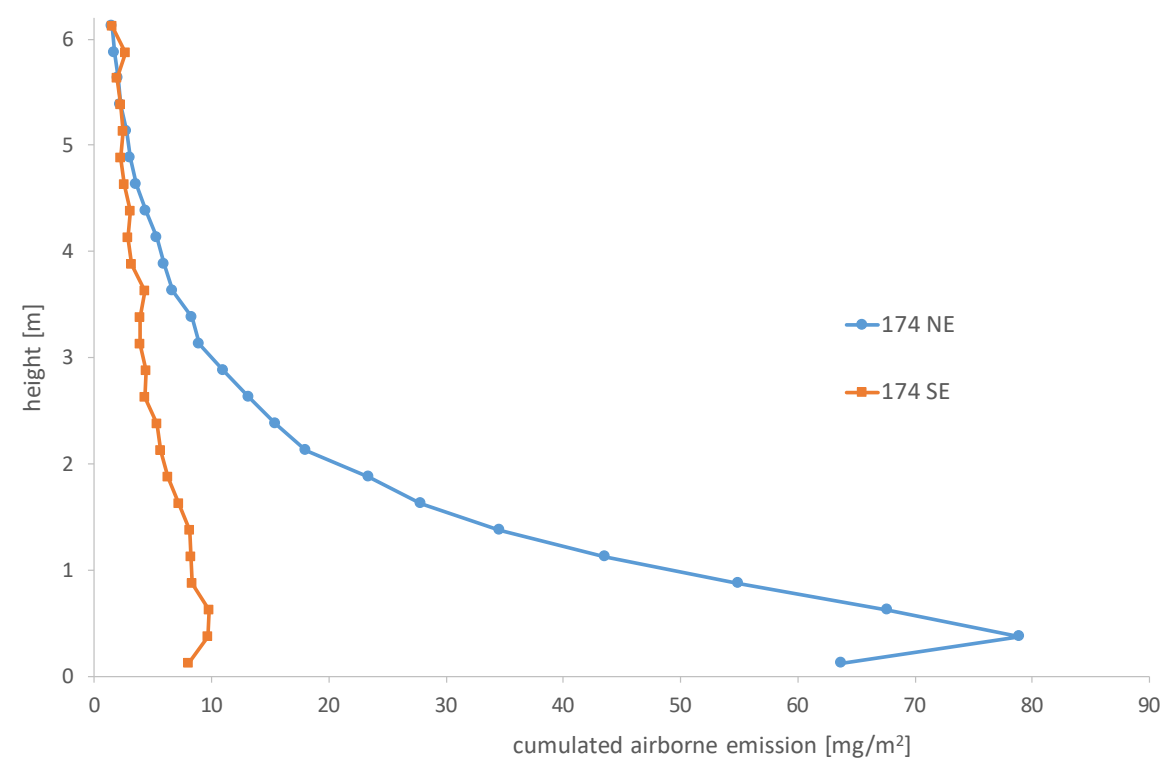

Figure 36 Airborne emission as a function of height; case 9. Simulation results for a 60m wide field at the NE and SE edges of field 174.

The cumulated airborne emission over height up to $6.25 \mathrm{~m}$ for a $60 \mathrm{~m}$ wide field was $130 \mathrm{mg} / \mathrm{m}$ at the NE edge, which again is relatively high due to the high concentration of products in the sprayed liquid. At the SE edge the cumulated emission was only $36 \mathrm{mg} / \mathrm{m}$, which is much lower caused by the effective wind direction of $71^{\circ}$. 


\subsection{Case 10: location 174, August 14, 2017}

Case 10 involves a treatment with a mixture of herbicides, fungicides and insecticides on field 174; field 30 was treated on the same day but using a different spray mixture (Table 12). Figure 37 shows the layout; the mixture used is given in Table 11. The spray application took place at 14 UT; the sprayer boom was supplied with Airmix 11003 nozzles; liquid pressure was 300 kPa (Table A.2, Annex 1). An air assistance technique was used, reducing emissions by $50 \%$ and corresponding to a DRT90 application technique. The small drop content $\left(\mathrm{V}_{100}\right)$ was $3.1 \%$. The effective wind direction at the NW edge was $21^{\circ}$, at the SW edge this was $69^{\circ}$ (Table A.2, Annex 1).

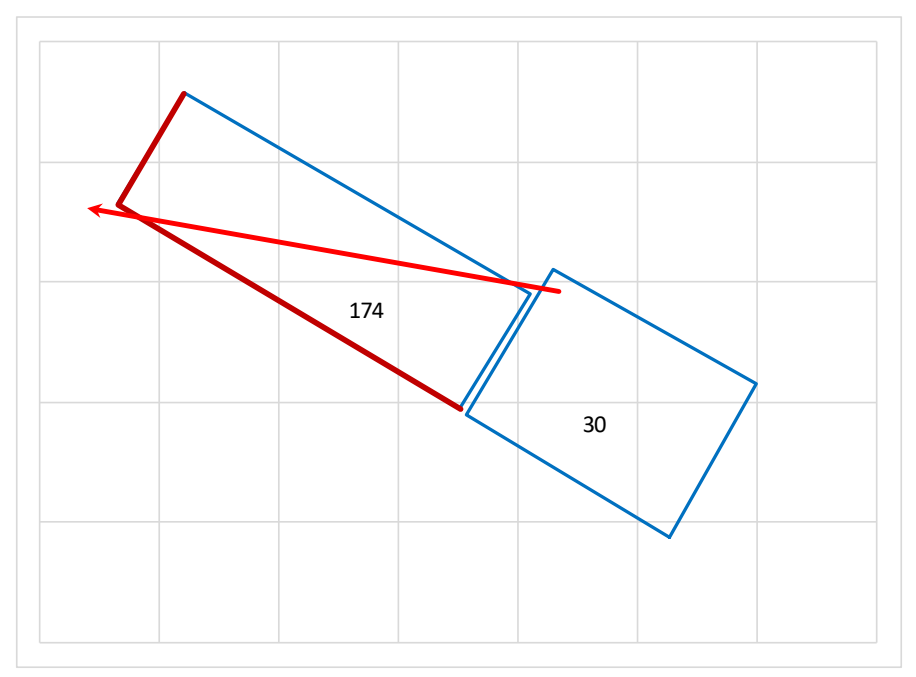

Figure 37 Schematic view of treated flower bulb fields at same day, case 10. Field 174 is the basis field; the adjacent field 30 was treated the same day but with a different spray mixture. The arrow indicates wind direction at time of spray application. Squares indicate an $100 \times 100 \mathrm{~m}^{2}$ area.

Table 12 Tank mixture and active ingredients in treatments of case 10.

\begin{tabular}{|c|c|c|c|c|c|}
\hline Fields & $\begin{array}{l}\text { Total } \\
\text { products } \\
\text { [kg/ha] }\end{array}$ & $\begin{array}{c}\text { Mixed in } \\
\text { tank } \\
\text { [g/L] }\end{array}$ & Active ingredients & $\begin{array}{l}\text { a.i. content } \\
\text { [kg/ha] }\end{array}$ & $\begin{array}{c}\text { a.i. fraction } \\
\text { [kg/kg] }\end{array}$ \\
\hline \multirow{5}{*}{174} & & & lambda-cyhalothrin & 0.01 & 0.001 \\
\hline & & & mineral oil & 4.80 & 0.522 \\
\hline & & & quinmerac & 0.028 & 0.003 \\
\hline & & & pymetrozine & 0.10 & 0.011 \\
\hline & & & mancozeb & 1.28 & 0.139 \\
\hline \multirow[t]{4}{*}{030} & 7.9 & 36.0 & mancozeb & 1.50 & 0.190 \\
\hline & & & mineral oil & 3.20 & 0.404 \\
\hline & & & prothioconazole & 0.096 & 0.012 \\
\hline & & & flonicamid & 0.070 & 0.009 \\
\hline
\end{tabular}

\subsubsection{Ground deposits}

Figure 38 shows the deposits of spray and spray drift at the crop and at the ground downwind from the crop at the NW and SW edges of fields 174 and 30. The curves are based on simulations for one swath and extrapolated for subsequent swaths, assuming an infinitely extended field in upwind 
direction. The distance presented in the graph is measured perpendicular to the field edge. The use of air assistance implied a reduction of $50 \%$ on all downwind deposits.

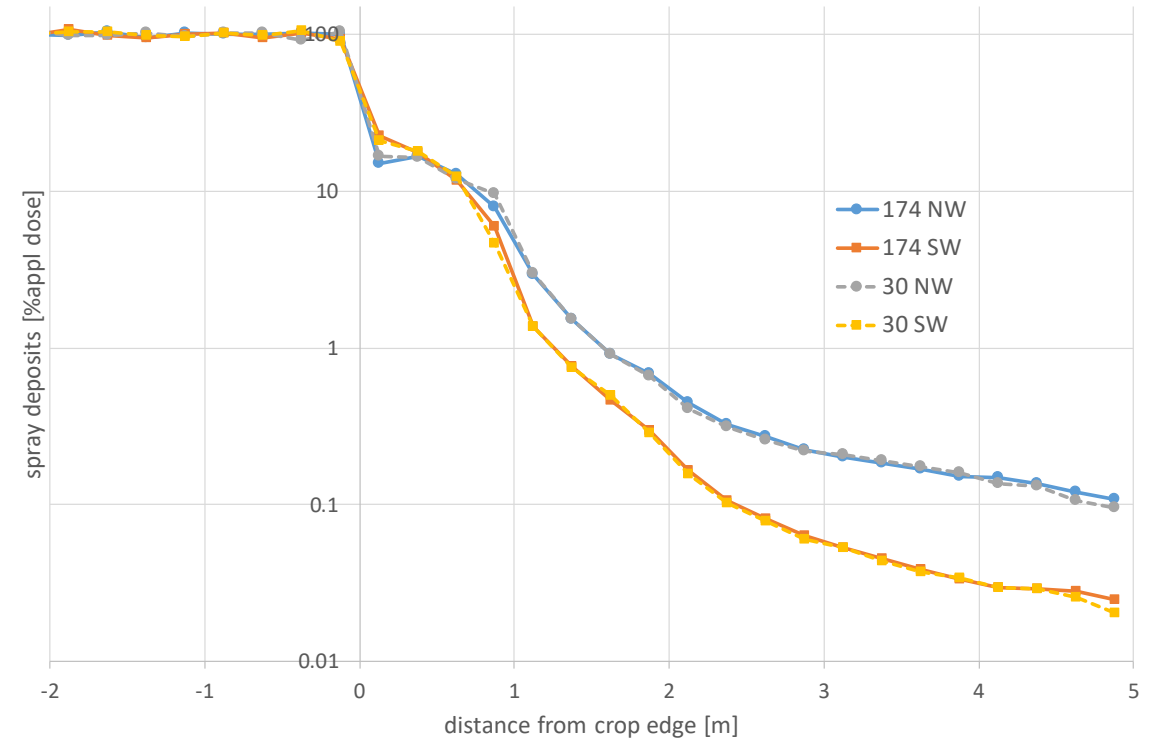

Figure 38 Spray deposits at the crop $(x<0)$ and at the ground downwind from treated field $(x>0)$, as a percentage of applied dose; case 10, fields 174 and 30 at NW and SW edges. 50\% reduction (air assistance) for downwind deposits $(X>0)$ is accounted for. An infinite field is assumed in upwind direction.

\subsubsection{Airborne emission}

The vertical profiles of airborne emission are shown in Figure 39 at $5 \mathrm{~m}$ off the NW and SW edges of fields 174 and 30. An upwind field width of $60 \mathrm{~m}$ was assumed. Emissions at $\mathrm{SW}$ edges were much lower than those at the NW edges due to the difference in effective wind direction. For field 30 the emissions are slightly lower than those for field 174, due to the lower concentration of the mixture in the sprayed liquid.

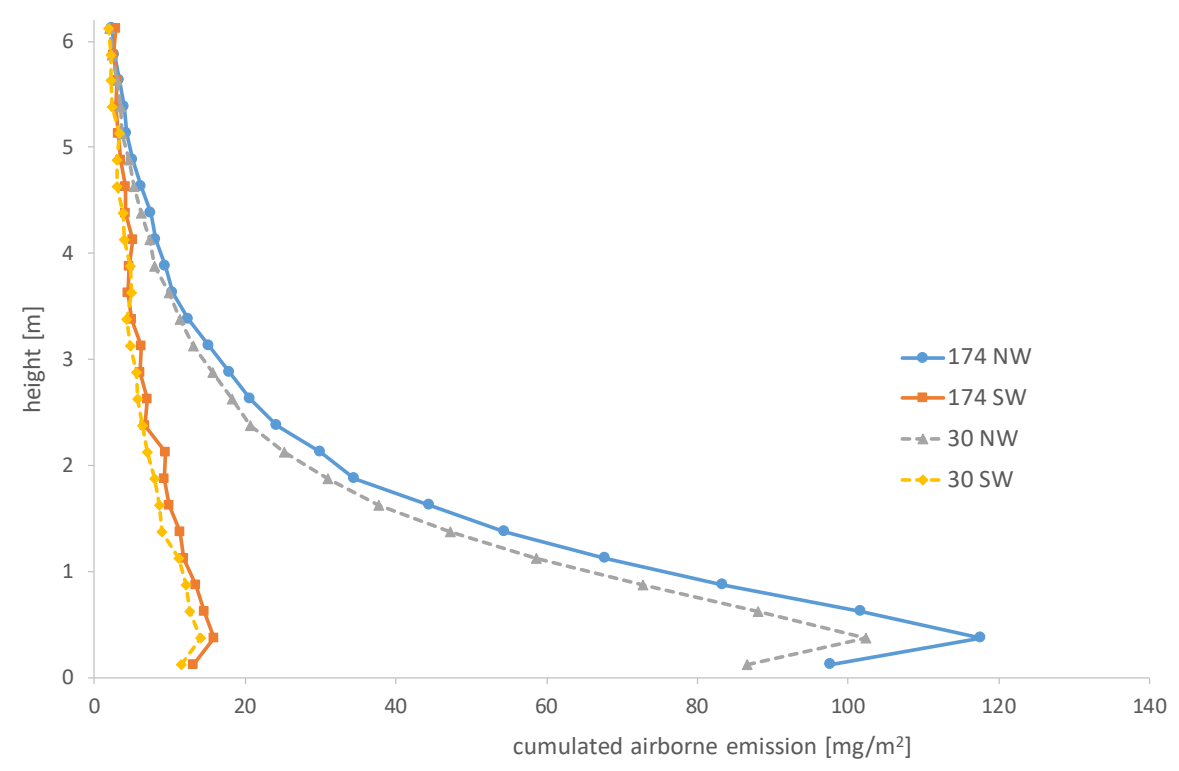

Figure 39 Airborne emission as a function of height; case 10. Simulation results for a 60m wide field at the NW and SW edges of fields 174 and 30. 
Note that the peak emission at about $0.5 \mathrm{~m}$ height for $174 \mathrm{NW}$ was almost $120 \mathrm{mg} / \mathrm{m}^{2}$, which exceeded all other cases. This corresponds with the concentration of the mixed products $(42 \mathrm{~g} / \mathrm{L})$, which also was highest of all cases (see Table A.1, Annex 1). The subsequent integrated emission over height up to $6.25 \mathrm{~m}$ appeared to be the highest as well: $200 \mathrm{mg} / \mathrm{m}$ at $174 \mathrm{NW}$ edge.

\subsection{Case 11: location 152, March 30, 2017}

Case 11 involves a treatment with a mixture of fungicides on field 152; no other fields were treated on the same day. Figure 40 shows the layout; the mixture used is given in Table 13. The spray application took place at 8 UT. The sprayer boom was supplied with DG 8003 nozzles that were placed only $25 \mathrm{~cm}$ apart; the liquid pressure was $300 \mathrm{kPa}$ (Table A.2, Annex 1). An air assistance technique was used, reducing emissions by $50 \%$. The height of the boom above the crop was lower than in the other cases: only $30 \mathrm{~cm}$. The small drop content $\left(\mathrm{V}_{100}\right)$ was $5.7 \%$. The combination of the nozzles used, lowered boom height and air assistance is classified as a DRT95 application technique (Table A.3, Annex 1). The effective wind direction at the actual NE edge (represented by the dashed line in Figure 40 ) was $11^{\circ}$, at the NW edge this was $79^{\circ}$ (Table A.2, Annex 1 ).

In the IDEFICS simulations a sprayer boom with inter-nozzle distance of only $25 \mathrm{~cm}$ has an imaginary swath width of $13 \mathrm{~m}$. To cover a sufficient field width, 5 swaths were simulated, representing a field width of $65 \mathrm{~m}$, which is comparable to the 3 swaths of $20 \mathrm{~m}$ in the previous cases.

\subsubsection{Ground deposits}

Figure 41 shows the deposits of spray and spray drift at the crop and at the ground downwind from the crop at the NE and NW edges of field 152. The curves are based on simulations for one swath and extrapolated for subsequent swaths, assuming an infinitely extended field in upwind direction. The distance presented in the graph is measured perpendicular to the field edge. The use of air assistance implied a reduction of $50 \%$ on all downwind deposits. Compared to other cases, deposits decrease with distance rapidly, mainly due to the lower boom height of only $30 \mathrm{~cm}$ above the crop.

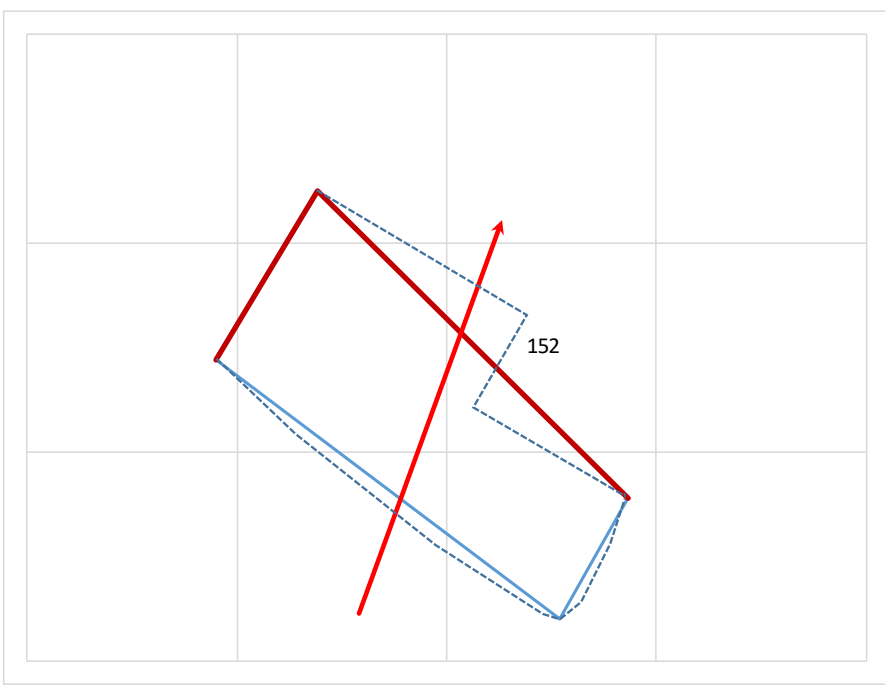

Figure 40 Schematic view of treated flower bulb fields at same day, case 11. Field 152 is the basis field; no other fields were treated that same day. The dashed lines indicate the actual field boundary. The arrow indicates wind direction at time of spray application. Squares indicate an $100 \times 100 \mathrm{~m}^{2}$ area. 
Table 13 Tank mixture and active ingredients in treatments of case 11.

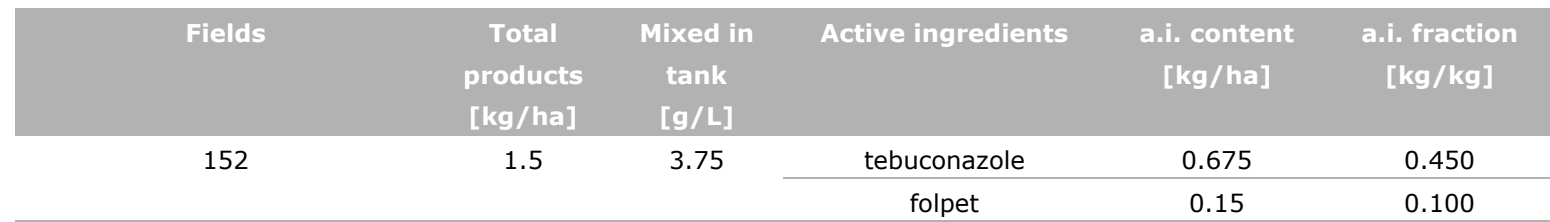

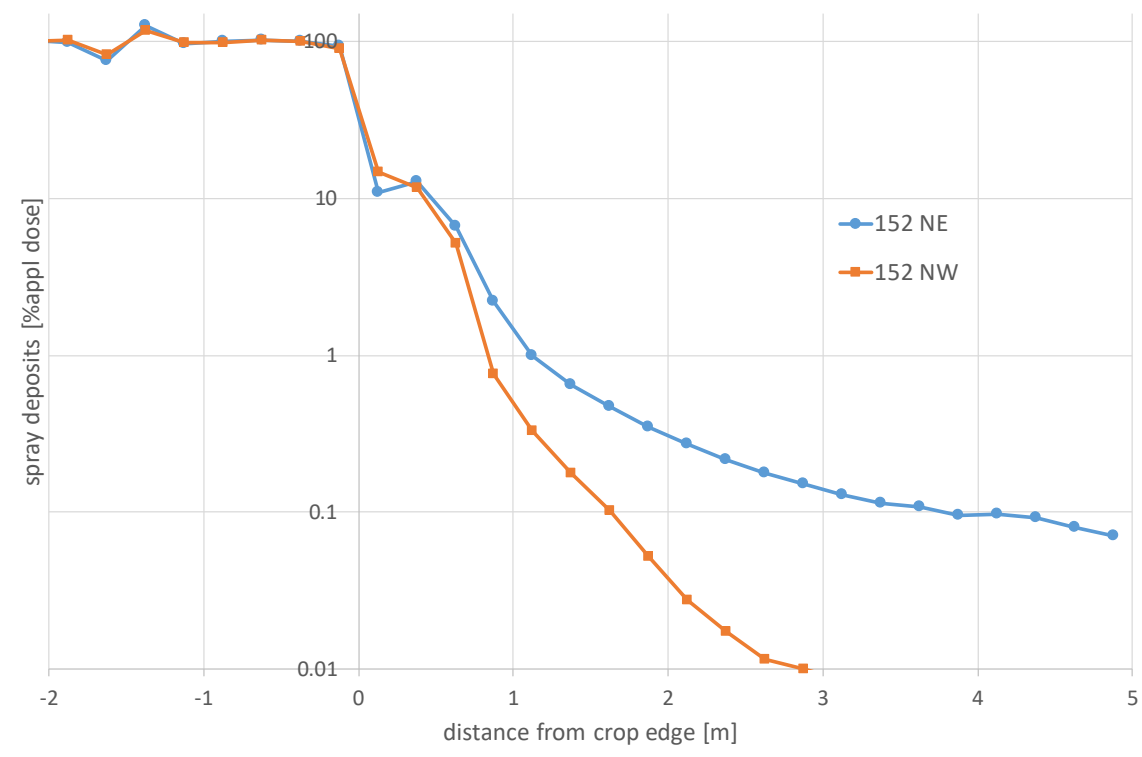

Figure 41 Spray deposits at the crop $(x<0)$ and at the ground downwind from treated field $(x>0)$, as a percentage of applied dose; case 11, field 152 at NE and NW edges. 50\% reduction (air assistance) for downwind deposits $(X>0)$ is accounted for. An infinite field is assumed in upwind direction.

\subsubsection{Airborne emission}

The vertical profiles of airborne emission are shown in Figure 42 at $5 \mathrm{~m}$ off the NE and NW edges of fields 174 and 30. An upwind field width of $65 \mathrm{~m}$ was assumed ( 5 swaths of $13 \mathrm{~m}$ width). Emissions at NW edge were much lower than those at the NE edge due to the difference in effective wind direction.

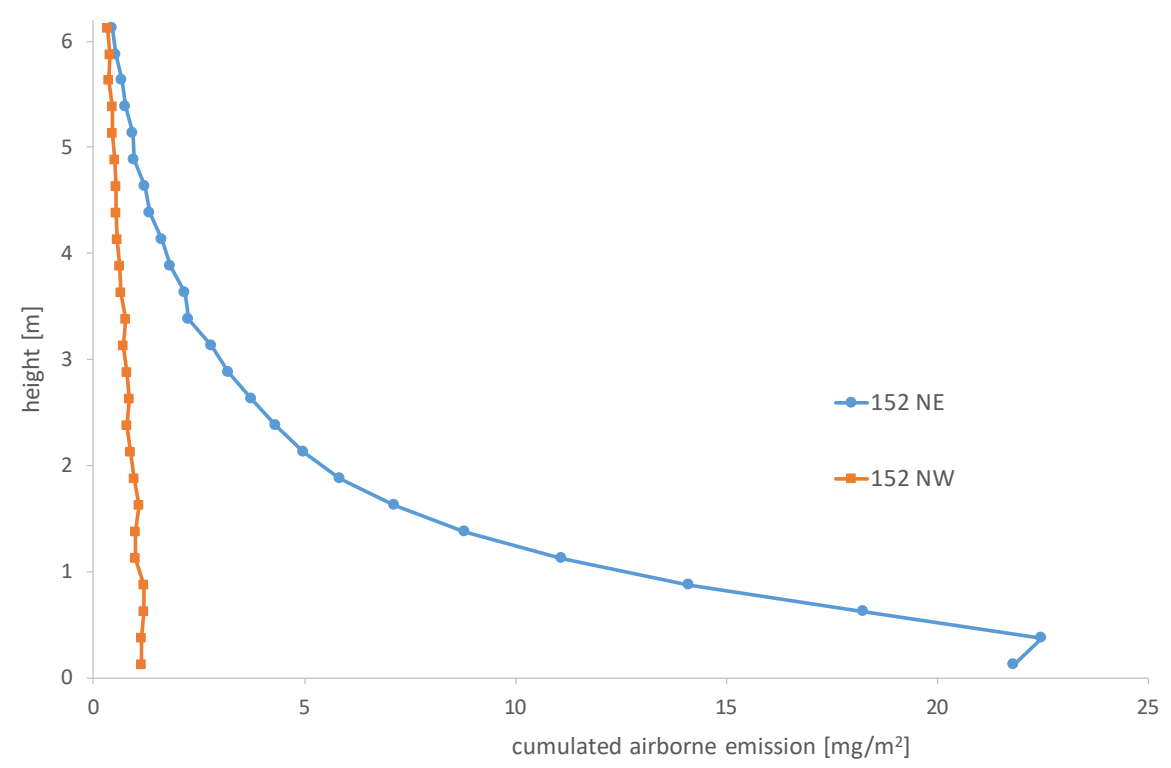

Figure 42 Airborne emission as a function of height; case 11. Simulation results for a 60m wide field at the NE and NW edges of field 152. 


\subsection{Case 12: location 152, June 18, 2017}

Case 12 involves an insecticide treatment on field 152, the same field as in Case 11; no other fields were treated on the same day. Figure 43 shows the layout; the mixture used actually contained only one product (Table 14). The spray application took place at 19 UT. The sprayer boom was supplied with DG 8003 nozzles that were placed only $25 \mathrm{~cm}$ apart; the liquid pressure was $300 \mathrm{kPa}$ (Table A.2, Annex 1). An air assistance technique was used, reducing emissions by $50 \%$. The height of the boom above the crop was lower than in the other cases: only $30 \mathrm{~cm}$. This is the same application technique as in case 11 and is classified as DRT95 (Table A.3, Annex 1 ). The small drop content $\left(\mathrm{V}_{100}\right)$ was $5.7 \%$. The effective wind direction at the SW edge was $43^{\circ}$, at the NW edge this was almost the same: $41^{\circ}$ (Table A.2, Annex 1 ).

In the IDEFICS simulations a sprayer boom with inter-nozzle distance of only $25 \mathrm{~cm}$ has an imaginary swath width of $13 \mathrm{~m}$. To cover a sufficient field width, 5 swaths were simulated, representing a field width of $65 \mathrm{~m}$, which is comparable to the 3 swaths of $20 \mathrm{~m}$ in the previous cases.

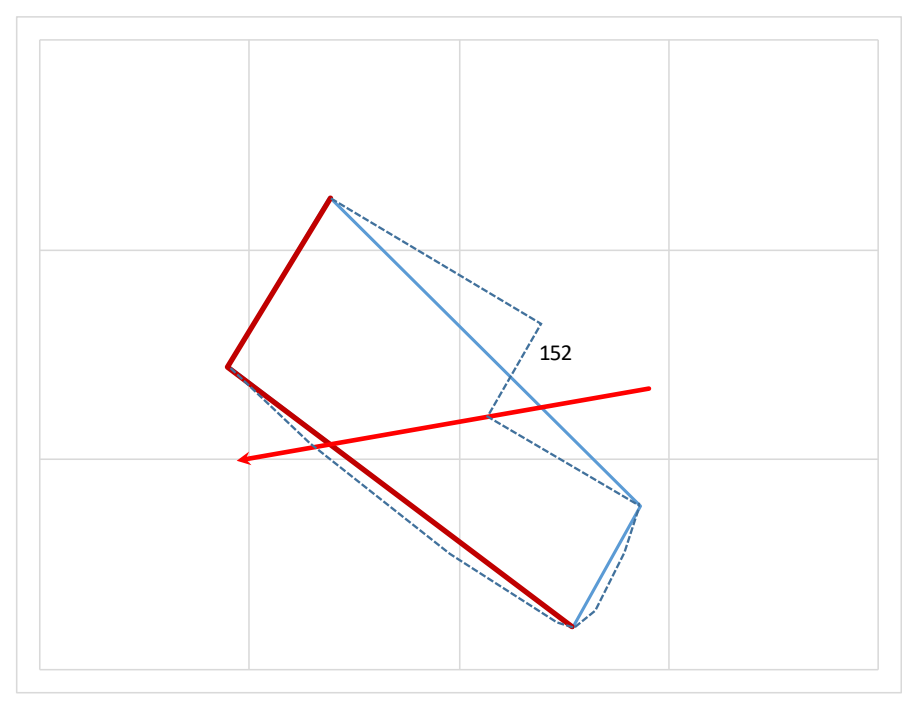

Figure 43 Schematic view of treated flower bulb fields at same day, case 12. Field 152 is the basis field; no other fields were treated that same day. The dashed lines indicate the actual field boundary. The arrow indicates wind direction at time of spray application. Squares indicate an $100 \times 100 \mathrm{~m}^{2}$ area.

Table 14 Tank mixture and active ingredients in treatments of case 12.

\begin{tabular}{|c|c|c|c|c|c|}
\hline Fields & $\begin{array}{c}\text { Total } \\
\text { products } \\
\text { [kg/ha] }\end{array}$ & $\begin{array}{c}\text { Mixed in } \\
\text { tank } \\
\text { [g/L] }\end{array}$ & Active ingredients & $\begin{array}{c}\text { a.i. content } \\
\text { [kg/ha] }\end{array}$ & $\begin{array}{l}\text { a.i. fraction } \\
{[\mathrm{kg} / \mathrm{kg}]}\end{array}$ \\
\hline 152 & 0.23 & 0.58 & acetamiprid & 0.046 & 0.200 \\
\hline
\end{tabular}

\subsubsection{Ground deposits}

Figure 44 shows the deposits of spray and spray drift at the crop and at the ground downwind from the crop at the SW and NW edges of field 152. The curves are based on simulations for one swath and extrapolated for subsequent swaths, assuming an infinitely extended field in upwind direction. The distance presented in the graph is measured perpendicular to the field edge. The use of air assistance implied a reduction of $50 \%$ on all downwind deposits. The curves are very similar since the effective wind direction is almost the same at the two edges. 


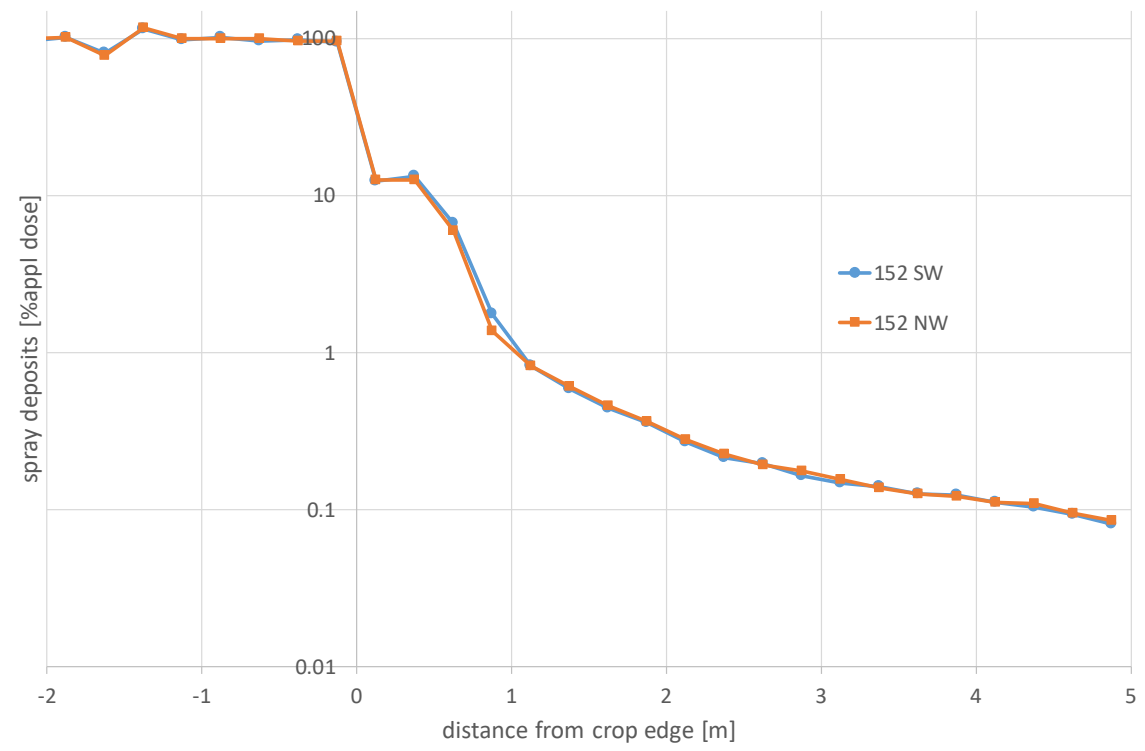

Figure 44 Spray deposits at the crop $(x<0)$ and at the ground downwind from treated field $(x>0)$, as a percentage of applied dose; case 12, field 152 at SW and NW edges. 50\% reduction (air assistance) for downwind deposits $(X>0)$ is accounted for. An infinite field is assumed in upwind direction.

\subsubsection{Airborne emission}

The vertical profiles of airborne emission are shown in Figure 45 at $5 \mathrm{~m}$ off the SW and NW edges of fields 152. An upwind field width of $65 \mathrm{~m}$ was assumed ( 5 swaths of $13 \mathrm{~m}$ width). Emissions at these two edges were almost the same, since effective wind direction was almost the same for these edges. However, even the small difference in wind direction caused a clearly visible difference in emission profiles. Apparently, airborne emissions are very sensitive to effective wind direction.

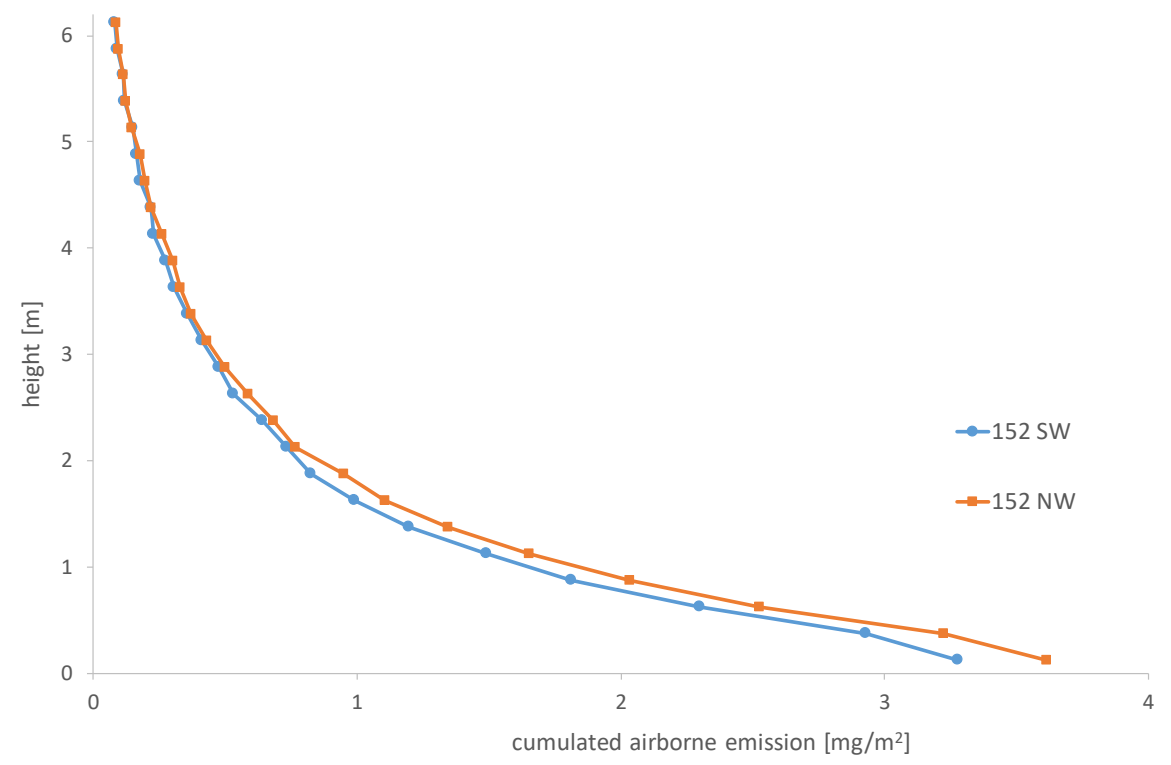

Figure 45 Airborne emission as a function of height; case 12. Simulation results for a 60m wide field at the SW and NW edges of field 152. 


\subsection{Case 13: location 181, May 26, 2017}

Case 13 involves a treatment with a fungicide and insecticide on field 181; no other fields were treated on the same day. Figure 46 shows the layout; the mixture used in the spray is shown in Table 15 . The application took place at 11 UT. According to the CLM survey, the sprayer boom was supplied with DG 8002 nozzles spraying at a pressure of $200 \mathrm{kPa}$. However, the corresponding drop size spectrum was not available for the simulations. Therefore, in the simulations the slightly coarser nozzle type DG 8003 nozzle was selected, spraying at a slightly higher pressure of $300 \mathrm{kPa}$ (Table A.2, Annex 1). The increased pressure might compensate for the coarser spectrum of the DG 8003, trying to achieve a similar drop size distribution as that in the actual situation (although the actual size distributions is unknown). The nozzles on the sprayer boom were placed $25 \mathrm{~cm}$ apart. An air assistance technique was used, reducing emissions by $50 \%$. The application involved a reduced boom height of $35 \mathrm{~cm}$ above the crop. The combined drift reducing measures taken imply an application technique that can be classified as DRT95 (Table A.3, Annex 1 ). The small drop content $\left(V_{100}\right)$ was $5.7 \%$. The effective wind direction at the actual SW edge (dashed line in Figure 46) was $49^{\circ}$, at the NW edge this was almost the same: $47^{\circ}$ (Table A.2, Annex 1).

In the IDEFICS simulations a sprayer boom with inter-nozzle distance of only $25 \mathrm{~cm}$ has an imaginary swath width of $13 \mathrm{~m}$. Therefore, similar to Case 12, 5 swaths were simulated corresponding to a field width of $65 \mathrm{~m}$.

Table 15 Tank mixture and active ingredients in treatments of case 13.

\begin{tabular}{|c|c|c|c|c|c|}
\hline Fields & $\begin{array}{l}\text { Total } \\
\text { products } \\
\text { [kg/ha] }\end{array}$ & $\begin{array}{c}\text { Mixed in } \\
\text { tank } \\
\text { [g/L] }\end{array}$ & Active ingredients & $\begin{array}{l}\text { a.i. content } \\
\text { [kg/ha] }\end{array}$ & $\begin{array}{c}\text { a.i. fraction } \\
{[\mathrm{kg} / \mathrm{kg}]}\end{array}$ \\
\hline \multirow{2}{*}{181} & & & fluopyram & 0.075 & 0.107 \\
\hline & & & esfenvalerate & 0.010 & 0.014 \\
\hline
\end{tabular}

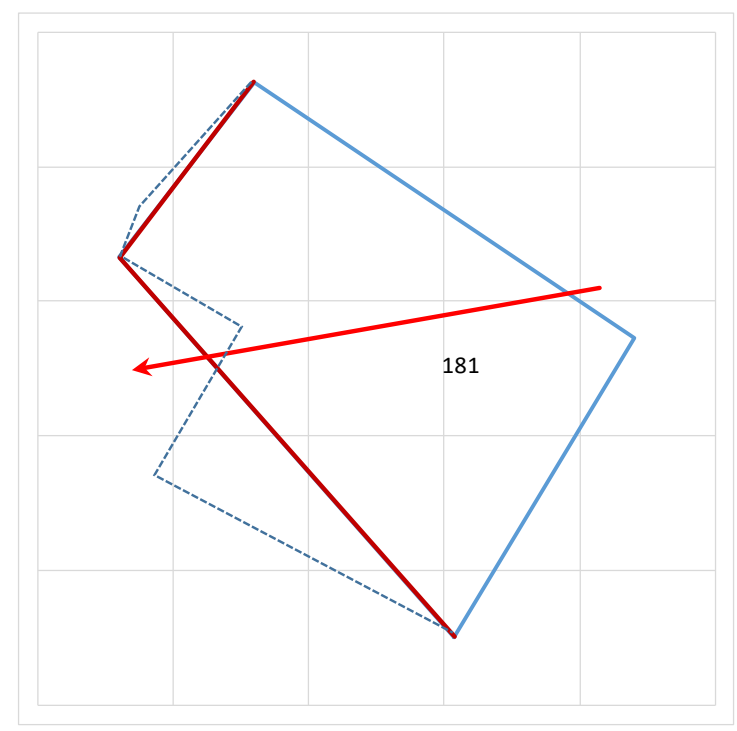

Figure 46 Schematic view of treated flower bulb fields at same day, case 13. Field 181 is the basis field; no other fields were treated that same day. The dashed lines indicate the actual field boundary. The arrow indicates wind direction at time of spray application. Squares indicate an $100 \times 100 \mathrm{~m}^{2}$ area. 


\subsubsection{Ground deposits}

Figure 47 shows the deposits of spray and spray drift at the crop and at the ground downwind from the crop at the SW and NW edges of field 181. The curves are based on simulations for one swath and extrapolated for subsequent swaths, assuming an infinitely extended field in upwind direction. The distance presented in the graph is measured perpendicular to the field edge. The use of air assistance implied a reduction of $50 \%$ on all downwind deposits. The curves are very similar since the effective wind direction is almost the same at the two edges.

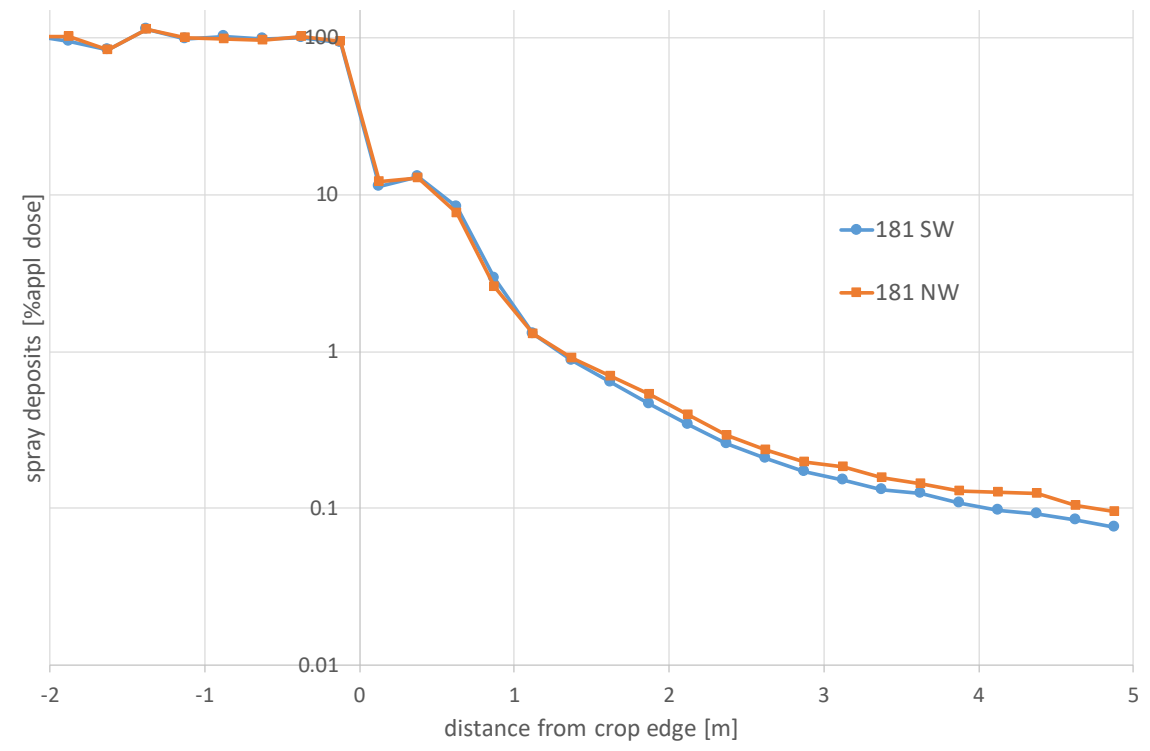

Figure 47 Spray deposits at the crop $(x<0)$ and at the ground downwind from treated field $(x>0)$, as a percentage of applied dose; case 13, field 181 at SW and NW edges. 50\% reduction (air assistance) for downwind deposits $(X>0)$ is accounted for. An infinite field is assumed in upwind direction.

\subsubsection{Airborne emission}

The vertical profiles of airborne emission are shown in Figure 48 at $5 \mathrm{~m}$ off the SW and NW edges of fields 181. An upwind field width of $65 \mathrm{~m}$ was assumed ( 5 swaths of $13 \mathrm{~m}$ width). Emissions at these two edges were almost the same, since effective wind direction was almost the same for these edges. However, even the slightly larger wind direction on the SW edge caused a reduced emission profile compared to that at the NW edge. 


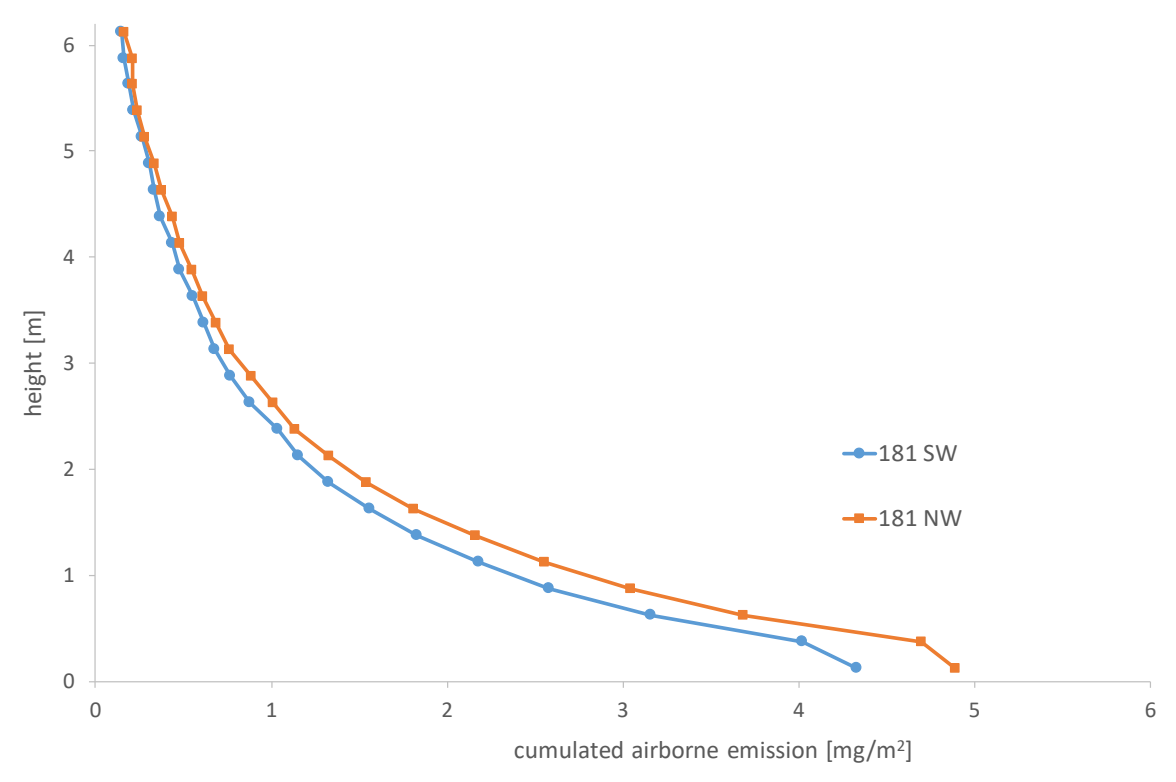

Figure 48 Airborne emission as a function of height; case 13. Simulation results for a $60 \mathrm{~m}$ wide field at the SW and NW edges of field 181.

\subsection{Case 14: location 182, April 13, 2017}

Case 14 involves a fungicide treatment on field 182; no other fields were treated on the same day. Figure 49 shows the layout; the mixture used actually consisted of only one product with one active ingredient (Table 16). The application took place at 16 UT. According to the CLM survey, the sprayer boom was supplied with AIXR 11004 nozzles spraying at a pressure of $300 \mathrm{kPa}$. However, the corresponding drop size spectrum was not available for the simulations. Therefore, in the simulations the slightly finer nozzle type AIXR 11003 was selected, spraying at a lower pressure of $200 \mathrm{kPa}$ (Table A.2, Annex 1); this application is classified as DRT75. The reduced pressure might compensate for the finer spectrum of the AIXR 11003, trying to achieve a similar drop size distribution as that in the actual situation (although the actual size distributions is unknown). An air assistance technique was used, reducing emissions by $50 \%$. The small drop content $\left(\mathrm{V}_{100}\right)$ was only $0.56 \%$. The effective wind direction at the SE edge was almost perpendicular to the edge $\left(8^{\circ}\right)$ (Table A.2, Annex 1 ). The NW edge was almost parallel to wind direction and it was not considered worthwhile to do drift simulations there.

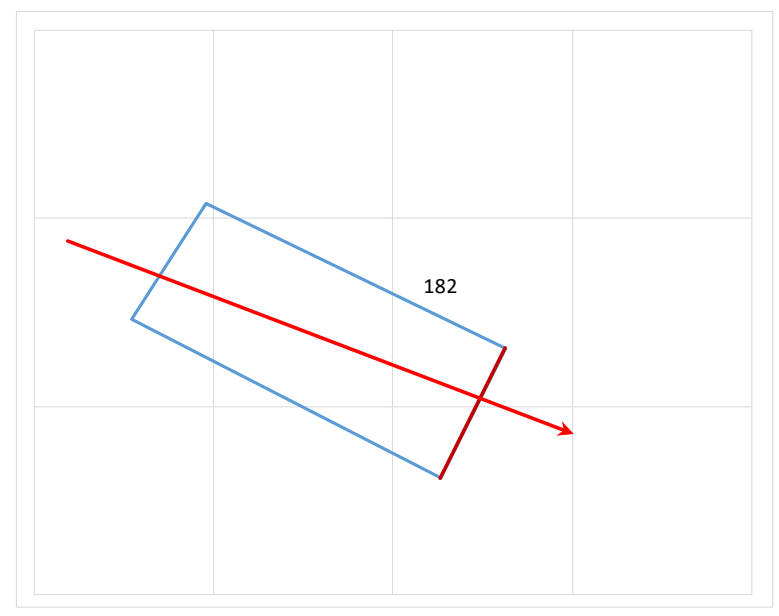

Figure 49 Schematic view of treated flower bulb fields at same day, case 14. Field 182 is the basis field; no other fields were treated that same day. The arrow indicates wind direction at time of spray application and was almost parallel to the NE edge. Squares indicate an $100 \times 100 \mathrm{~m}^{2}$ area. 
Table 16 Tank mixture and active ingredients in treatments of case 14.

\begin{tabular}{|c|c|c|c|c|c|}
\hline Fields & $\begin{array}{c}\text { Total } \\
\text { products } \\
\text { [kg/ha] }\end{array}$ & $\begin{array}{c}\text { Mixed in } \\
\text { tank } \\
\text { [g/L] }\end{array}$ & Active ingredients & $\begin{array}{c}\text { a.i. content } \\
\text { [kg/ha] }\end{array}$ & $\begin{array}{l}\text { a.i. fraction } \\
{[\mathrm{kg} / \mathrm{kg}]}\end{array}$ \\
\hline 182 & 0.25 & 1.25 & trifloxystrobin & 0.125 & 0.500 \\
\hline
\end{tabular}

\subsubsection{Ground deposits}

Figure 50 shows the deposits of spray and spray drift at the crop and at the ground downwind from the crop at the SW edge of field 182. The curve is based on simulations for one swath and extrapolated for subsequent swaths, assuming an infinitely extended field in upwind direction. The distance presented in the graph is measured perpendicular to the field edge.

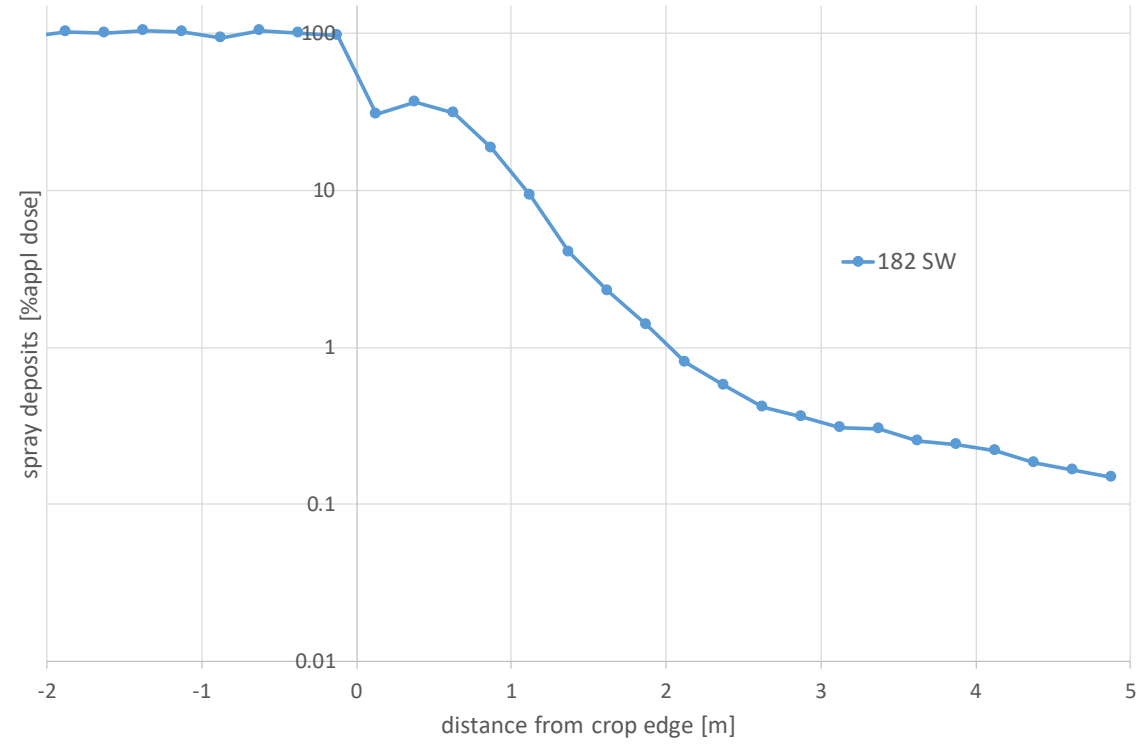

Figure 50 Spray deposits at the crop $(x<0)$ and at the ground downwind from treated field $(x>0)$, as a percentage of applied dose; case 14, field 182 at SW edge. An infinite field is assumed in upwind direction.

\subsubsection{Airborne emission}

The vertical profile of airborne emission is shown in Figure 51 at $5 \mathrm{~m}$ off the SW edge of fields 182 . An upwind field width of $60 \mathrm{~m}$ was assumed. Emissions appeared to be relatively low due to the coarse nozzles used, even though wind speed was relatively high and evaporation rate was moderate. This is mainly due to the low dose of products applied. 


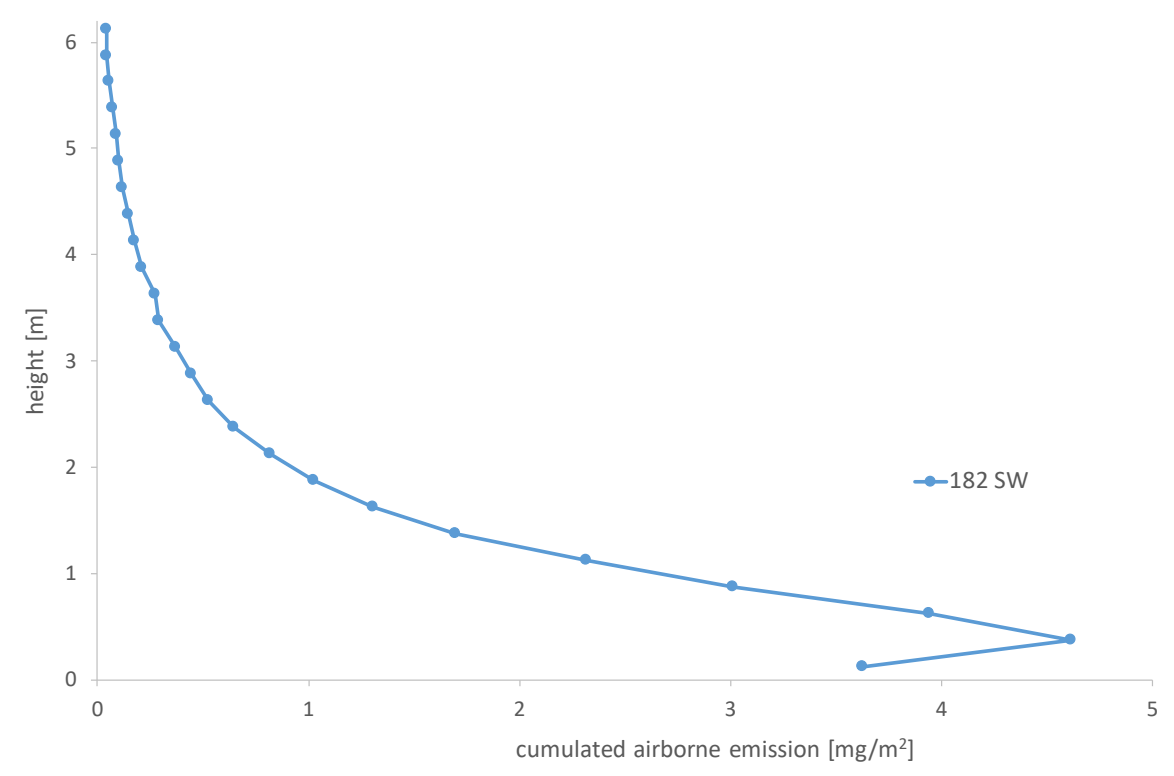

Figure 51 Airborne emission as a function of height; case 14. Simulation results for a 60m wide field at the SW edge of field 182.

\subsection{Case 4 under worse conditions}

Originally, in case 4 the wind speed during application was $4 \mathrm{~m} / \mathrm{s}$ at $10 \mathrm{~m}$ height. The effective wind direction at the SW edge of field 121 was $57^{\circ}$. Air temperature was $10.2^{\circ} \mathrm{C}$ and relative humidity $65 \%$ (Table A.2, Annex 1). The applied dose of the formulated products was $2.85 \mathrm{~kg} / \mathrm{ha}$ (or $285 \mathrm{mg} / \mathrm{m}^{2}$ ) (Table 5; Section 4.4). This original situation will be identified as case A. Assuming the wind speed would have been $8 \mathrm{~m} / \mathrm{s}$ at $10 \mathrm{~m}$ height, and its direction perpendicular to that field edge, the situation for drift would be considerably worse. In this case (identified as case B) many more drops would drift downwind and airborne emission would increase. An even worse situation (case $C$ ) would occur when in case $\mathrm{B}$ the evaporation would be enhanced, say when air temperature would have raised to $20^{\circ} \mathrm{C}$ and $\mathrm{RH}$ lowered to $25 \%$. In that case small airborne drops would lose their water content very fast. Medium sized drops that might have deposited onto the ground under normal conditions, may contribute to airborne emission in case C. Figure 52 shows the airborne emission profiles with height at $5 \mathrm{~m}$ downwind from the SW field edge. As before, a field width of $60 \mathrm{~m}$ is assumed. Case A (blue curve) represents the original situation of case 4, equal to the blue curve in Figure 18 (Section 4.4.2). A cross wind of $8 \mathrm{~m} / \mathrm{s}$ (at $10 \mathrm{~m}$ height) leads to an enormous increase in airborne emission, particularly at low heights (orange curve). A further increase (grey curve) is obtained under the highly evaporative conditions of case $\mathrm{C}$.

In Figure 53 the particle size distributions of airborne emission at $5 \mathrm{~m}$ downwind are shown. The graph on the left shows the actual size classes of drops and dried particles together. Case $B$ (orange bars) differs slightly from cases $A$ and $C$, showing that more particles of larger sizes are present. This is caused by the high wind speed, that rapidly blows larger particles to the evaluation zone at $5 \mathrm{~m}$ downwind. Although this is equal to case $C$, in the latter case the rapid decrease of droplet sizes due to enhanced evaporation limits the number of larger airborne drops. The graph on the right shows the same distributions, assuming all drops would have dried when reaching the evaluation zone. Now case $B$ is much more similar to cases $A$ and $C$. 


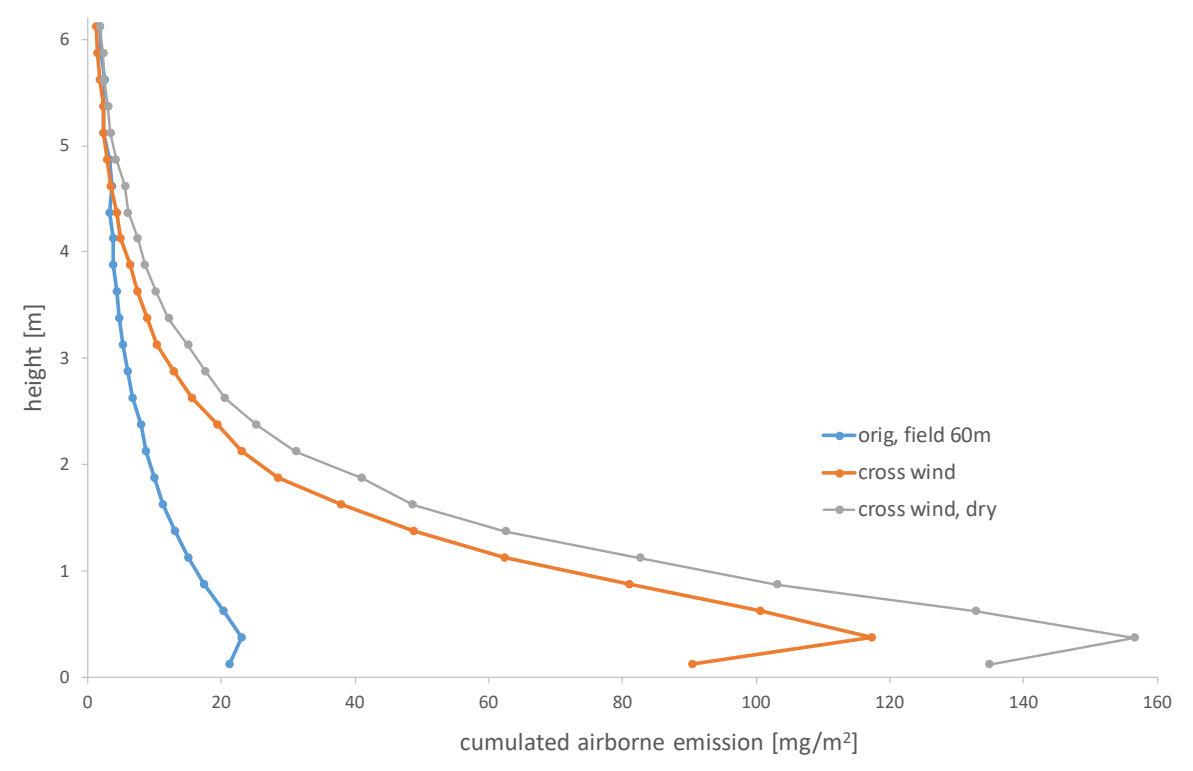

Figure 52 Comparison of airborne emission profiles with height in cases $A, B$ and $C$, derived from original Case 4. Simulation results for a $60 \mathrm{~m}$ wide field at the SE edge of field 121.
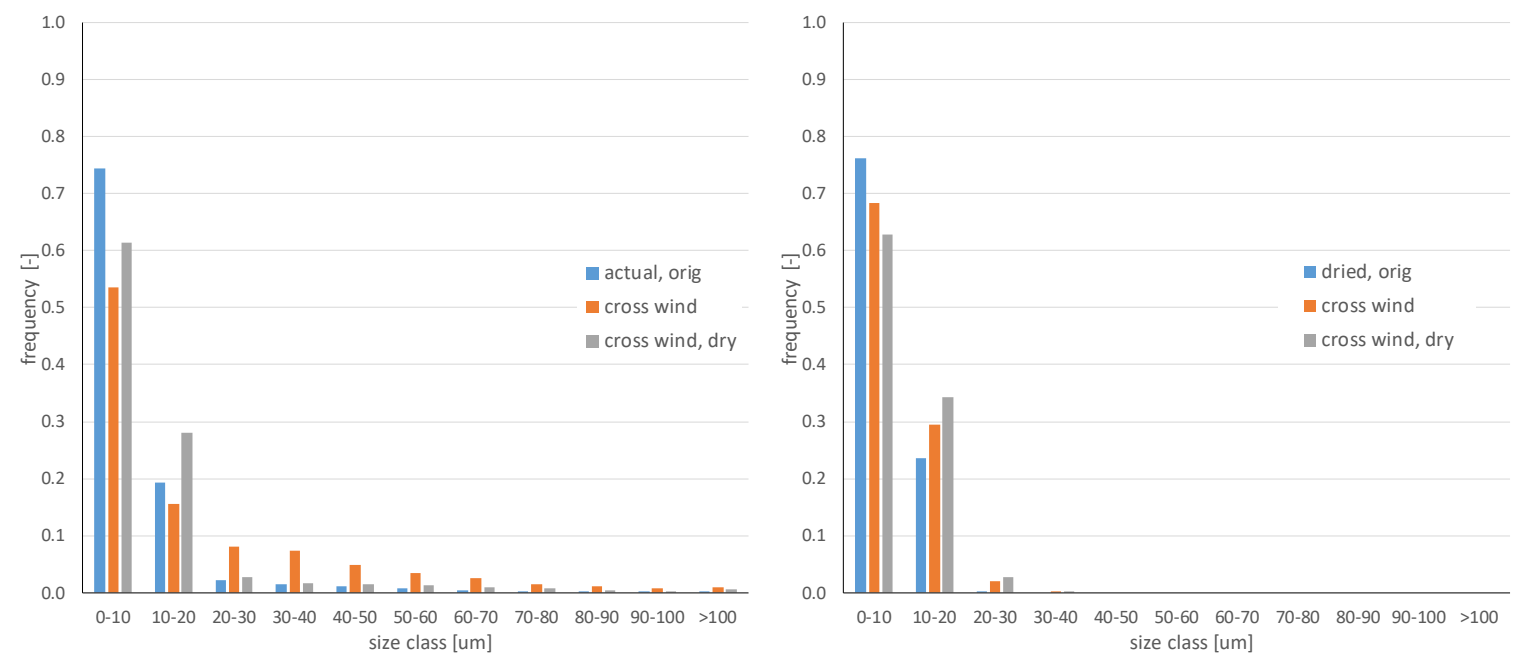

Figure 53 Particle size distribution at $5 \mathrm{~m}$ downwind, for cases A, B and C. Left: actual particle size (droplets and dry particles); right: distribution when all drops would have dried completely.

Not only airborne emissions are affected, but downwind ground deposits as well. In Figure 54 ground deposits are shown for the three cases. The lowest deposits occur in the original situation (orange curve). With increased wind speed (and perpendicular wind direction), ground deposits increase significantly (blue curve). Again, at higher evaporation rate the deposits increase further, as drops that would deposit nearer to the field edge may now deposit further downwind as their size is reduced by evaporation (grey curve). Note that at $5 \mathrm{~m}$ downwind the deposits in case $\mathrm{C}$ are about 10 times higher than in the original situation. 


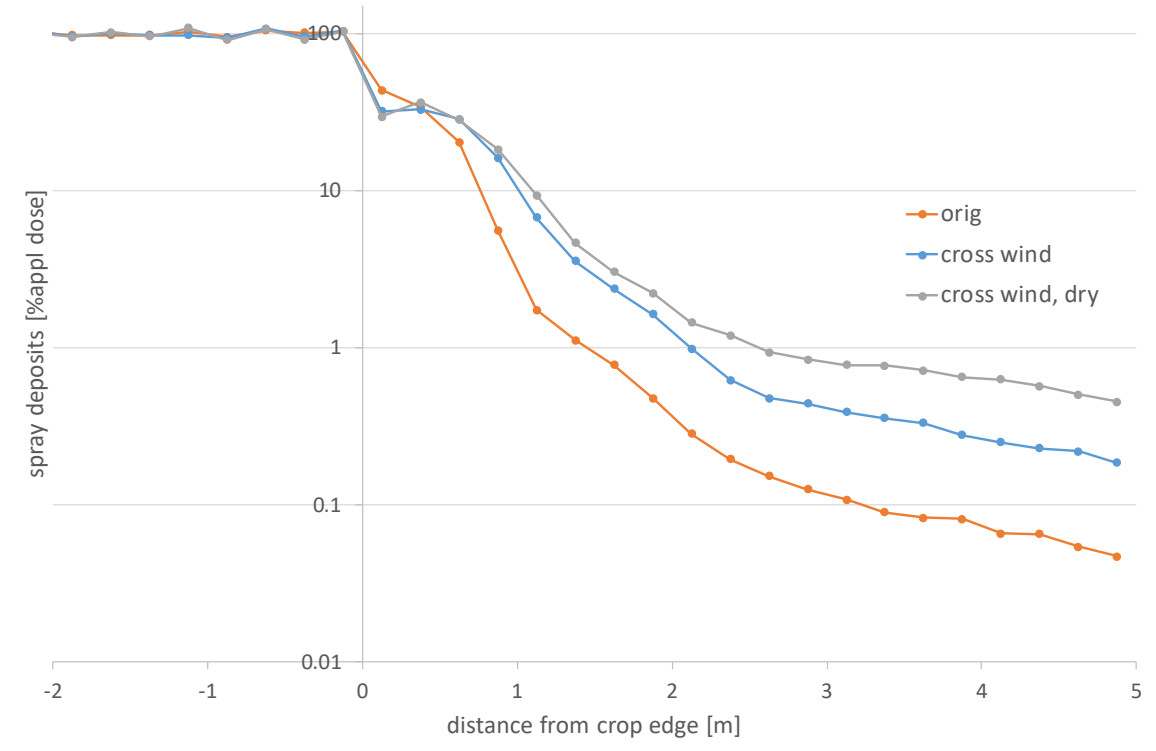

Figure 54 Downwind ground deposits for cases A, B and C. An increased wind speed and evaporation rate leads to increased downwind deposits.

Setting the evaluation zone at $5 \mathrm{~m}$ downwind is rather arbitrary. At this distance the OPS model takes over the simulation of the dispersion of airborne particles (Section 3.2). Yet, in the IDEFICS model the evaluation zone can be set to other distances. For instance, evaluating airborne emissions at $20 \mathrm{~m}$ and $50 \mathrm{~m}$ downwind yields Figure 55. Roughly, at $20 \mathrm{~m}$ the airborne emission is half the emission at $5 \mathrm{~m}$, and at $50 \mathrm{~m}$ it is about half that at $20 \mathrm{~m}$.

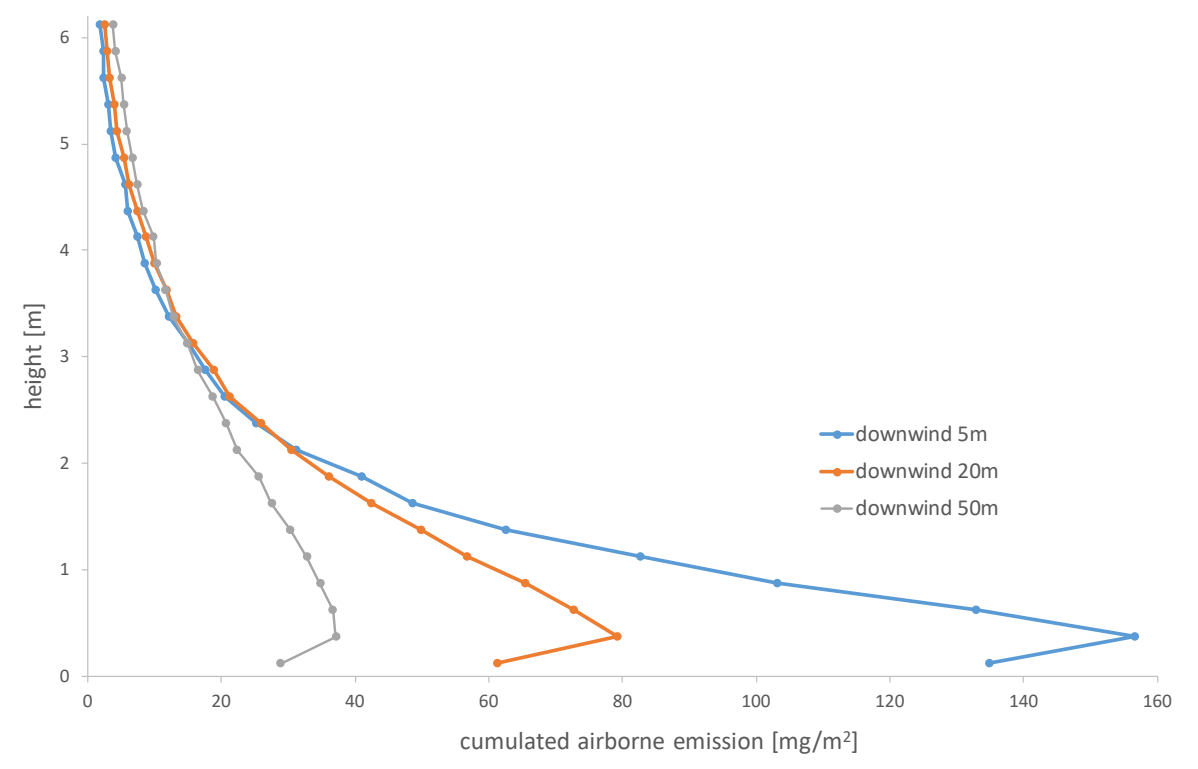

Figure 55 Airborne emission profiles for case C, evaluated at three downwind distances: $5 \mathrm{~m}, 20 \mathrm{~m}$ and $50 \mathrm{~m}$.

Looking at ground deposits down to $50 \mathrm{~m}$ off the edge, a similar trend can be seen; Figure 56 . Near the field edge the deposits decrease with distance rapidly (due to sedimentation of relatively large drops), but further downwind the decrease is more slowly and completely governed by the expanding aerosol cloud touching the ground. It can be shown that at all distances evaluated (5, 20 and $50 \mathrm{~m}$ ) the ratio of the airborne emission peak and local ground deposits is about 100, similar to findings for other cases in previous sections. 


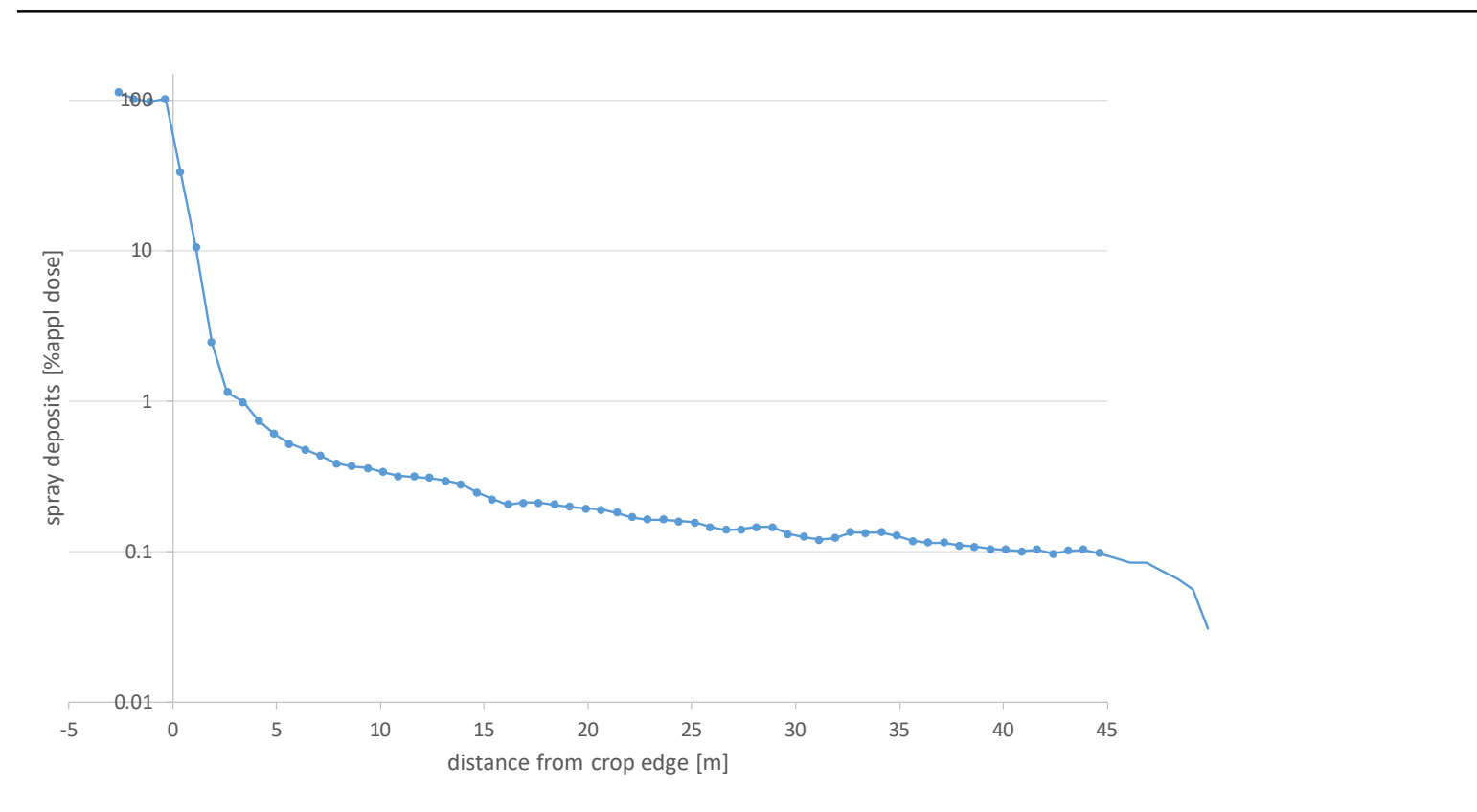

Figure 56 Downwind ground deposits down to $45 \mathrm{~m}$ off the field edge; cross wind of $8 \mathrm{~m} / \mathrm{s}$, case $\mathrm{C}$. 


\section{Discussion}

During the simulations and looking at the model results, several questions and remarks came up. These are combined in this chapter.

For simplicity, fields were presented by quadrangles. In some cases the actual field boundaries were clearly different from a quadrangle. Whenever it was assumed worthwhile, the actual boundaries were taken into account, particular to compute the effective wind direction at downwind edges, since it turned out that this wind direction is important for the values of airborne emissions.

A related issue is the assumption that upwind field width is $60 \mathrm{~m}$. In many cases the contribution of nozzles further upwind than $60 \mathrm{~m}$ could be shown to be very small. On the other hand, even if a field stretches several hundreds of meters upwind, wind direction often was far from perpendicular which caused the effective upwind fetch to be much less than the real width of the field. In fact not only width but also length of the field should have been taken into account. This involved a different approach of the simulations, which is currently not easy to implement. Therefore, using a finite but fixed field width of $60 \mathrm{~m}$ seemed a reasonable assumption.

For IDEFICS the required wind speed is the average wind speed at $2 \mathrm{~m}$ height above cut grass. It can be derived from the KNMI data which give the wind speed at $10 \mathrm{~m}$ height. Unfortunately, by mistake the wind speed at $2 \mathrm{~m}$ height in the crop area was used in the simulations (i.e. $1.5 \mathrm{~m}$ above a crop of $0.5 \mathrm{~m}$ height). This resulted in an underestimation of wind speed of about $10 \%$. Consequently, spray drift results are slightly underestimated as well, yet it is not known to what extent the results are underestimated. A sensitivity analysis on the results should give answers to this question.

Dealing with unfinished ('broken') particle tracks by assigning these to one of the final partitions (crop deposits, ground deposits, airborne emission) was a numerical work-around. Ideally, a full rerun of all simulations with a sufficiently large number of iteration steps per particle track would have been preferred. However, since the problem of significant numbers of broken tracks was acknowledged only after all simulation runs were carried out, a full rerun was not feasible considering the limited project resources left. Still, the work-around appears solid enough to give trustworthy results.

In case 1 and case 2 it was shown that airborne emissions of spray drift can be much higher than ground deposits at equivalent downwind distances. This is a general feature of spray treatments; ratios of airborne emissions to ground deposits between 100 and 200 are often observed. However, airborne emissions of spray drift only last for (less than) one hour, while ground deposits may be present for many days. Which of these routes is the more important one for exposure of people cannot be answered here.

Similarly, it was shown that the peak in airborne emission was about $10 \%$ and almost $25 \%$ of the applied dose in case 1 and case 2, respectively. For most cases a value of about $10 \%$ was found, ranging from $2 \%$ (case 5 ) up to $24 \%$ (case 2 ). Wind speed appeared to be an important factor. Again, this confirms that airborne emissions of spray drift at $5 \mathrm{~m}$ downwind and $0.5 \mathrm{~m}$ above the ground can often take very high values.

In some cases the CLM survey was yet incomplete at the time the spray drift simulations were carried out. In those cases a best guess was made to be able to carry out the simulations. Although in principle this may have led to spray drift results not representing the reality, the differences are probably relatively small and conclusions will hold. Factors such as weather conditions and concentrations of compounds are more important in determining the absolute emissions and these factors were present in the CLM survey. On the other hand, in cases where relevant information on the spray application became available after the simulations had been carried out, adequate corrections were estimated and applied to the simulation results. 
Nearby deposits of spray drift (expressed as percentage of applied dose) on the ground next to the treated field are insensitive to the concentration of product in the sprayed liquid. These nearby deposits mainly depend on initial drop size distribution and wind speed. Obviously, when ground deposits would have been expressed in absolute units instead, the applied dose rate onto the field has to be taken into account. In contrast, airborne emissions depend on product concentration both in relative and in absolute units. Product concentration in the sprayed liquid determines the final size of dried particles, which usually are abundant in airborne emissions.

In case 5 and 6 some fields are relatively narrow with widths of $30 \mathrm{~m}$ or even only $20 \mathrm{~m}$. Corresponding airborne emissions appeared to be significantly lower due to reduced field widths, depending on factors like wind speed and evaporation rate. Particularly in case 5, the effect of field width on airborne emission was only limited. This seems in contrast with the significance of a second and third swath or even subsequent swaths (as in case 1) to contribute to airborne emissions. However, case 5 represented an application in winter with low temperature and high relative humidity, while wind speed was low. Under these circumstances, evaporation rates of airborne droplets are very low while their downwind transport is slow. As a result, the airborne emission is relatively low in such conditions and originates primarily from the first swath. Under circumstances with high wind speed and high evaporation rates, the effect of field width on airborne emissions is expected to be more pronounced.

Spray drift deposits at $5 \mathrm{~m}$ downwind range from about $0.01 \%$ up to about $0.15 \%$ of the applied dose, with an average of about $0.1 \%$ for the cases studied. Although application technique may be a factor of importance, the main factors seem to be wind speed and wind direction. This has not been investigated in detail yet. Still, for case 4 additional simulations under worse conditions (higher wind speed, wind perpendicular to field edge, highly evaporative conditions) clearly show that wind speed and wind direction are important factors for both ground deposits and airborne emissions.

In field experiments on potato crops, airborne emissions and ground deposits of spray drift were compared as well (Van de Zande et al., 2017). Their results showed that the ratios of airborne emissions to ground deposits range from $1-4$ at $5 \mathrm{~m}$ downwind, up to about 140 at $40 \mathrm{~m}$ downwind, depending on application technique. Apparently, at $5 \mathrm{~m}$ downwind the ratios were considerably less than those found in the current study. However, in the experiments average airborne emissions ( $0-3 \mathrm{~m}$ height) were compared rather than the peak values. Also, differences in atmospheric stability will affect the breadth and strength of the peak and thus affect the observed ratios. The additional simulations for case 4 , down to $50 \mathrm{~m}$ off the field edge, indicate that the ratio of airborne emission and ground deposits is relatively insensitive to downwind distance.

Van de Zande et al. (2018) reported measured peak values of airborne emissions of $10-30 \%$ of the applied dose at $5 \mathrm{~m}$ downwind using standard XR11004 nozzles. For DRT90 nozzles XLTD11004 peak values of $1-3 \%$ of the applied dose were found. These are values in the same order of magnitude as found in the current simulation study. The experimental airborne emission peaks appeared to be about 30 times higher than ground deposits of spray drift at $5 \mathrm{~m}$ downwind, which still is significantly lower than the ratios of $100-200$ as found in the current simulation study. 


\section{Conclusions}

The spray drift model IDEFICS has been developed primarily for computing downwind deposits of spray drift on the ground next to a field treated with a pesticide spray. However, this report shows that the airborne emissions computed by IDEFICS can be used to estimate the emissions of small drops and dried particles that remain airborne for a long time while travelling long distances.

The IDEFICS model has been validated for ground deposits. Validation for airborne emissions, however, has been carried out only on a limited scale. To support and strengthen the results of this study, extended validation of the model is required.

In the OBO project, the main focus was on exposure of residents to pesticides due to airborne emission. Direct exposure to ground deposits of spray drift, for instance deposits in gardens of nearby residents, was not determined. Extending the IDEFICS results to distances further downwind than $5 \mathrm{~m}$ off the field edge may help to estimate this exposure route.

In the model train the time resolution was selected to be one hour. In general, spray drift events and exposure to airborne emissions take place well within one hour. High local emission fluxes may occur at the moment the boom sprayer passes the position of a resident on some downwind placement. Typically, such high emission fluxes pass in seconds or tens of seconds. Usually, an outdoor resident will avoid direct exposure to the a spray drift cloud. The results given in this study represent emission fluxes integrated over time (one hour) and therefore do not show the extreme concentrations that are possible locally for a short time. Whether or not it is worthwhile to study such exposure peak fluxes is a discussion not to be held in this report. The IDEFICS model, however, may help to quantify emissions fluxes on a short time resolution scale.

The current study describes 14 real cases of spray applications in Dutch flower bulbs for which spray drift has been computed. Each case has its own sprayer settings and weather conditions. The full set of results might be used to study statistically, for instance to study the sensitivity of several relevant factors. Wind speed, wind direction and application techniques are likely parameters to affect the level of spray drift, both in ground deposits and in airborne emissions. A future analysis of the current results might clarify such relations.

Ratios of airborne emissions of spray drift to ground deposits were obtained ranging from $100-200$. Experimental studies resulted in ratios up to about 30, which is significantly lower. A further analysis of model parameters and results might help to understand the extent of these ratios.

Both simulations and experiments indicate that at $5 \mathrm{~m}$ downwind peak airborne emissions of $20-30 \%$ of the applied dose may occur occasionally. It is worrying that such values occurred even for applications classified as DRT50 or higher. Although in general the residents will avoid the exposure to drifting spray clouds of a crop sprayer passing by, a nearby playing child or a human passing by on an edge-of-field road may be exposed to extreme concentrations of pesticides under unfavourable conditions. Besides, the cloud of airborne emission may travel considerable distances downwind, although it will spread gradually and concentrations decrease. Again, further study is needed to investigate which conditions are particularly unfavourable and at what rate the concentration of airborne emissions decrease while flowing downwind. 


\section{References}

Bogers, R.P., D. Schram-Bijkerk, J. Devilee, A.B. Knol \& O.R.P. Breugelmans, 2014. Verkenning van mogelijkheden voor onderzoek naar blootstelling aan gewasbeschermingsmiddelen bij omwonenden. RIVM, RIVM rapport 630030002/2014, Bilthoven. 2014. 92p.

CLM, OBO Deliverable 112. Spray registrations. 2017.

Health Council of the Netherlands. Crop protection and local residents. The Hague: Health Council of the Netherlands, 2014; publication no. 2014/02E; 192 pp.

Holterman, H. J., Van de Zande, J. C., Porskamp, H. A. J., Huijsmans, J. F. M. 1997. Modelling spray drift from boom sprayers. Computers and Electronics in Agriculture 19(1), 1-22.

Holterman, H.J., Michielsen, J.M.G.P., Van de Zande, J.C. 1998. Spray drift in crop protection: validation and usage of a drift model. Paper presented at the International Conference on Agricultural Engineering (AgEng), Oslo (Norway), August 24-27, 1998, Paper no. 98-A-012, 9 pp.

ISO 22866, 2005. Equipment for crop protection - Methods for the field measurement of spray drift. International Standardisation Organisation, Geneva. 2005.

Jacobs, C., Van den Berg, F.E., Holterman, H.J., Van de Zande, J.C., 2018. Atmospheric transport of small droplets and vapour during and after application of plant protection products. OBO Deliverable 87; $37 \mathrm{pp}$.

OBO, 2017. Research on exposure of residents to pesticides (OBO-project). https://www.bestrijdingsmiddelen-omwonenden.nl/english

TCT, 2018. List with certified drift reducing nozzles (DRD-lijst) and spray techniques (DRT-lijst) in the Netherlands; https://www.helpdeskwater.nl/publish/pages/138134/drd-lijst_20171215.pdf https://www.helpdeskwater.nl/publish/pages/138135/drt-lijst_20180724.pdf

Zande, J.C. van de, J.M.G.P. Michielsen \& H. Stallinga, 2017. Spray drift exposure of bystanders and residents when spraying field crops. Wageningen UR, Wageningen Plant Research Report 722. Wageningen. 29 pp.

Zande, J.C. van de, H. Stallinga, P. van Velde \& J.M.G.P. Michielsen, 2018. Potential exposure of residents to spray drift within $50 \mathrm{~m}$ of a sprayed field. Wageningen Research, Wageningen Plant Research Report WPR-756. Wageningen. 114 pp. (OBO Deliverable 36) 


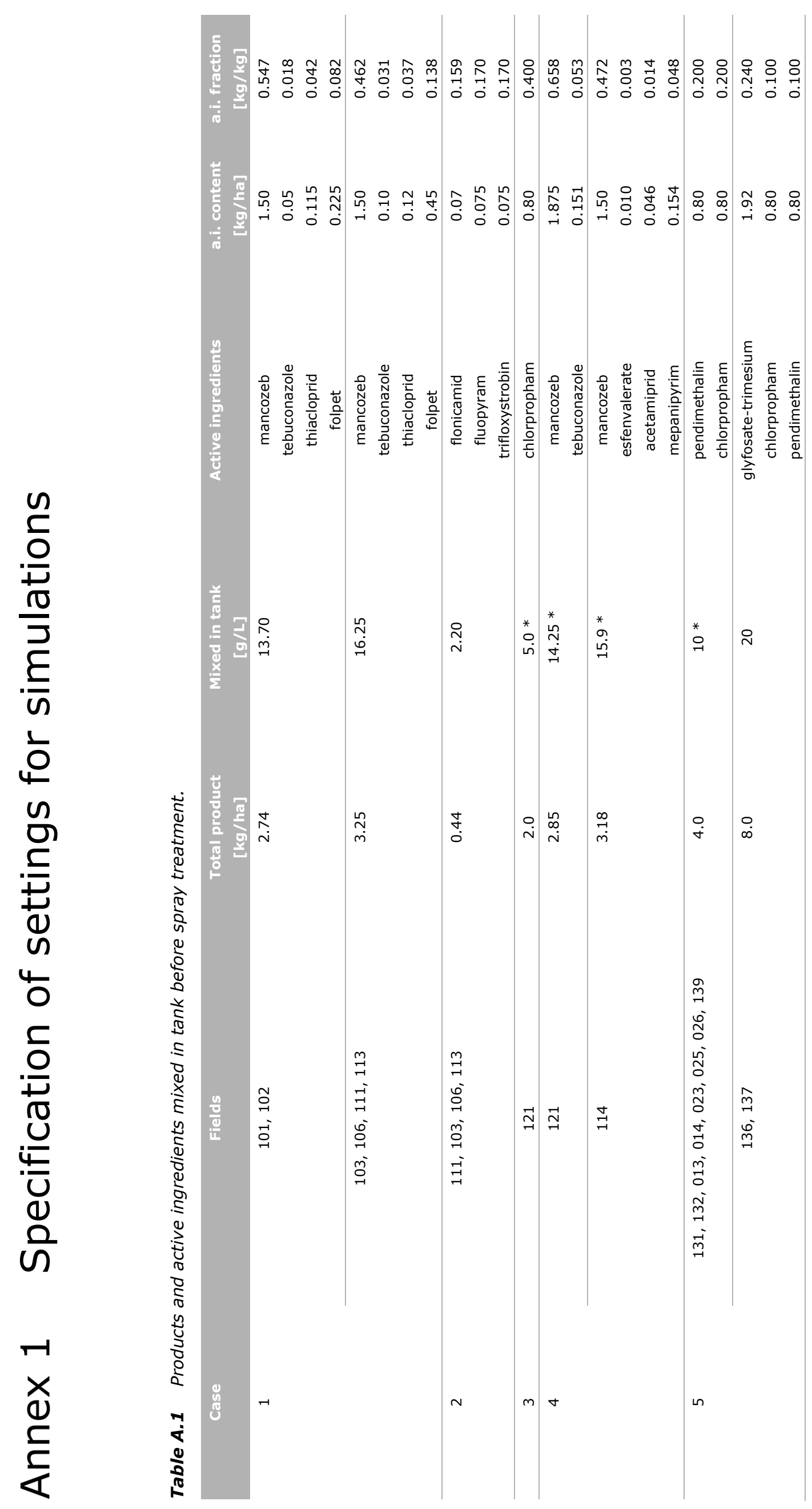




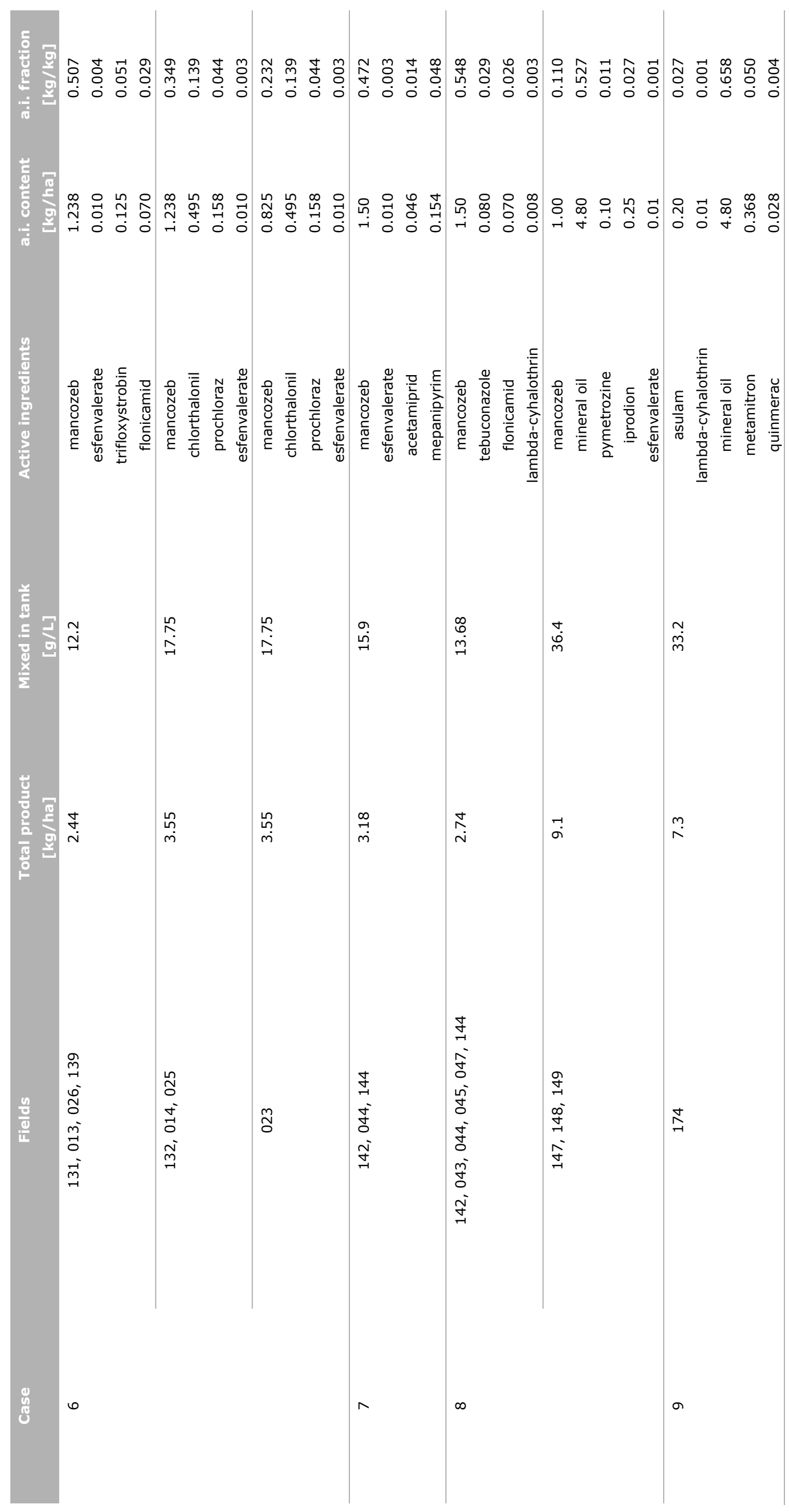




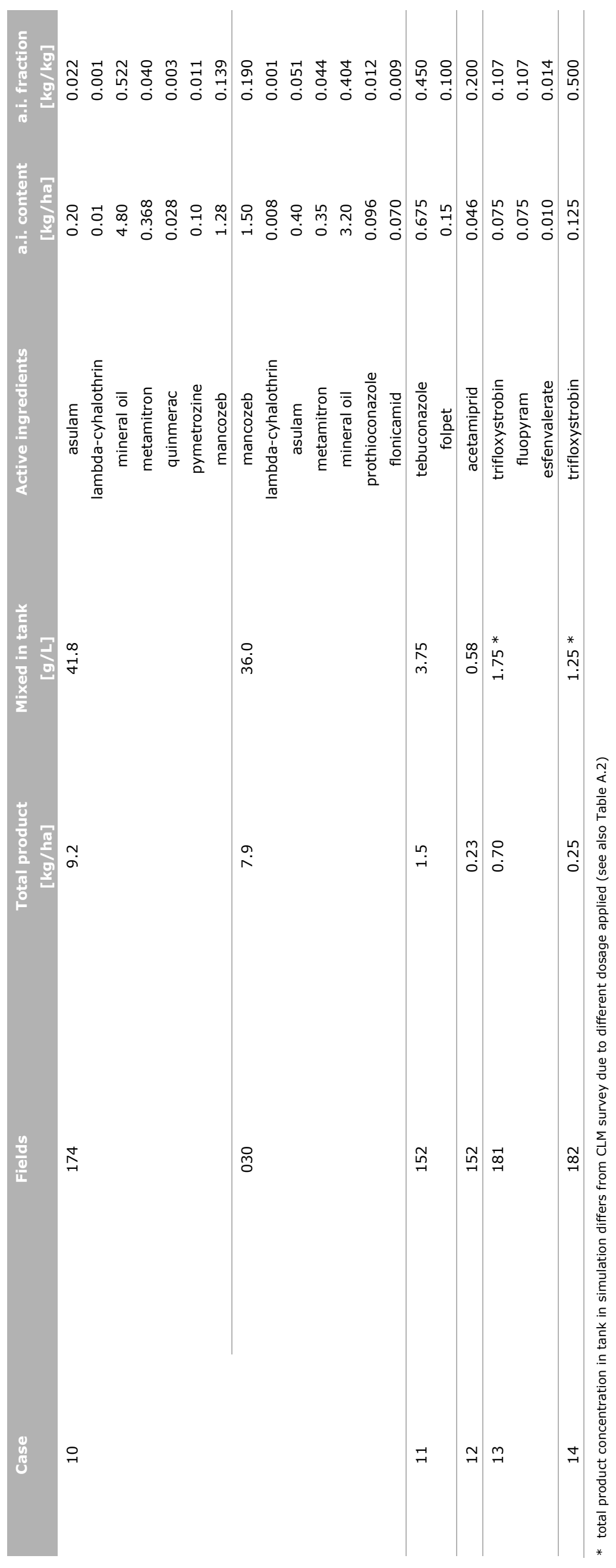




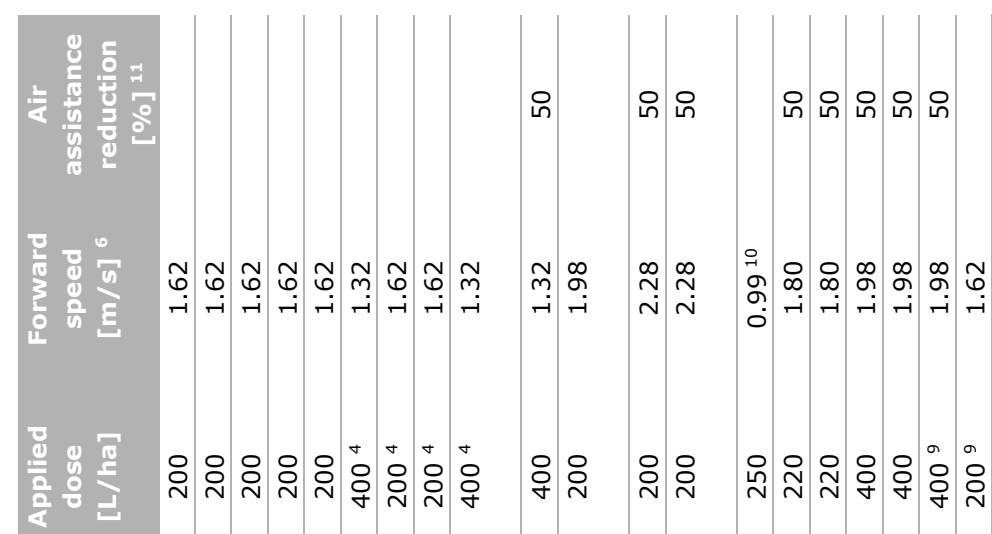

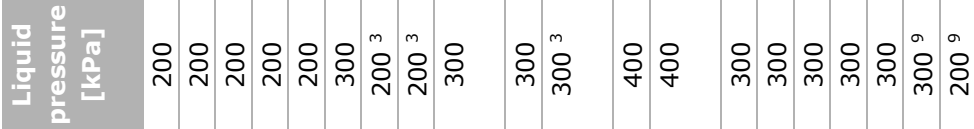

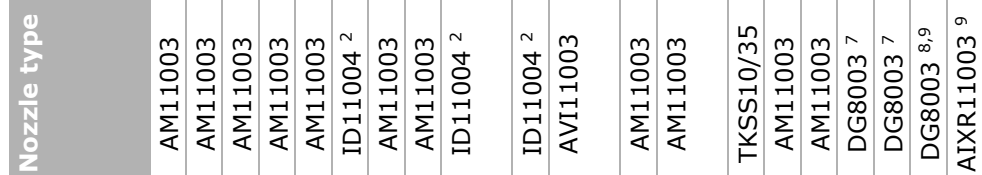

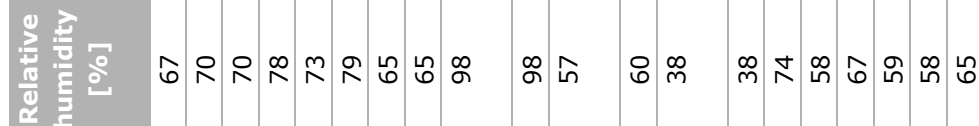

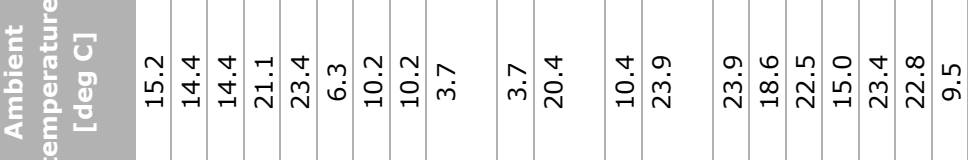

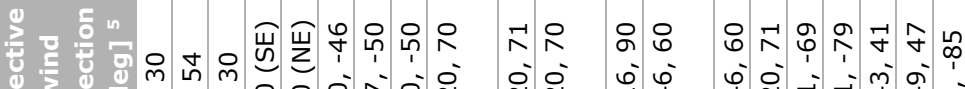

กั

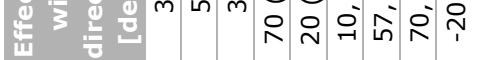

ஸें

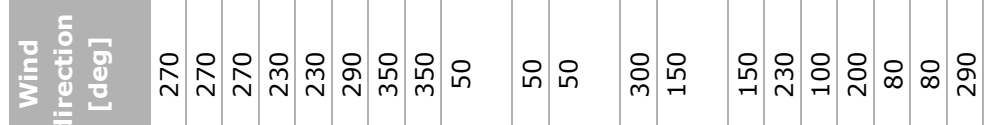

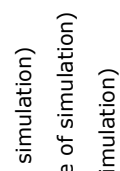

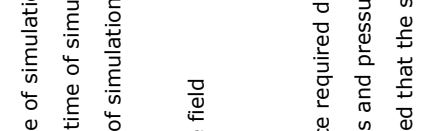

乌ิ

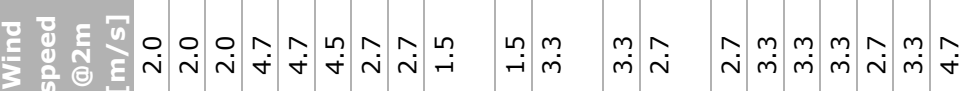

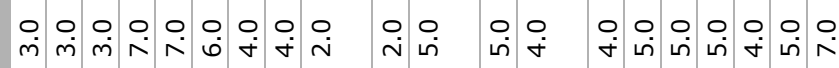


Table A.3 Nozzles used for spray application in flower bulbs, their drift reduction classification and classification of combined drift reducing measures.

\begin{tabular}{|c|c|c|c|c|c|c|}
\hline Case & Fields & Nozzle type & $\begin{array}{l}\text { Liquid } \\
\text { pressure } \\
\text { [kPa] }\end{array}$ & $\begin{array}{l}\text { DRN }^{1} \\
\text { reduction } \\
\text { [\%] }\end{array}$ & $\begin{array}{c}\text { Air assistance } \\
\text { reduction } \\
{[\%]}\end{array}$ & $\begin{array}{c}\text { DRT }^{2} \\
\text { reduction } \\
{[\%]}\end{array}$ \\
\hline 2 & & AM11003 & 200 & 75 & & 75 \\
\hline 3 & & ID11004 & 300 & 90 & & 90 \\
\hline \multirow[t]{2}{*}{5} & $131,132, \ldots$ & ID11004 & 300 & 90 & & 90 \\
\hline & 136,137 & ID11004 & 300 & 90 & 50 & 95 \\
\hline 6 & & AVI11003 & 300 & 50 & & 50 \\
\hline 7 & & AM11003 & 400 & 50 & 50 & 90 \\
\hline 10 & & AM11003 & 300 & 50 & 50 & 90 \\
\hline 11 & & DG8003 & 300 & 3 & 50 & $95^{4}$ \\
\hline 12 & & DG8003 & 300 & 3 & 50 & $95^{4}$ \\
\hline 13 & & DG8003 & 300 & 3 & 50 & $95^{4}$ \\
\hline 14 & & AIXR11003 & 200 & 75 & & 75 \\
\hline
\end{tabular}

1 DRN = Drift reducing nozzle in classes 50\%, 75\%, 90\%, 95\% following NL certification; DRD list:

https://www.helpdeskwater.nl/publish/pages/138134/drd-lijst_20171215.pdf

2 DRT = Drift Reducing Technology in classes 50\%, 75\%, 90\%, 95\%, 97.5\%, 99\%, following NL certification:

https://www.helpdeskwater.nl/publish/pages/138135/drt-lijst_20180724.pdf

3 nozzle-pressure combination not certified separately

4 Spray technique combination: the combination $30 \mathrm{~cm}$ boom height, nozzle spacing $25 \mathrm{~cm}$, nozzle type ID90015 (300 kPa) with air assistance is certified as DRT97.5; it is assumed that spray quality of the DG8003 at $300 \mathrm{kPa}$ is comparable to that of the ID90015 and can be classified accordingly; to account for the uncertainty in this assumption the current combination is classified one class lower (DRT95). 
Corresponding address for this report:

P.O. Box 16

6700 AA Wageningen

The Netherlands

$\mathrm{T}+31(0) 317480700$

www.wur.eu/plant-research

Report WPR-878
The mission of Wageningen University \& Research is "To explore the potential of nature to improve the quality of life". Under the banner Wageningen University \& Research, Wageningen University and the specialised research institutes of the Wageningen Research Foundation have joined forces in contributing to finding solutions to important questions in the domain of healthy food and living environment. With its roughly 30 branches, 5,000 employees and 10,000 students, Wageningen University \& Research is one of the leading organisations in its domain. The unique Wageningen approach lies in its integrated approach to issues and the collaboration between different disciplines. 



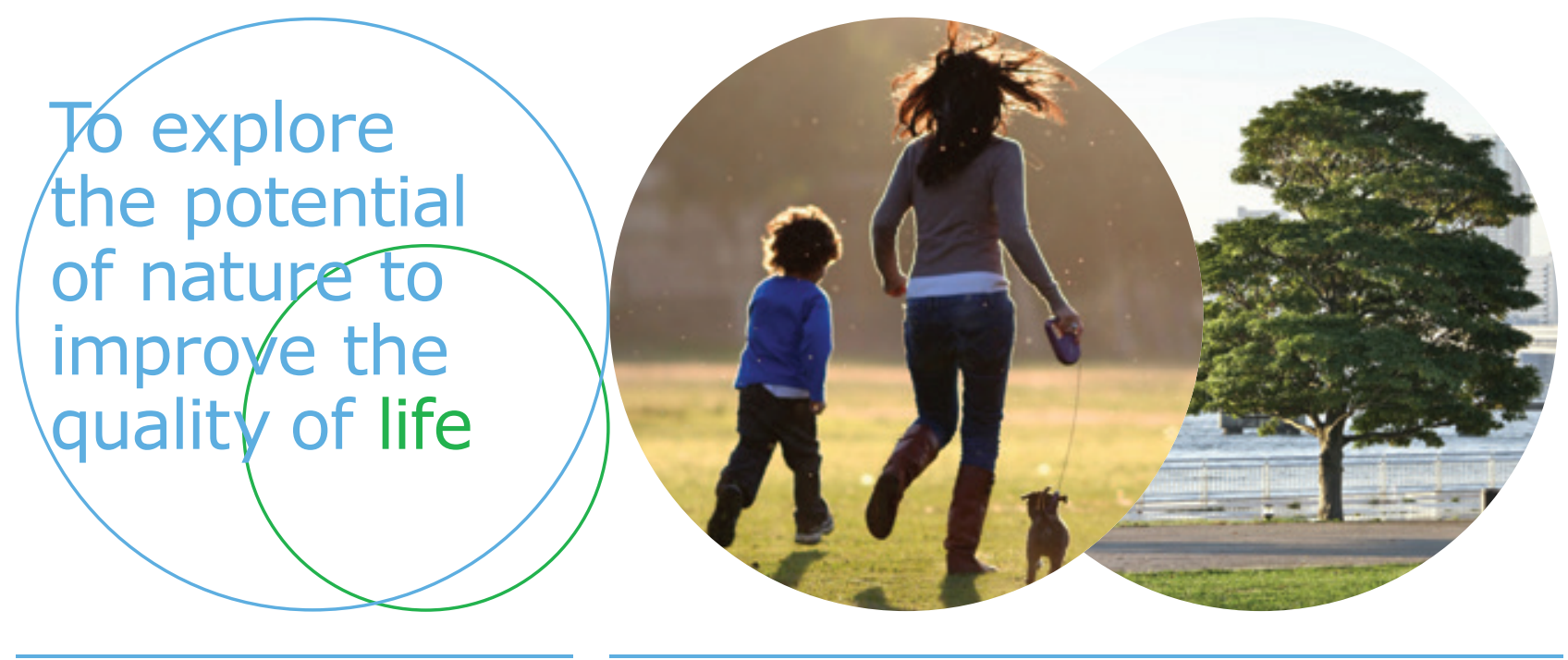

Corresponding address for this report: P.O. Box 16

6700 AA Wageningen

The Netherlands

T +31 (0)317480700

www.wur.eu/plant-research

Report WPR-878
The mission of Wageningen University \& Research is "To explore the potential of nature to improve the quality of life". Under the banner Wageningen University \& Research, Wageningen University and the specialised research institutes of the Wageningen Research Foundation have joined forces in contributing to inding solutions to important questions in the domain of healthy food and living environment. With its roughly 30 branches, 5,000 employees and 10,000 students, Wageningen University \& Research is one of the leading organisations in its domain. The unique Wageningen approach lies in its integrated approach to issues and the collaboration between different disciplines. 